\title{
Moral Hazard Heterogeneity: Genes and Health Insurance Influence Smoking after a Health Shock
}

\author{
Pietro Biroli * $\quad$ Laura Zwyssig ${ }^{\dagger}$
}

March 5, 2021

\begin{abstract}
Decision-making in the realm of health behaviors, such as smoking or drinking, is influenced both by biological factors, such as genetic predispositions, as well as environmental factors, such as financial liquidity and health insurance status. We show how the choice of smoking after a cardio-vascular health shock is jointly determined by the interaction between these biological and environmental constraints. Individuals who suffer a health shock when uninsured are 25.6 percentage points more likely to reduce smoking, but this is true only for those who have a low index of genetic predisposition to smoking. Individuals with a low index of genetic predisposition are more strategic and flexible in their behavioral response to an external shock. This differential elasticity of response depending on your genetic variants is evidence of individual-level heterogeneity in moral hazard. These results suggest that genetic heterogeneity is a factor that should be considered when evaluating the importance and fairness of health insurance policies.
\end{abstract}

Keywords: Moral Hazard, Genetics, Smoking, Medicare JEL CODES: I12, I13, D63, D91

\section{Introduction}

Moral hazard shapes behaviors in all domains characterized by asymmetric information (Arrow, 1963; Finkelstein, 2014). Propensity to moral hazard can differ across individuals, the same as preferences and beliefs. Unlike preferences and beliefs, heterogeneity in moral hazard has been proposed but never directly measured (Dubois and Vukina, 2009; Einav et al., 2013; Kowalski, 2018). Leveraging information on genetic variants associated with smoking behavior, we provide a novel approach to measuring heterogeneity in moral hazard.

To measure heterogeneity in moral hazard, we estimate how individuals carrying different genetic variants differentially change their smoking behavior following a cardio-vascular health shock when they are not covered by health insurance. Combining the genetic and moral hazard

${ }^{*}$ University of Zurich and UBS Center. Corresponding author. Email: pietro.biroli@uzh.ch

${ }^{\dagger}$ University of Zurich. Email: laura.zwyssig@uzh.ch

${ }^{\ddagger}$ We thank Vittorio Bassi, Gregory Crawford, Thomas Dohmen, Ernst Fehr, Titus Galama, Stephanie von Hinke, Alessandro Iaria, Hans van Kippersluis, Philipp Koellinger, Richard Karlsson Linner, Nicholas Papageorge, Kevin Thom, David Yanagizawa-Drott, Christian Zünd, all of the members of GEIGHEI team, and the various seminar participants for useful discussions, comments, and suggestions. Regina Seibel, Pia Arce, Jeremy Vollen, and Alex Thannhuber are the brave and fierce programmers whose research assistantship brought this project to a new level. All remaining errors are probably Pietro's fault. We gratefully acknowledge financial support from NORFACE DIAL (Grant Reference 462-16-100). 
factors shaping health behaviors, we contribute to the burgeoning literature studying geneenvironment interactions (Barcellos, Carvalho and Turley, 2018; Belsky et al., 2018; Caspi et al., 2002; Fletcher, 2012; Papageorge and Thom, 2020; Schmitz and Conley, 2017a,b; Wedow et al., 2018). Specifically, this study is the first to show how genetic risk and insurance coverage jointly influence individual choices of health behavior. We show that moral hazard stemming from health insurance (financial risk) interacts with the genetic predisposition for smoking (Sgenetic risk) in determining the probability of smoking cessation following a health shock. Using data from the Health and Retirement Study (HRS), a longitudinal population-based study of elderly Americans, we estimated how experiencing a health shock between survey waves affected the smoking probability of individuals with different coverage levels and genetic predispositions for smoking.

To cleanly identify this interplay between genes and the environment, we leverage a key feature of the US health insurance system: Medicare, which provides public health insurance to all US citizens older than 65. Before the introduction of the Affordable Care Act (Obama, 2016), a significant fraction of the population younger than 65 was still uninsured (Barnett and Vornovitsky, 2016; Cohen et al., 2009). Exploiting the differential timing of health shocks before or after the Medicare-eligibility age of 65 for previously uninsured individuals, we estimate that Medicare eligibility reduced smoking cessation rates after a health shock by 25.6 percentage points, but only for those individuals with a low index of genetic propensity to smoking. Comparing this effect between individuals with a high versus a low index of genetic predisposition for smoking allows for an assessment of how the moral hazard problem found in previous research interacts with genetic risk.

We focus on smoking behavior because chronic diseases and health care costs caused by tobacco use are estimated to be one of the biggest health challenges in industrialized countries, and have rapidly increased in importance in the developing world (Goodchild, Nargis and Tursan d'Espaignet, 2018; United States Department of Health and Human Services, 2014). In the US, smoking is estimated to cause more than 400,000 premature deaths annually (Ma et al., 2018), and the economic costs of smoking-related illness amount to around $\$ 300$ billion each year, including almost $\$ 170$ billion for direct medical care and an additional $\$ 156$ billion in lost productivity (United States Department of Health and Human Services, 2014; Xu et al., 2015). Both the health burden from smoking-related illness as well as the economic burden on an already strained health care system have made it a priority to understand what factors affect individuals' smoking decisions, and how health care can effectively encourage cessation.

Smoking cessation, like many other health behaviors, is influenced both by environmental and genetic factors. One environmental factor that has been associated with a reduction in tobacco consumption is health insurance coverage (Dave and Kaestner, 2009; Marti and Richards, 2017; Richards and Marti, 2014), especially after experiencing a severe smoking-related health shock, like the onset of a cardiovascular illness (Clark and Etilé, 2002; Falba, 2005; Keenan, 2009; Khwaja, Sloan and Chung, 2006a; Sundmacher, 2012). Alleviating the financial burden of health care costs, health insurance can have the unintended side effect of preventing beneficial behavior changes that would have taken place if the individuals were fully responsible for the financial consequences of poor health (Marti and Richards, 2017). This adverse incentive created by health insurance is a typical example of "moral hazard": the notion that individuals change their behavior in an undesired way because the consequences of their actions are not (fully) 
borne by themselves (Einav and Finkelstein, 2018; Zweifel and Manning, 2000).

Another factor that is tightly linked to smoking behavior is genetic makeup. Genetic factors can explain around $30 \%$ to $85 \%$ of the variance in regular smoking, according to several studies comparing identical and fraternal twins (Boardman, Blalock and Pampel, 2010; Hall, Madden and Lynskey, 2002; Heath et al., 1993; Li et al., 2003; Sullivan and Kendler, 1999). In recent years, significant progress has been made in identifying genetic variants associated with susceptibility to smoking (Liu et al., 2010, 2019; The Tobacco and Genetics Consortium et al., 2010; Thorgeirsson et al., 2010, 2008). In particular, most genetic variants from the CHRNA5CHRNA3-CHRNB4 gene cluster, which influences nicotine response and metabolism and which studies link to nicotine dependence, are strongly associated with smoking phenotypes (Stoker and Markou, 2013). Genetic variants near dopamine receptors are strongly associated with daily smoking and difficulty in cessation, but not with smoking initiation-related phenotypes, suggesting that dopamine-related variants become more relevant as an individual's nicotine use progresses (Liu et al., 2019). Indices of genetic predisposition to smoke have been shown to be related to smoking initiation, and individuals of higher genetic risk are more likely to develop dependence faster and more frequently and to fail in their cessation attempts (Belsky et al., 2013). Thus, genetic data may capture an individual's predisposition for smoking behaviors via multiple biological channels including addiction in addition to nicotine response.

These developments in mapping the genetic architecture of health behaviors, together with an increased availability of genetic measures in large representative surveys, allow for a better understanding of how genetics can interact with other environmental factors in determining smoking behavior and nicotine dependence. For example, adolescent environmental shocks have been shown to alter the influence of specific genetic variants on an individual's risk of developing nicotine dependence (Bierut, Johnson and Saccone, 2014; Chen et al., 2009; Johnson et al., 2010). More generally, the relationship between genetic variants and smoking has been shown to depend on neighborhood characteristics (Meyers et al., 2013) the cohort of birth (Domingue et al., 2016; Wedow et al., 2018), military service in the Vietnam era (Schmitz and Conley, 2016), and tobacco taxes (Fletcher, 2012; Slob and Rietveld, 2020).

Our results highlight the importance of considering genetic predisposition when evaluating behavioral responses to shocks and policies, such as health insurance coverage (Harper, 1993; Morrison, 2005). Genetic predispositions can curb the negative behavioral consequences and the moral hazard associated with changes in health insurance status. Besides being relevant for the debate about equal and fair access to health insurance, our results highlight a new avenue of potential future research: leveraging recent advances in molecular and human genetics, we identify a new form of individual heterogeneity in the response to treatments. This heterogeneity used to be unobserved, which could lead to incorrect policy conclusions. In the era of genomics and personalized medicine, an individual genetic makeup can be a factor not only in the treatment they receive, but also in their response to insurance coverage (Khera et al., 2018; Ritz et al., 2017; Schork, Schork and Schork, 2018; Torkamani, Wineinger and Topol, 2018). A new form of individual heterogeneity in treatment effects (Papageorge and Thom, 2020). Since individuals are endowed at conception with their genetic makeup, and they have not done anything to deserve it or be held accountable for it (Barth, Papageorge and Thom, 2019; Harden, In Press; Kweon et al., 2020; Pereira, 2021), this differential response to insurance shocks raises questions of fairness and equality in the public debate over health insurance policies. 
More generally, we show how leveraging recent developments in behavioral and molecular genetics can shed new light on fundamental economic concepts, such as elasticity of response to health shocks and heterogeneity in moral hazard. These concepts are formalized more precisely in the model in Appendix E. Indices of genetic predisposition to health behaviors provide readily available individual measures of heterogeneity that can enrich our economic models.

\section{Data}

\subsection{Study Sample}

The HRS is a nationally representative longitudinal household survey initiated in 1992 among US citizens aged 50 and older, followed for 12 biannual waves over 22 years, containing detailed medical, economic, social, psychological, and genetic information about the respondents (Sonnega et al., 2014). ${ }^{1}$

Genetic information comes from DNA samples collected in face-to-face interviews, for which a random subset of HRS households were selected to participate in 2006, 2008, and 2010. Saliva samples are collected and genotyped for more than 15,000 participants (Ware, Schmitz and Faul, 2017). More information on the DNA extraction and the genotyping process is provided in Section C.1 in the Appendix.

The analysis is done on a subsample of the data selected based on criteria of age (between 60-70 at the time of interview), ever-smokers at baseline (their first observation), observed in at least 2 different time periods, and genetically of European descent. 5,854 HRS respondents satisfy these criteria and have non-missing values for the main variables of interest (smoking status, polygenic score (PGS) for regular smoking, insurance status, and the occurrence of heart conditions or strokes). ${ }^{2}$ The age restriction imposed on the study sample increases comparability between those experiencing a health shock before or after age 65. The restriction imposed on genetic ancestry is best-practice in social-science genetics to avoid issues of population stratification, for example, mistaking a genetic variant with different allele frequencies in Asians and Caucasians for a marker of ability to use chopsticks (Hamer and Sirota, 2000). The restriction also increases the sample's similarity with the genetic profile of the discovery sample used in the genome-wide association study (GWAS) that informed the weights for the Single Nucleotide Polymorphisms (SNPs) used for calculating the PGS (Freese, 2018; Martin et al., 2017). ${ }^{3}$ Also, we exclude respondents who reported the onset of a cardiovascular illness since the last survey wave when interviewed at ages 65 or 66 . Since HRS surveys are only conducted every 2 years, it is not possible to determine Medicare eligibility status at the time of the health shock for these

\footnotetext{
${ }^{1}$ Response rates vary between $80 \%$ and $90 \%$ (HRS, $2017 a$ ). Every 6 years, a new 6 -year birth cohort of participants is enrolled (HRS, 2017b). It is sponsored by the National Institute on Aging (grant number NIA U01AG009740) and is conducted by the University of Michigan (HRS, n.d.). The first core interview with every participant is conducted face-to-face, and all follow-up interviews are either face-to-face or over the phone (HRS, 2017b).

${ }^{2}$ See Section C.2 in the Appendix for more information on the construction of the study sample.

${ }^{3}$ Martin et al. (2017) convincingly show that past attempts to use polygenic scores to compare racial or ethnicgroup achievements were scientifically flawed. Sadly, this reduces the external validity of any study that uses polygenic scores informed by GWAS of white participants. It might also exacerbate existing health disparities across ethnicity and hamper the potential for scientific knowledge and innovation to improve everyone's lives (Martin et al., 2019). Thankfully, multi-ancestry GWAS are becoming more common, but not yet for smoking behavior (Peterson et al., 2019).
} 
individuals. $^{4}$

\section{$2.2 \quad$ Variables of interest}

Genetic propensity. As a measure of an individual's genetic propensity to smoke, we leverage recent developments in molecular and behavioral genetics to construct an index known as a polygenic score (PGS). A polygenic score is a weighted average of the number of risky genetic variants $G_{i j}$ associated with the probability of smoking that are carried by a particular individual. For our measure of genetic variants $G_{i j}$, we follow the literature and use the most common form of genetic variation: Single Nucleotide Polymorphisms (SNP), a one base-pair substitution at a particular location (locus) on the human genome.

Specifically, the scores are calculated as follows:

$$
P G S_{i}=\sum_{j=1}^{J} W_{j} G_{i j},
$$

where $G_{i j}$ is the genotype for individual $i$ at each of the more than 10 million SNP $j$; the weight $W_{j}$ is the effect size for SNP $j$ estimated via meta-analysis in a different sample than the HRS by the GWAS and Sequencing Consortium of Alcohol and Nicotine use (GSCAN) (Liu et al., 2019). The scores have been normalized to have a mean of zero and a standard deviation of one. ${ }^{5}$

To avoid functional form assumptions and maximize power in the statistical analysis, the sample is divided into high- and low-genetic propensity to smoking based on the PGS. A high-PGS indicator is defined to take the value 1 for individuals in the top $2 / 3$ of the PGS distribution. ${ }^{6}$ As shown in Figure 1, the distribution of the PGS is bell-shaped, it is shifted to the right for baseline smokers, and it is predictive of current smoking behavior: $\approx 30 \%$ of individuals with a PGS higher than 2.5 are current smokers, while only $\approx 10 \%$ of individuals with a PGS lower than -2.5 currently smoke.

Health shocks. Following previous studies (Falba, 2005; Keenan, 2009; Khwaja, Sloan and Chung, 2006a,b; Smith et al., 2001), we focus on the first occurrence of an acute cardiovascular condition. Cardiovascular conditions include either a heart problem (heart attack, coronary heart disease, angina, congestive heart failure, or other heart problems) or a stroke (or transient ischemic attack). These conditions have strong

\footnotetext{
${ }^{4}$ The results do not change if these individuals are included.

${ }^{5}$ As a robustness check, shown in Appendix Section D.3.3, we also use the polygenic score provided by the HRS (Ware, Schmitz and Faul, 2017) for the smoking phenotype "regular smoking" (having smoked more than 100 cigarettes throughout one's life). This score is constructed as a weighted sum of the genotype over the 779,538 SNPs that overlap between the HRS genetic database and a 2010 GWAS meta-analysis conducted by the Tobacco and Genetics Consortium (The Tobacco and Genetics Consortium et al., 2010). See Section C.3.5 in the Appendix for more information on the construction of the PGS.

${ }^{6}$ We initially ran the analysis separately for each tertile of the PGS distribution, as shown in Appendix Section D.3.1, but the results are concentrated in the lower part of the distribution of the PGS, and therefore for simplicity we consider only high and low PGS. Results are robust to splitting the same above and below the median PGS score, as shown in Appendix Section D.3.2.
} 
Figure 1: PGS distribution and correlation with smoking behavior.

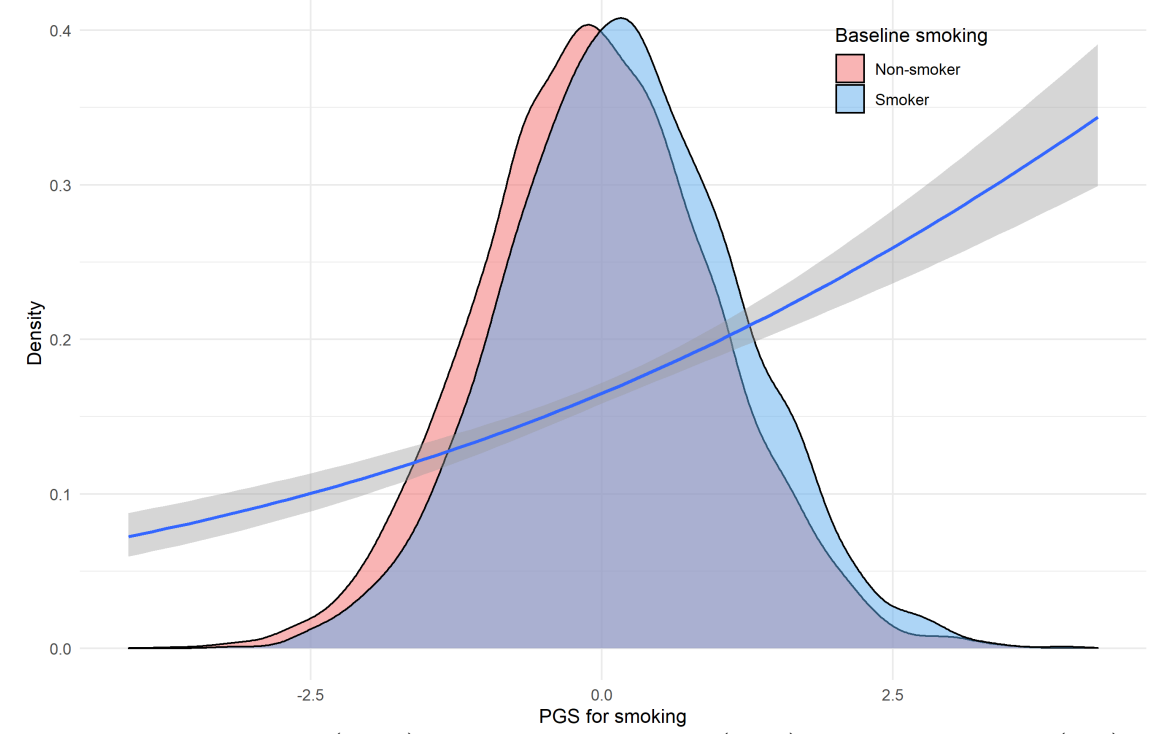

Notes: Distribution of Polygenic Score (PGS) for baseline smokers (blue) and non-smokers (red). Generalized linear smoothed correlation between current smoking and PGS shown in the blue line (with $95 \%$ confidence intervals in shaded grey area).

Data used: HRS waves 1-13, restricted to observations with age between 60 and 70 years.

links to tobacco use, have a relatively high incidence among older adults, and are likely to require immediate and intensive use of costly medical services (Lloyd-Jones et al., 2010; Teo et al., 2006; Thorpe, Florence and Joski, 2004). Additionally, they can occur repeatedly for the same individual and thereby incentivize improvements in health behaviors to prevent a recurrence.

The health shock is a binary indicator set to 1 if the respondent is diagnosed with a new cardiovascular condition during the time since the last HRS survey, but does not have a history of cardiovascular disease prior to this diagnosis. The exact timing of the health shock within the past 2 years since the last interview is not observed, and the diagnoses are all self-reported.

As shown in Figure 2, the rate of cardiovascular health problems increase with age from about $2 \%$ to $4 \%$ annually, but it is not strongly related to the PGS and, most importantly, does not jump around the age of 65 (see also Figure 11 in the Appendix).

Health Insurance. Before the age of 65, HRS respondents are classified as uninsured in a given survey wave if they report not being covered by any health insurance plan. Respondents are classified as being persistently uninsured if they were uninsured in every wave between 60 and 65 .

The share of persistently uninsured individuals is shown in panel A of Figure 3.

After the age of 65, individuals are considered eligible for Medicare. As shown in Panel B of Figure 3, the vast majority of individuals are aware of Medicare eligibility: 
Figure 2: Prevalence of cardiovascular health shock.

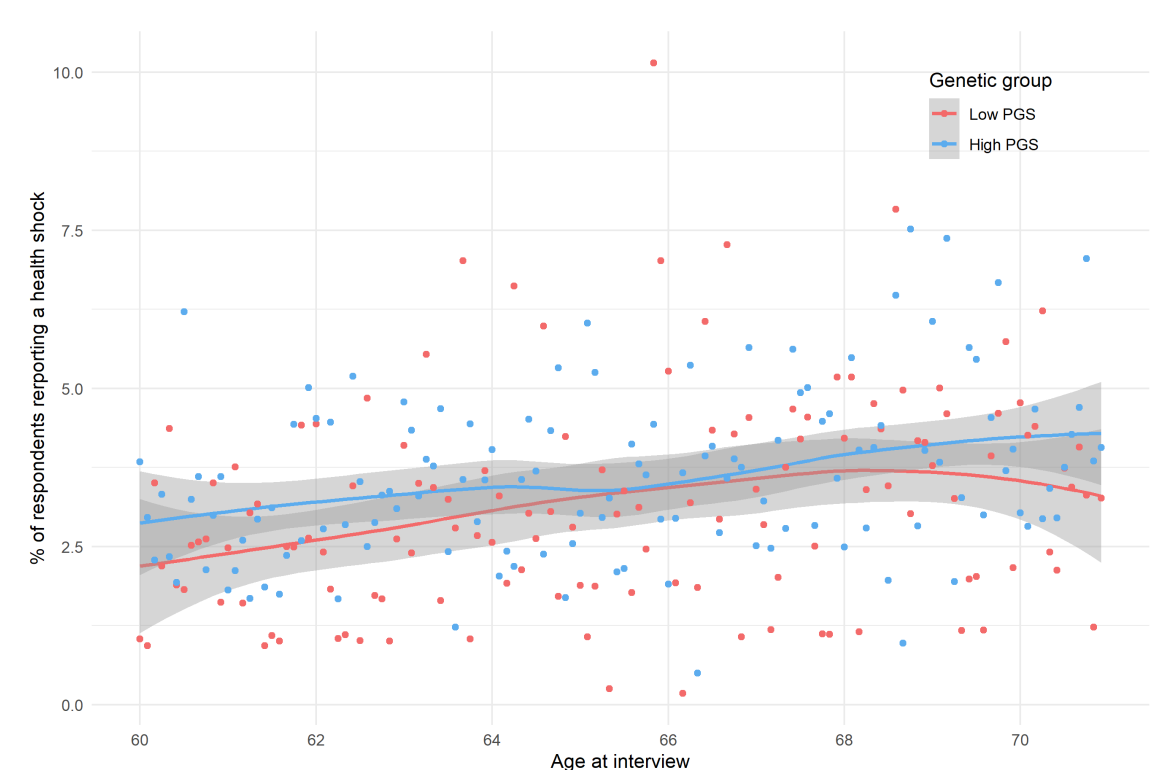

Notes: Self-reported indicator of having been diagnosed for the first time with a cardiovascular condition since the last HRS survey. Age refers to the time of the survey, not the time of the health shock, which is unknown up to a 2-year windows, since HRS surveys are bi-annual. Bin-scattered plot and generalized linear smoothed correlation between age at interview and cardiovascular health shock shown in red (low PGS = lowest tertile of polygenic score) and blue (high PGS = upper two tertiles of polygenic score).

Data used: HRS waves 1-13, restricted to observations with age between 60 and 70 years.

more than $90 \%$ of individuals report being covered by Medicare after the age of 65 .

Smoking status. The outcome of interest is a self-reported binary indicator for current smoking status. It is set to 1 if the respondent is an ever-smoker (having smoked more than 100 cigarettes throughout one's life) and smoking at the time of the survey.

As shown in Figure 4, the prevalence of smokers in the sample decreases with age and is about 5 percentage points higher for the individuals with a high PGS.

More information on the construction of all variables used in the analysis can be found in Section C.3 in the Appendix.

\subsection{Sample Characteristics}

Characteristics of the study sample used in the analysis are summarized in the first column of Table 1. The study sample consists of 5,854 individuals (and 26,022 personyear observations). The average age at baseline is 61.2 years, $49.9 \%$ of the sample is made up of women, and $29.5 \%$ smoke at baseline. Individuals are observed for 4.5 waves on average, a good panel dimension even if restricted to the 60-70 age range. $5.9 \%$ of individuals in the sample are uninsured in all observations before the age of 65 , and $12.3 \%$ experience a cardiovascular health shock during the observation period. The second and third columns in Table 1 describe the sample stratified into 2 genetic 
Figure 3: Share uninsured and enrolled in Medicare across the age 65 threshold by PGS.

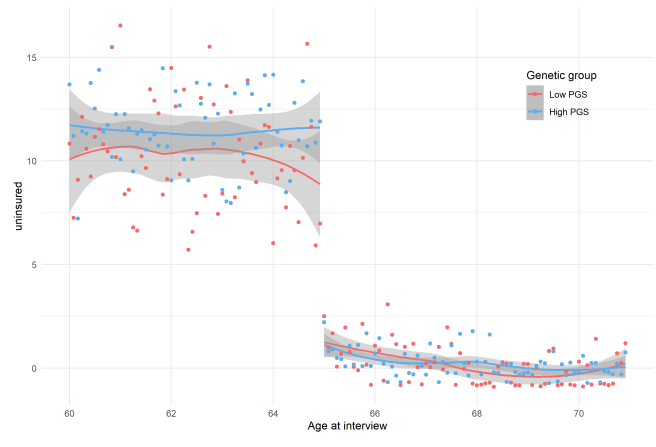

(a) Share uninsured

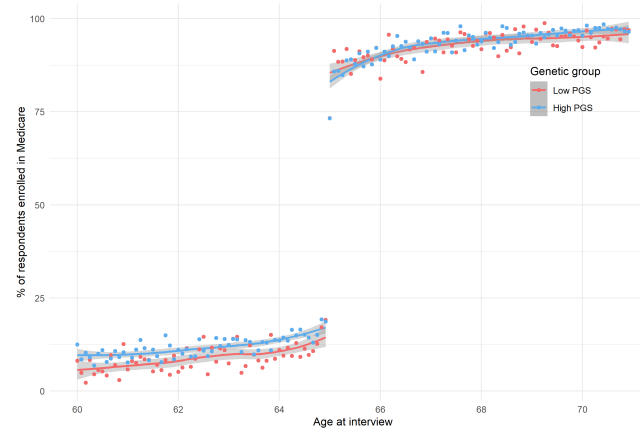

(b) Share Enrolled in Medicare

Notes: Self-reported indicator for lack of any insurance coverage and being enrolled in Medicare. Bin-scattered plot and generalized linear smoothed correlation between age and outcome variables shown in red (low PGS = lowest tertile of polygenic score) and blue (high PGS = upper two tertiles of polygenic score).

Data used: HRS waves 1-13, restricted to observations with age between 60 and 70 years.

Figure 4: Prevalence of smoking.

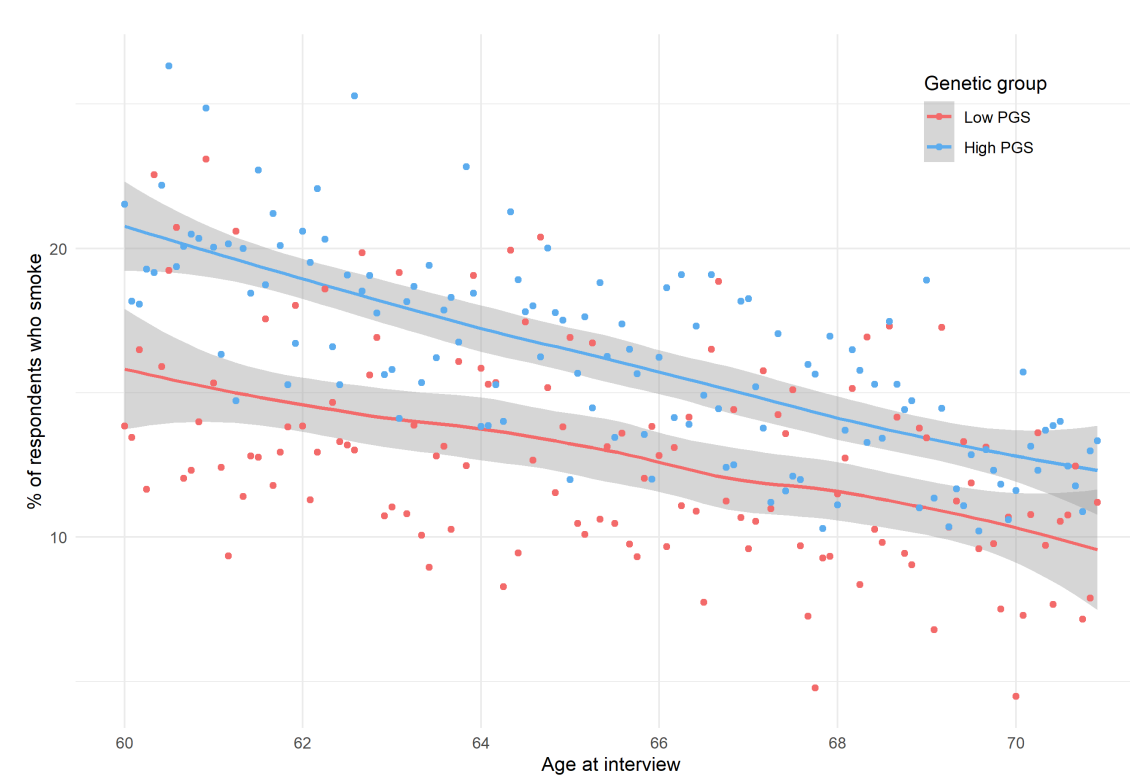

Notes: Self-reported smoking rate by age and high or low PGS. Bin-scattered plot and generalized linear smoothed correlation between age and smoking shown in red (low PGS = lowest tertile of polygenic score) and blue (high PGS $=$ upper two tertiles of polygenic score).

Data used: HRS waves 1-13, restricted to observations with age between 60 and 70 years.

groups. High-PGS respondents are 4 percentage points more likely to smoke at baseline, 0.7 percentage points more likely to be uninsured before the age of 65 , and included relatively more women compared to the low-PGS respondents. ${ }^{7}$

\footnotetext{
${ }^{7}$ This slight gender imbalance is a feature of our sampling strategy and not of the PGS, which is balanced across genders in the original paper (Liu et al., 2019). None of the results are driven by gender differences, which are always controlled for in the analysis. Appendix Section D.1 provides additional descriptive information about the study sample that experienced a health shock.
} 
Table 1: Descriptive Statistics for the Study Sample, Stratified by Genetic Group

\begin{tabular}{llll}
\hline & All & Low PGS & High PGS \\
\hline & Mean (SD) & Mean (SD) & Mean (SD) \\
\hline Age (baseline) & $61.17(1.93)$ & $61.18(1.96)$ & $61.16(1.92)$ \\
Smoking PGS & $0.11(0.99)$ & $-0.96(0.51)$ & $0.64(0.71)$ \\
No. waves present & $4.44(1.38)$ & $4.46(1.37)$ & $4.43(1.39)$ \\
& $\%$ & $\%$ & $\%$ \\
Female & 50.42 & 46.97 & 52.14 \\
Smoking (baseline) & 29.55 & 27.06 & 30.79 \\
Persistently uninsured & 5.85 & 5.39 & 6.08 \\
CV health shock & 12.44 & 11.82 & 12.74 \\
\hline No. of individuals & 5813 & 1929 & 3884 \\
No. Person-year observations & 25800 & 8602 & 17198 \\
\hline
\end{tabular}

Notes: Low PGS = lowest tertile of the polygenic score distribution; high PGS = upper two tertiles of the polygenic score distribution. Baseline = first wave used in the study sample for the empirical analysis. Smoking PGS = polygenic score for smoking constructed according to equation 1 used as a proxy for genetic propensity to smoke. Persistently uninsured $=$ binary indicator for being uninsured in every observation of the study sample before the age of 65 . CV health shock $=$ binary indicator for having suffered a cardiovascular health shock for the first time since the previous wave. See section 2.2 for a thorough definition of the variables used and Section 2.1 for a definition of the study sample.

Data used: HRS study sample, $\mathrm{n}=5,854$.

\section{Empirical Analysis}

In a within-person analysis with individual fixed effects, we compare the change in smoking rates after suffering a health shock across four types of persistently uninsured people: younger or older than 65 (as a proxy of exposure to health insurance via Medicare) and high or low genetic propensity to smoking. We focus on persistently uninsured people, i.e. people who reported being uninsured in every observation of the study sample before age 65 , to zoom in on the potential for moral hazard.

The identification strategy builds on previous work (Marti and Richards, 2017) and leverages the differential timing of health shocks before or after Medicare eligibility at age 65. Conditional on having suffered a health shock, the exact timing of the shock is arguably both exogenous and unanticipated. While the probability of experiencing a health shock increases with age (Lloyd-Jones et al., 2010), no observable jump or change in trend can be seen in our data in the percentage of respondents reporting a health shock around the age of 65 (see Figures 2 and 11 as well as Section C.4.1 in the appendix for details). Notice, however, that only the age at the time of the interview is known, not the age at the time of the cardiovascular health shock, which could have happened any time since the prior interview (about 2 years before). Therefore, our dataset is not precise enough to estimate a possible discontinuity in the probability of suffering a cardiovascular health shock at age 65 . Nevertheless, the absence of a jump at the time of Medicare eligibility is consistent with the work of Card, Dobkin and Maestas 
(2009, 2008) who, using much more granular data, find a sharp increase in health care utilization at age 65 , but no discontinuity in the probability of suffering from a health shock.

The absence of a jump is reassuring for our identification strategy, which relies on a comparison before and after the age of 65: accounting for age, respondents experiencing the shock after 65 should not be systematically different from respondents experiencing the shock before 65 . This setting thus provides a good framework for estimating the causal effect of health care eligibility on the smoking response to a health shock in individuals who are uninsured before the age of 65 .

Conceptually, this design aims to mimic the following hypothetical comparison: within both the low-PGS and the high-PGS group, compare the change in smoking status after suffering a health shock for two respondents with similar characteristics (ever smokers, persistently uninsured, similar genetic propensity to smoke, gender, etc). The only difference between the two individuals is the point in time at which they experience the shock and, hence, their exposure to the financial costs associated with it. Who responds more to the financial exposure: the high-PGS or the low-PGS type?

Methodologically, we use ordinary least squares (OLS) regression to estimate a linear probability model for smoking. Current smoking status $(Y)$ is regressed on the full set of interactions between the indicators for the health shock (shock), being uninsured pre-65 (uninsured), Medicare eligibility (post65), and high polygenic score for smoking $(g)$ :

$$
\begin{aligned}
& Y_{i t}=\beta \text { shock }_{i t}+\gamma{\text { post } 65_{i t}} \\
& +\lambda_{1}\left(\text { shock }_{i t} \times \text { post } 65_{i t}\right) \\
& +\lambda_{2}\left(\text { shock }_{i t} \times \text { uninsured }_{i}\right)
\end{aligned}
$$

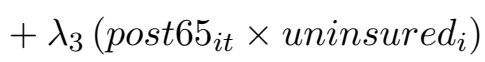

$$
\begin{aligned}
& +\lambda_{4}\left(\text { shock }_{i t} \times g_{i}\right) \\
& +\lambda_{5}\left({\text { post } \left.65_{i t} \times g_{i}\right)}_{1}\right. \\
& +\delta_{1}\left(\text { shock }_{i t} \times{\text { post } \left.65_{i t} \times \text { uninsured }_{i}\right)}\right. \\
& +\delta_{2}\left(\text { shock }_{i t} \times \text { uninsured }_{i} \times g_{i}\right)
\end{aligned}
$$

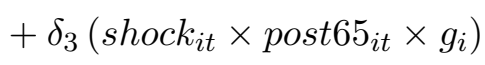

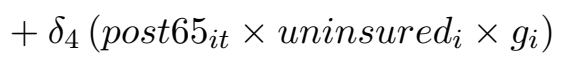

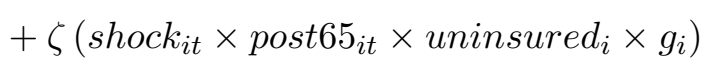

$$
\begin{aligned}
& +\sum_{a=1}^{3} \phi_{a} a g e_{i t}^{a}+\eta_{i}+\tau_{t}+\varepsilon_{i t}
\end{aligned}
$$

Individual fixed effects $\left(\eta_{i}\right)$ are included to control for unobserved time-invariant 
differences between respondents, and time fixed effects $\left(\tau_{t}\right)$ to control for time-specific confounders. In addition, a third-degree polynomial of the respondent's age in years at the time of the interview (age) is added to non-linearly control for the reduction in smoking rates shown in Figure 4. Standard errors are clustered at the individual level.

The statistical method resembles a difference-in-differences approach: focusing on the group of previously uninsured individuals, we compared the effect of a health shock for those experiencing it before or after Medicare eligibility, and who have either a low or high genetic propensity to smoke.

We are interested in 3 different types of effects for the group of previously uninsured individuals:

First, what is the marginal effect of a health shock on smoking? This effect is calculated for 4 different subgroups, given by the combinations of shock timing (pre- or post-65) and genetic risk (high or low), and shown in Figure 5. For each subgroup, the effect is comprised of the sum of all coefficient estimates from Equation (2) that applied for the given group. For example, for previously uninsured individuals who experienced the shock before the age of 65 and who had a low genetic susceptibility for smoking, the effect of the health shock is calculated by summing up the estimates for $\beta$ and $\lambda_{2}$. If the health shock is instead experienced after 65 , the effect of the shock (for the same group of previously uninsured low-PGS individuals) is the sum of the estimates for $\beta$, $\lambda_{1}, \lambda_{2}$, and $\delta_{1}$.

Second, what is the causal effect of Medicare eligibility (and hence a change in the financial costs associated with a health shock) on smoking? This effect is calculated using the difference between the pre-65 shock effect and the post-65 shock effect for each of the 2 genetic groups. For the low-PGS group, it is given by the sum of the estimates for $\lambda_{1}$ and $\delta_{1}$. For the high-PGS group, it is given by the sum of $\lambda_{1}, \delta_{1}, \delta_{3}$, and $\zeta$.

Lastly, does the effect of health insurance vary according to individual genetic predisposition? Comparing the effect of Medicare eligibility on the post-shock smoking decision between the high- and the low-PGS groups we can assess the presence of genetic heterogeneity in moral hazard. The presence of genetic heterogeneity in moral hazard is estimated by the sum of $\delta_{3}$ and $\zeta$ in Equation (2). ${ }^{8}$

\section{Results}

\subsection{Estimation Results}

The effect of a health shock on the smoking probability of individuals who are uninsured before the age of 65 - the subgroup of interest - for the 4 combinations of shock timing (before or after 65) and polygenic score (high or low) is shown in Figure 5 and Panel A of Table 2. Since we are controlling for individual fixed effects, these coefficients can be

\footnotetext{
${ }^{8}$ See Appendix Section C.5 for a derivation of these effects.
} 
interpreted as the change in the probability of smoking after suffering a health shock.

All of the regression coefficients are presented in the last column of Table 3.

Figure 5: Effect of a Health Shock on the Smoking Probability in the Pre-65 Uninsured Subgroup, Stratified by Timing of the Shock and Genetic Type

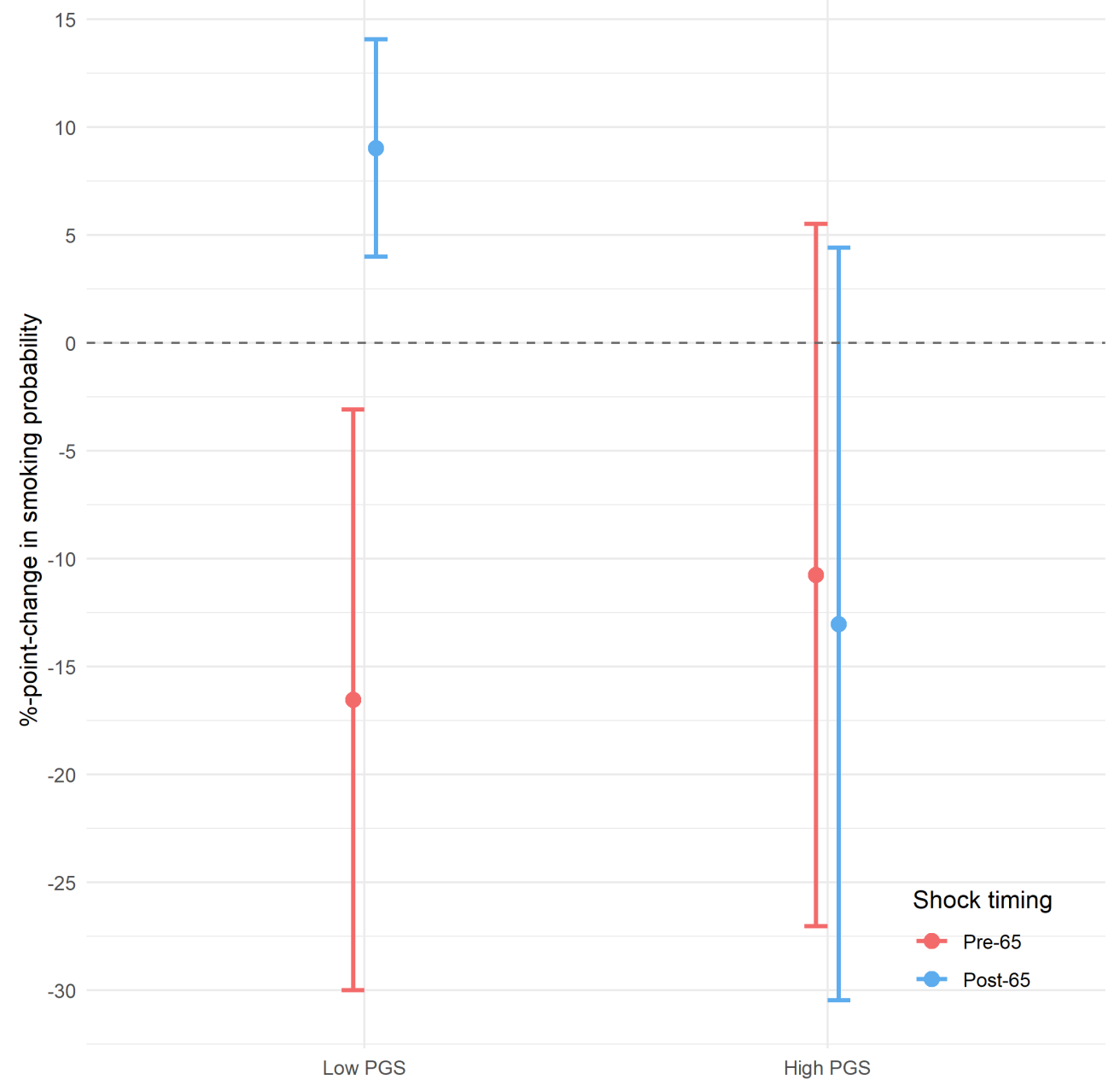

Notes: Low PGS = lowest tertile of the polygenic score distribution; high PGS = upper two tertiles of the polygenic score distribution. Pre-65: Health shock since the last survey reported at ages 60-64. Post-65: Health shock since the last survey reported at ages 67-70. Estimates and standard errors are shown in Panel A of Table 2. Effects are estimated using the coefficients in the last column of Table 3 and following the derivation described in C.5. Bars show 95\% confidence intervals, standard error clustered at the individual level.

Data used: HRS study sample, $\mathrm{n}=5,854$.

Following a health shock, persistently uninsured individuals with a high polygenic score tend to reduce their smoking behavior by about 10 percentage points, irrespective of whether the health shock happens before or after the age of 65 . Since the response to the health shock is the same before and after the age of Medicare eligibility, there is no evidence of moral hazard in this subgroup. With a $30.8 \%$ baseline probability of smoking, this 10 percentage point reduction is non-negligible, but it is very nosily estimated and is indistinguishable from zero. 
Table 2: Summary of Statistical Results for the Pre-65 Uninsured Subgroup, Stratified by Timing of the Shock and Genetic Group

\begin{tabular}{|c|c|c|}
\hline \multicolumn{3}{|c|}{ Effect of health shock on smoking probability } \\
\hline & Low PGS & High PGS \\
\hline Pre 65 & $\begin{array}{l}-0.165^{* *} \\
(0.069)\end{array}$ & $\begin{array}{l}-0.108 \\
(0.083)\end{array}$ \\
\hline Post 65 & $\begin{array}{l}0.09 * * * \\
(0.026)\end{array}$ & $\begin{array}{l}-0.13 \\
(0.089)\end{array}$ \\
\hline \multicolumn{3}{|c|}{ Effect of health insurance on effect of health shock } \\
\hline & Low PGS & High PGS \\
\hline Post 65 - Pre 65 & $\begin{array}{l}0.256 * * * \\
(0.079) \\
\end{array}$ & $\begin{array}{l}-0.023 \\
(0.121) \\
\end{array}$ \\
\hline \multicolumn{3}{|c|}{ Differential effect of health insurance by genetic group } \\
\hline & High PGS & - low PGS \\
\hline Post 65 - Pre 65 & $\begin{array}{c}-0.279 * \\
(0.144)\end{array}$ & \\
\hline
\end{tabular}

Low PGS = lowest tertile of the polygenic score distribution; high PGS = upper two tertiles of the polygenic score distribution. Pre-65: Health shock since the last survey reported at ages 60-64. Post-65: Health shock since the last survey reported at ages 67-70. ${ }^{*} \mathrm{P}<0.1$; ${ }^{* *} \mathrm{P}<0.05 ;{ }^{* * *} \mathrm{P}<$ 0.01 . Robust standard errors in parentheses are clustered at the individual level. The covariance matrix used for calculating standard errors is shown in Appendix Table 7. Effects are estimated using the coefficients in the last column of Table 3 and following the derivation described in C.5.

Data used: HRS study sample, $\mathrm{n}=5,854$.

On the contrary, the response of low polygenic score individuals differs markedly by the timing of the health shock: if the shock happens before the age of 65 , while not covered by Medicare or another health insurance, they reduce smoking by 17 percentage points. With a baseline probability of smoking of $27 \%$, this reduction is very sizable. On the other hand, if the health shock happens after the age of Medicare eligibility, low polygenic score individuals increase their smoking rate by 9 percentage points as compared to the rest of the population. Against the backdrop of a steady decline in smoking rates, as shown in Figure 4, this positive coefficient can be interpreted as a lower decrease in smoking for this particular sub-population. ${ }^{9}$

The difference in the smoking response depending on the timing of the health shock, before or after the age of 65, is summarized in Panel B of Table 2: individuals with a

\footnotetext{
${ }^{9}$ Notice that the magnitude of this coefficient (0.09) is similar to the ones estimated for high polygenic score individuals $(-0.108$ and -0.13$)$, but it is much more precisely estimated. The main reason behind smaller standard errors for the estimated effect of health shock after 65 for the low polygenic score individuals is the negative covariance $\operatorname{Cov}\left(\hat{\delta}_{1}, \hat{\lambda}_{2}\right)=-0.0057$. See Appendix Table 7 for the variance-covariance matrix of the estimated coefficients of equation 2. $\lambda_{2}$ captures the effect of the health shock in the uninsured population, and $\delta_{1}$ the incremental effect of that same health shock in the uninsured population after the age of 65 .
} 
low polygenic score are 25.6 percentage points more likely to stop smoking if the health shock happens before the age of 65 , when they are not covered by health insurance. High polygenic score individuals, on the other hand, are 2.3 percentage points more likely to do the opposite, a small and (statistically) insignificant difference.

Such marked difference in the response across the two genetic types is evidence of genetic heterogeneity in the effect of Medicare eligibility on the response to the shock. This genetic heterogeneity, a form of 'gene-environment interaction' (or $\mathrm{G} \times \mathrm{E}$ ) according to behavioral geneticists, ${ }^{10}$ is summarized in Panel C of Table 2: low PGS individuals are 27.9 percentage points less likely than high PGS individuals to stop smoking if the health shock happens when they are uninsured.

The evidence in favor of genetic heterogeneity is remarkably stable to the inclusion of different controls and fixed effects, as shown in the different columns of Table 3. The first column does not include polynomial controls for age or any type of time or

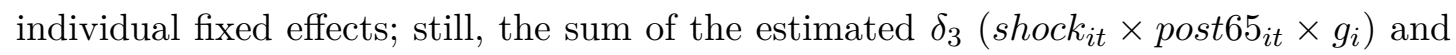

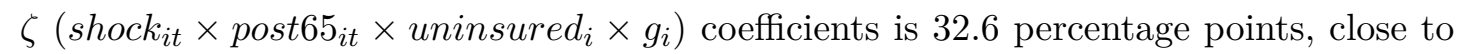
the 27.9 estimated with age controls and time and individual fixed effects, as reported in Panel C of Table 2.

How can we interpret this evidence of genetic heterogeneity? This result is consistent with the interpretation that high polygenic score individuals are less responsive and elastic in their response to shocks and changes in the environment. Regardless of whether the health shock happens when they are covered by health insurance, and therefore whether they are financially liable for the consequences of the health shock, they reduce smoking the same amount. Individuals with a low polygenic score are instead more flexible, strategic, and reactive to the environment: they reduce their smoking only when they bear the full cost of the consequences of negative health shocks. This result is therefore consistent with genetic heterogeneity in moral hazard.

\subsection{Other Interpretations}

Is it really Medicare? Other factors besides eligibility to Medicare may be at play around the age of 65 , the most prominent being retirement. Such factors might affect smoking behavior after health shocks and change the interpretation of our coefficient. Our empirical result about genetic heterogeneity would still stand, but the post-65 dummy could not be considered purely as a measure of health care eligibility, and the differential reduction in smoking before 65 would not be evidence of moral hazard heterogeneity.

However, these alternative interpretations are at odds with two findings: there is no effect for those already insured before the age of 65 , and there is no differential effect

\footnotetext{
${ }^{10}$ See for instance Anastasi (1958); Haldane (1946); Ottman and Rao (1990); Plomin (1990); Plomin, DeFries and Loehlin (1977).
} 
Table 3: Coefficients from estimating the linear probability model in equation (2) using OLS

\begin{tabular}{|c|c|c|c|c|c|}
\hline & \multicolumn{5}{|c|}{ Dependent variable: } \\
\hline & \multicolumn{5}{|c|}{ Smoking status } \\
\hline & (1) & (2) & (3) & (4) & (5) \\
\hline Health Shock & $\begin{array}{c}-0.027 \\
(0.040)\end{array}$ & $\begin{array}{c}-0.028 \\
(0.040)\end{array}$ & $\begin{array}{c}-0.027 \\
(0.040)\end{array}$ & $\begin{array}{r}-0.046^{*} \\
(0.024)\end{array}$ & $\begin{array}{r}-0.045^{*} \\
(0.024)\end{array}$ \\
\hline Post-65 & $\begin{array}{c}-0.064^{* * *} \\
(0.008)\end{array}$ & $\begin{array}{c}-0.020 \\
(0.012)\end{array}$ & $\begin{array}{c}-0.020 \\
(0.012)\end{array}$ & $\begin{array}{c}-0.010 \\
(0.008)\end{array}$ & $\begin{array}{c}-0.009 \\
(0.008)\end{array}$ \\
\hline Uninsured & $\begin{array}{l}0.169^{* * *} \\
(0.027)\end{array}$ & $\begin{array}{l}0.169^{* * *} \\
(0.027)\end{array}$ & $\begin{array}{l}0.169^{* * *} \\
(0.027)\end{array}$ & & \\
\hline High PGS & $\begin{array}{l}0.033^{* * *} \\
(0.012)\end{array}$ & $\begin{array}{l}0.033^{* * *} \\
(0.012)\end{array}$ & $\begin{array}{l}0.033^{* * *} \\
(0.012)\end{array}$ & & \\
\hline Shock $\times$ Post- 65 & $\begin{array}{c}0.008 \\
(0.056)\end{array}$ & $\begin{array}{c}0.018 \\
(0.056)\end{array}$ & $\begin{array}{c}0.016 \\
(0.056)\end{array}$ & $\begin{array}{c}0.026 \\
(0.032)\end{array}$ & $\begin{array}{c}0.025 \\
(0.032)\end{array}$ \\
\hline Shock $\times$ Uninsured & $\begin{array}{c}-0.193 \\
(0.184)\end{array}$ & $\begin{array}{c}-0.187 \\
(0.185)\end{array}$ & $\begin{array}{c}-0.188 \\
(0.184)\end{array}$ & $\begin{array}{c}-0.118 \\
(0.073)\end{array}$ & $\begin{array}{r}-0.120^{*} \\
(0.073)\end{array}$ \\
\hline Post-65 $\times$ Uninsured & $\begin{array}{c}0.068 \\
(0.048)\end{array}$ & $\begin{array}{c}0.067 \\
(0.048)\end{array}$ & $\begin{array}{c}0.067 \\
(0.048)\end{array}$ & $\begin{array}{r}-0.052^{*} \\
(0.031)\end{array}$ & $\begin{array}{r}-0.052^{*} \\
(0.031)\end{array}$ \\
\hline Shock $\times$ High PGS & $\begin{array}{c}0.028 \\
(0.049)\end{array}$ & $\begin{array}{c}0.029 \\
(0.049)\end{array}$ & $\begin{array}{c}0.026 \\
(0.049)\end{array}$ & $\begin{array}{c}0.015 \\
(0.029)\end{array}$ & $\begin{array}{c}0.015 \\
(0.029)\end{array}$ \\
\hline Post-65 × High PGS & $\begin{array}{c}-0.0003 \\
(0.010)\end{array}$ & $\begin{array}{c}-0.0005 \\
(0.010)\end{array}$ & $\begin{array}{c}-0.0005 \\
(0.010)\end{array}$ & $\begin{array}{c}-0.005 \\
(0.008)\end{array}$ & $\begin{array}{c}-0.005 \\
(0.008)\end{array}$ \\
\hline Shock $\times$ Post- $65 \times$ Uninsured & $\begin{array}{c}0.343 \\
(0.256)\end{array}$ & $\begin{array}{c}0.336 \\
(0.256)\end{array}$ & $\begin{array}{c}0.336 \\
(0.255)\end{array}$ & $\begin{array}{l}0.230^{* * *} \\
(0.086)\end{array}$ & $\begin{array}{l}0.230^{* * *} \\
(0.085)\end{array}$ \\
\hline Shock $\times$ Uninsured $\times$ High PGS & $\begin{array}{c}0.184 \\
(0.219)\end{array}$ & $\begin{array}{c}0.182 \\
(0.220)\end{array}$ & $\begin{array}{c}0.183 \\
(0.219)\end{array}$ & $\begin{array}{c}0.041 \\
(0.112)\end{array}$ & $\begin{array}{c}0.042 \\
(0.112)\end{array}$ \\
\hline Shock $\times$ Post- $65 \times$ High PGS & $\begin{array}{c}-0.047 \\
(0.068)\end{array}$ & $\begin{array}{r}-0.047 \\
(0.068)\end{array}$ & $\begin{array}{c}-0.045 \\
(0.068)\end{array}$ & $\begin{array}{r}-0.078^{*} \\
(0.042)\end{array}$ & $\begin{array}{r}-0.078^{*} \\
(0.042)\end{array}$ \\
\hline Post-65 $\times$ Uninsured $\times$ High PGS & $\begin{array}{r}-0.116^{*} \\
(0.061)\end{array}$ & $\begin{array}{r}-0.117^{*} \\
(0.062)\end{array}$ & $\begin{array}{r}-0.117^{*} \\
(0.062)\end{array}$ & $\begin{array}{c}0.042 \\
(0.036)\end{array}$ & $\begin{array}{c}0.042 \\
(0.036)\end{array}$ \\
\hline Shock $\times$ Post- $65 \times$ Uninsured $\times$ High PGS & $\begin{array}{c}-0.279 \\
(0.311)\end{array}$ & $\begin{array}{c}-0.278 \\
(0.312)\end{array}$ & $\begin{array}{c}-0.278 \\
(0.311)\end{array}$ & $\begin{array}{c}-0.199 \\
(0.151)\end{array}$ & $\begin{array}{r}-0.200 \\
(0.150)\end{array}$ \\
\hline $\begin{array}{l}\text { Age } \\
\text { Year FE } \\
\text { Individual FE }\end{array}$ & & Yes & $\begin{array}{l}\text { Yes } \\
\text { Yes }\end{array}$ & $\begin{array}{l}\text { Yes } \\
\text { Yes }\end{array}$ & $\begin{array}{l}\text { Yes } \\
\text { Yes } \\
\text { Yes }\end{array}$ \\
\hline $\begin{array}{l}\text { Observations } \\
\mathrm{R}^{2}\end{array}$ & $\begin{array}{c}26,022 \\
0.015\end{array}$ & $\begin{array}{c}26,022 \\
0.017\end{array}$ & $\begin{array}{c}26,022 \\
0.017\end{array}$ & $\begin{array}{c}26,022 \\
0.823\end{array}$ & $\begin{array}{c}26,022 \\
0.823\end{array}$ \\
\hline
\end{tabular}

Notes: Health shock = binary indicator for having suffered a cardiovascular health shock for the first time since the previous wave. Post- $65=$ indicator for age $>65$ at the time of the interview. Uninsured = binary indicator for being persistently uninsured in every observation of the study sample before the age of 65 . High PGS = indicator for being in the upper two tertiles of the polygenic score distribution. Age $=$ controls for $3^{\text {rd }}$ degree polynomial in age. $\mathrm{FE}=$ adding fixed effects. Robust standard errors in parentheses are clustered at the individual level. ${ }^{*} \mathrm{p}<0.1{ }^{* *} \mathrm{p}<0.05{ }^{* * *} \mathrm{p}<0.01$. Data used: HRS study sample, $\mathrm{n}=5,854$. 
on income or retirement.

First, as Table 3 shows, the estimated coefficient on the shock $x$ post- 65 interaction is close to 0 and not statistically significant, suggesting no differential effect of the health shock on the probability of smoking for those individuals already covered by health insurance before the age of 65 . If other factors rather than health insurance status were to cause the difference between the effects of a pre- vs. post-65 health shock in the low-PGS group, one could expect to also see an effect for those already insured before the age of 65 .

Secondly, as Panels (a), (b), and (c) of Figure 6 show, there is no apparent jump in income or the probability of retirement exactly at the age of 65 in our sample. Contrasting this with the sharp change in enrollment in Medicare (Figure 3) and drop in the share of uninsured (Figure 3) suggests that the main event captured by the post-65 dummy for the sample of previously uninsured individuals is access to health coverage.

Finally, as shown in Figure 8, there is no differential effect of the health shock before or after the age of 65 on the reported income or the probability of retirement of persistently uninsured individuals. The absence of any discernible effect suggests that neither income nor retirement are potential mechanisms behind the observed change in smoking responses.

Figure 6: Retirement and income across the age 65 threshold by PGS.

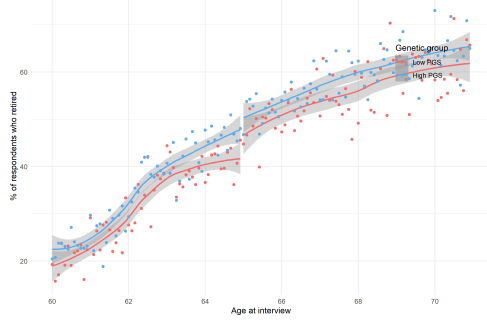

(a) Share retired

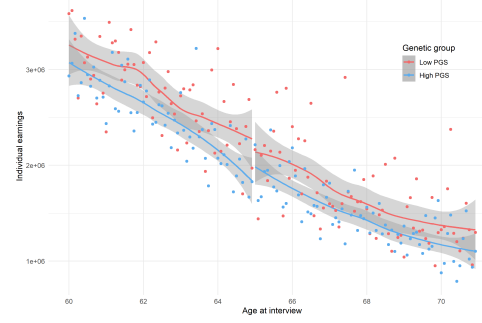

(b) Earned Income

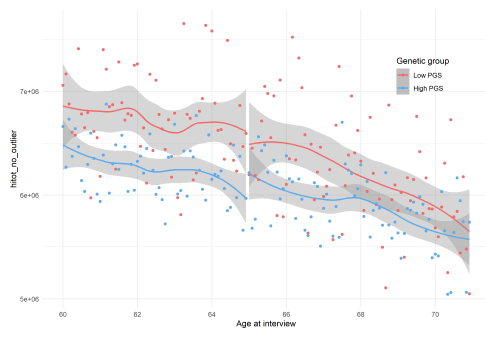

(c) Total Household Income

Notes: Self-reported retirement status, earned income, and total-household income over time. Bin-scattered plot and generalized linear smoothed correlation between age and outcome variables shown in red (low PGS = lowest tertile of polygenic score) and blue (high PGS = upper two tertiles of polygenic score).

Data used: HRS waves 1-13, restricted to observations with age between 60 and 70 years.

Is it really genes? Other individual-level characteristics, besides genetic predispositions, might be driving this heterogeneity in moral hazard. For instance, education, cognitive abilities, personality traits, or risk aversion might be a better proxy of individual level heterogeneity driving a differential response to health shocks. Given the richness of the HRS data, we can run the same analysis outlined in equation 2 but replacing $g_{i}$ with other individual characteristics.

None of the other individual measures that we have tried seems to be driving hetero- 
geneity in moral hazard, as shown in Figure 7. Specifically, we tested for years of education (highly educated people might be more knowledgeable of the insurance system), a proxy of cognitive abilities ${ }^{11}$ (smart people might be more strategic), risk aversion measured through hypothetical gambles on lifetime income (individual risk preferences might moderate both smoking behaviors and the response to health shocks), the Big-5 personality trait conscientiousness (conscientious people might be more likely to follow the doctor's advice of stopping smoking after a health shock), gender (social scientist's favorite sample split to engage in ex-post rationalizations), and individual and household income (which might be a buffer for the negative shock). ${ }^{12}$ For completeness, results are shown split by tertiles for continuous measures, and in two for binary measures.

Is this driven by confounders? One might worry that the differential change in smoking behavior might be driven by other confounding factors that coincidentally happen around the age of 65 , or are triggered by the health shock. For example, suffering a heart attack might reduce people's income, induce them to retire, change their marital status, increase their out-of-pocket medical spending, or shorten their life expectancy. Any of these changes happening differentially for people with high or a low polygenic score, and before or after the age of 65 , could invalidate our results or at least our interpretation of the effect as evidence of moral hazard. To test the plausibility of these concerns, we estimate equation 2 again including each of these potential confounders as an outcome variable $Y_{i t}$, as suggested by Pei, Pischke and Schwandt (2018).

None of these potential confounders seems to be driving our results, as shown in Figure 8. If anything, the symmetric results for out-of-pocket medical expenditure shown in panel (e) suggest that the size of the health shock is comparable for both high and low PGS individuals: both report an increase of about $2 \%$ in out-of-pocket medical expenditure if the shock happens before the age of 65 (when uninsured) and a change smaller than $0.3 \%$ if the shock happened after for low PGS, and a reduction of about $1 \%$ for those with high PGS (and not statistically significant for neither of these last two estimators).

\footnotetext{
${ }^{11}$ Calculated by HRS as the sum of a word recall task (Total Recall Index) and a counting, naming, and vocabulary task (Mental Status Index).

${ }^{12}$ Notice that some of these variables are not quite predetermined, baseline characteristics of the individuals. Some might actually be mediators of the overall effect, or "bad controls" in the terminology of Angrist and Pischke (2008), especially income. We still report the results for completeness, but caution the reader prone to causal interpretations. In this regard, genetic variants represent the ideal measure of heterogeneity of treatment effects: they are fixed since conception, immutable, identically measured across the whole human species, and indexing plausible biological channels which are increasingly studied and documented by a wide range of disciplines. In Appendix D.3.4, we report the results of using different polygenic scores as a proxy for $g_{i}$. Moral hazard heterogeneity is also detected in the group having a high PGS for educational attainment or cognitive abilities (Lee et al., 2018), and a low PGS for risk tolerance (Karlsson Linnér et al., 2019) and a low PGS for non-cognitive skills (Demange et al., 2020). On the other side, there is no evidence of heterogeneity of moral hazard by the PGS for Body-Mass-Index (Yengo et al., 2018) or the PGS for cigarettes per day (Liu et al., 2019). These results suggest that potential mechanisms for the observed heterogeneity should include not only biological channels related to nicotine addiction, but also cognitive processes related to risky and strategic behavior, which are closely related to the concept of moral hazard.
} 
Figure 7: Other Individual Characteristics as Proxy for Moral Hazard Heterogeneity

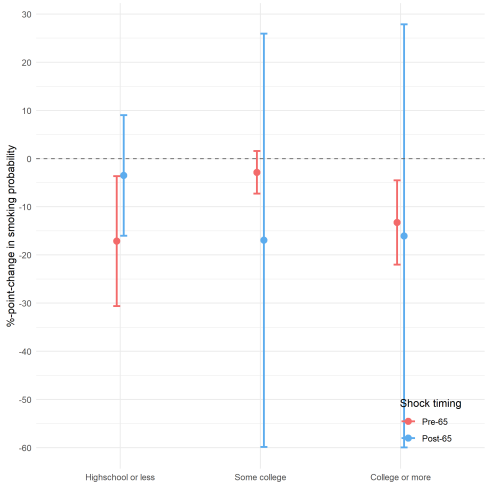

(a) Years of Education

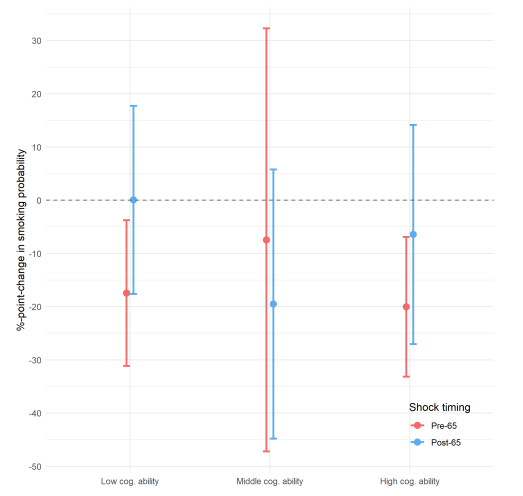

(b) Cognitive Skills

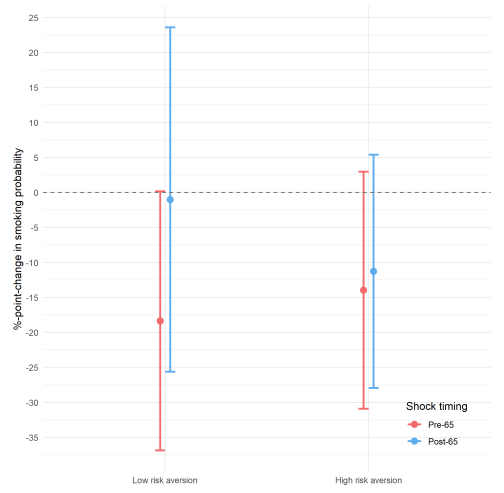

(c) Risk Aversion

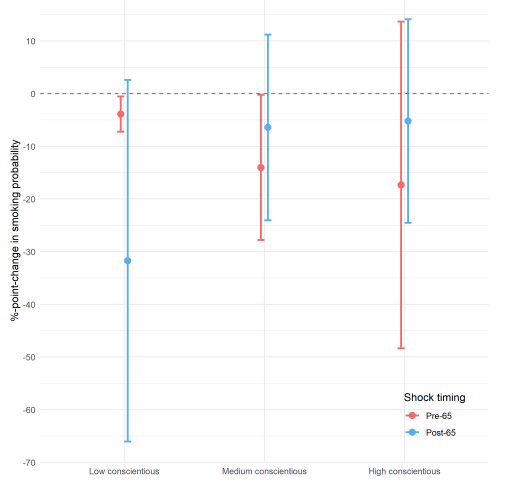

(d) Conscientiousness (Big-5)

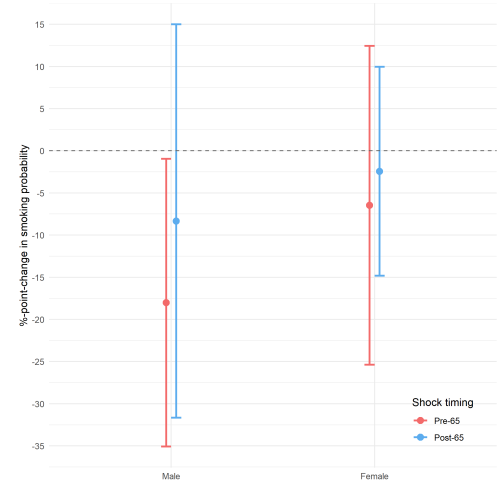

(e) Gender

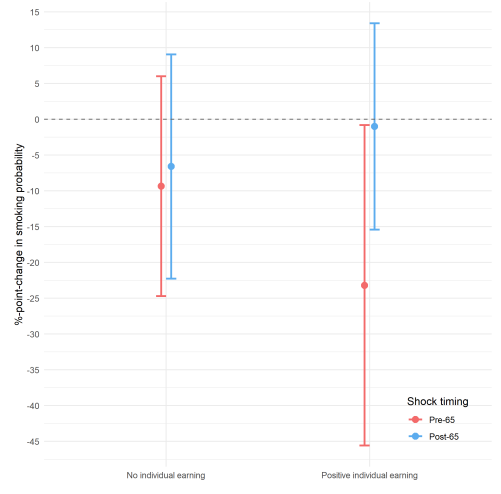

(f) Earnings

Notes: The figures report the effect of suffering a health shock on the probability of smoking for the pre-65 uninsured subgroup, stratified by timing of the shock (before and after the age of 65) and different measures of individual characteristics. Effects are estimated using a combination of the coefficients from equation 2 where $g_{i}$ is replaced by the different individual characteristics reported in the sub-figure captions, following the derivation described in C.5. Pre-65: Health shock since the last survey reported at ages 60-64. Post-65: Health shock since the last survey reported at ages $67-70$. Bars show $95 \%$ confidence intervals, standard error clustered at the individual level. Data used: HRS study sample, $\mathrm{n}=5,854$.

\subsection{Robustness checks}

These results are robust to changes in the definition of the high-PGS indicator (having a PGS above the median, using a linear PGS, using an older GWAS for the weights) and the definition of the pre-65 uninsured status indicator (uninsured in $33 \%$ or $66 \%$ of all pre-65 observations instead of $100 \%$ ). Relaxing the definition of the uninsured indicator to include respondents uninsured in a minimum of $33 \%$ of pre- 65 observations leaves the directions of the effects unchanged, but the magnitudes are smaller and statistical significance is lost. Furthermore, the findings of this study do not depend on the exclusion of HRS respondents for whom Medicare eligibility status at the time of the shock is unknown (when health shocks are reported at ages 65 or 66). Estimation results for all robustness checks are shown in Section D.3 in the Appendix. 
Figure 8: Testing for Potential Confounders

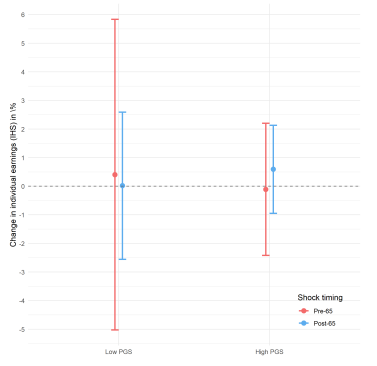

(a) Earned Income (IHS)

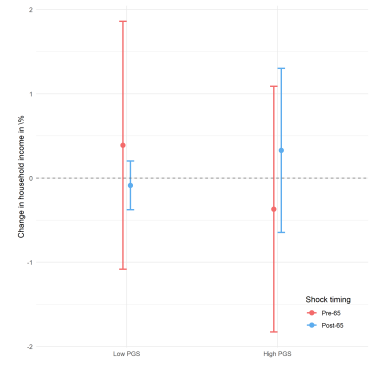

(b) Total Household Income (IHS)

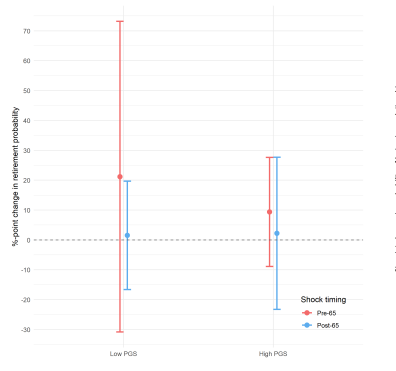

(c) Probability of Retiring

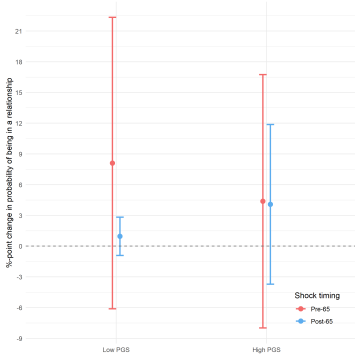

(d) Relationship status

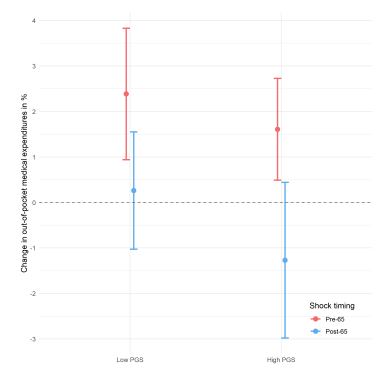

(e) Medical expenditure

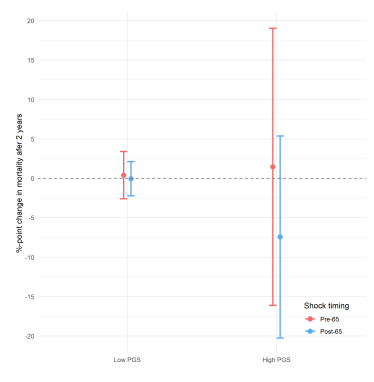

(f) 2 Year Mortality

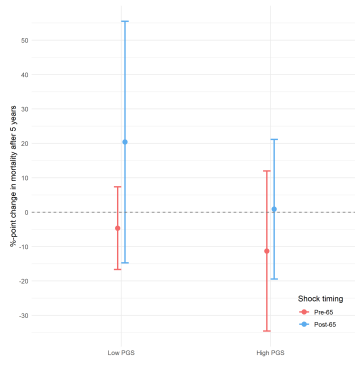

(g) 5 Year Mortality

Notes: The figures report the effect of suffering a health shock for the pre- 65 uninsured subgroup, stratified by timing of the shock (before and after the age of 65) and having a high or low polygenic score, on various possible confounders. Effects are estimated using a combination of the coefficients from equation 2 where the outcome $Y_{i t}$ is replaced by the different confounders reported in the sub-figure captions, following the derivation described in C.5. Low PGS = lowest tertile of the polygenic score distribution; high PGS = upper two tertiles of the polygenic score distribution. IHS: inverse hyperbolic sine (similar to log). Pre-65: Health shock since the last survey reported at ages 60-64. Post-65: Health shock since the last survey reported at ages 67-70. Estimates and standard errors are shown in Panel A of Table 2. Effects are estimated using the coefficients in the last column of Table 3 and following the derivation described in C.5. Bars show $95 \%$ confidence intervals, standard error clustered at the individual level.

Data used: HRS study sample, $\mathrm{n}=5,854$.

\section{Discussion}

In this study, experiencing a cardiovascular health shock is associated with a significant reduction in the smoking probability of uninsured 60- to 64-year-old individuals with a low index of genetic propensity to smoke. Medicare eligibility after age 65 (and hence a lower exposure to the financial costs of illness) fully neutralized this cessation effect, indicating the presence of moral hazard caused by insurance coverage. For individuals with a high genetic propensity to smoke, experiencing a health shock does not significantly affect the smoking probability, irrespective of whether the shock is at a time of high or low exposure to the financial costs of illness.

The effect of health shocks on changes in smoking behavior, as well as the underlying mechanisms, have been addressed before (Clark and Etilé, 2002; Falba, 2005; Keenan, 2009; Khwaja, Sloan and Chung, 2006a,b; Marti and Richards, 2017; Richards and Marti, 2014; Smith et al., 2001; Sundmacher, 2012; Wray et al., 1998). Previous 
empirical work has found strong evidence of an increase in smoking cessation after a health shock (Clark and Etilé, 2002; Falba, 2005; Keenan, 2009; Marti and Richards, 2017; Richards and Marti, 2014; Sundmacher, 2012; Wray et al., 1998). The mechanism that has received a lot of attention in earlier research is a changed perception of personal health risks and survival probability, motivating the individual to reduce tobacco consumption to improve future health (Clark and Etilé, 2002; Khwaja, Sloan and Chung, $2006 a, b$; Smith et al., 2001).

Marti and Richards (2017); Richards and Marti (2014) have highlighted the role that financial costs associated with health shocks, as opposed to only the health considerations, can play in determining the post-shock smoking decision. In individuals with high financial risk exposure, health shocks may bring about significant out-of-pocket medical costs. At the same time, the financial consequences of smoking-related illness are likely more complex and opaque to the individual than the health-related consequences of smoking.

The mechanism presented in these studies suggests that through improving their grasp on the financial cost of smoking, the increase in out-of-pocket health care costs following the health shock can serve as an impetus for smoking cessation. Using the same design that we follow in this analysis (the age-based eligibility threshold for the Medicare program), a recent study has provided robust evidence for this mechanism (Marti and Richards, 2017). Without investigating potential heterogeneity between genetic groups, they found that, on average, moral hazard is present, and Medicare eligibility reduced the cessation effect that a cardiovascular health shock had for uninsured individuals.

Our analysis shows that this average effect is likely driven by individuals with a low genetic predisposition for smoking only. The effect cannot be observed for the subgroup of individuals with a high genetic predisposition for smoking, suggesting that genetic makeup can act as a constraint and limit the extent to which incentives for behavior change are translated into actual behavior change.

The question of how insurance policies can interact with genetic predispositions for risky health behaviors is interesting from a policy perspective for several reasons. The finding that insurance affected the post-shock smoking decision only in part of the sample suggests that the considered type of moral hazard in health insurance, which causes excess smoking among an already sick population, is less prevalent than an initial inspection may suggest. This insight may alleviate one possible concern against universal public health care coverage (Einav and Finkelstein, 2018; Mendoza, 2016).

On a broader level, awareness of the possibility of interactions between genetics and health insurance is important for understanding how the health insurance system can increase or reduce genetically induced health inequalities in a society. By highlighting the role of genetic influences on the propensity for and ability to quit unhealthy behaviors, this study also points to possible limitations on the extent to which insurance can 
cause health behavior changes through financial incentives.

Genetically determined limitations on the effectiveness of financial incentives are important to consider not just when evaluating the effectiveness of health insurance policies, but also the fairness therein. With recent technological advances, for example in the field of wearable tech, health insurers are discovering more and more possibilities for monitoring health behaviors. This information is increasingly used for pricing, with the explicit goal of motivating behavior change through financial incentives in the form of lower insurance premiums or deductibles (Olson, 2014; Young, 2017).

In light of this development, the possibility that genetic predisposition prevents individuals from changing health behaviors, despite strong incentives for doing so, is becoming increasingly relevant. By emphasizing the correlation between genetic risk and an inability to quit unhealthy behaviors, the findings in this study may raise the following question: To what extent do insurance policies that price differentiate based on health behaviors ultimately also discriminate based on genetics? Under current US legislation, the 2008 Genetic Information Nondiscrimination Act prohibits health insurers from discriminating based on explicit genetic information. Not wanting to punish those who are disadvantaged in terms of their genetic makeup is one of the motivations behind this legislation. To create a health insurance system that can incentivize healthy behaviors and simultaneously reflect society's perception of fairness, it will be important for future research to further enhance our understanding of how genetics and health insurance interact and jointly affect health behaviors.

\subsection{Limitations}

This study has a few limitations. First, the results hinge on a small number of respondents who suffer a health shock around the age of 65 . Although the total sample size used in the regression is greater than 5 thousand individuals, the number of people in each cell (i.e. those who suffer a health shock, before or after the age of 65 , and have a certain polygenic score) is between 110 and $274 .{ }^{13}$ We encourage and welcome a replication of our results, preferably in a within-family design which can better account for the thorny issue of ancestry and population structure, but we are unaware of an existing dataset that contains all of the necessary information about genetic predispositions, health insurance coverage, and smoking behaviors.

Second, the analysis focused on the short-run smoking response to a health shock, and only considered changes in the extensive margin - i.e., changes between smoking and not smoking. From a public health perspective, interactions of genetics with both the long-term persistence of the behavior change as well as behavior changes along the intensive margin of smoking - i.e., changes in the number of cigarettes smoked or the

\footnotetext{
${ }^{13}$ See number of observations in Appendix Table 5.
} 
intention to quit smoking - may be of interest.

Third, a few caveats regarding the internal validity of the study. This study relied on self-reported information regarding smoking behavior, health diagnoses, and insurance status. If participants of different ages and different genotypes differentially misreported their smoking status, for example, the estimated effect of Medicare eligibility on the smoking response to a health shock could be biased. We have found no published evidence that misreporting might be associated with individual genotypes. It is also possible that those identified as continuously uninsured before the age of 65 had insured spells in between the biennial HRS interviews. These unmeasured episodes with coverage may have biased the results towards not finding a significant effect of Medicare eligibility. Finally, this study may also suffer from survivorship bias and attrition. Because DNA collection and genotyping took place relatively late during the HRS (starting in 2006), it is possible that study participants with very high genetic susceptibility for smoking, and hence particularly unhealthy smoking habits, passed away before the DNA collection and are systematically excluded from the study population. Within the study population, participants with the highest genetic propensity to smoke may have been less likely to reach the age of Medicare eligibility, hence leading to relatively lower genetic risk in the group that experienced health shocks post-65. Both problems would likely have lead to an underestimation of the difference between lowand high-PGS individuals.

Lastly, a few words of caution on the external validity of the study. The transition from being uninsured to being eligible for Medicare at age 65 is a setting that is very specific to the health care system in the US. While Medicare can generally be seen as just one example of universal health care coverage, it only applies to a specific age group, and it is not clear whether smoking behaviors in response to a health shock in this age group are representative for all ages in the population. Another possible concern may be that Medicare eligibility does not necessarily translate into Medicare coverage, as take-up rates are not at $100 \%$. As Figure 3 shows, however, the fraction of eligible HRS respondents in the study sample who are actually enrolled in Medicare is high - approximately $90 \%$ at age 65 , increasing to $98 \%$ at age 70 . Additionally, take-up patterns do not differ much between the genetic groups. Table 14 in the Appendix shows that using actual Medicare enrollment status rather than Medicare eligibility status in the empirical analysis does not change the results.

\section{Conclusions}

Medicare eligibility significantly lowered the probability of smoking cessation after a health shock in individuals aged between 60 and 70 years who are uninsured before the age of 65 and have a low genetic predisposition for smoking. Health insurance can 
plausibly affect the smoking response to a health shock by lowering the financial risk associated with the shock, and thereby eroding additional incentives for behavior change. This change in behavior following Medicare eligibility is indicative of moral hazard and is not observable among individuals with a high genetic predisposition for smoking. The differential effect of Medicare eligibility for the two genetic groups suggests that biological constraints can overpower both health-related and financial incentives for smoking cessation, and provides a readily available measure of heterogeneity in moral hazard. Heterogeneity in moral hazard can be used to enrich economic models of health behavior $^{14}$ and our understanding of how individual biological characteristics can influence decision-making.

Building on previous work analyzing the interplay between genes and exogenous environmental changes (Barcellos, Carvalho and Turley, 2018; Fletcher, 2012; Schmitz and Conley, 2017a), this study provides a contribution to the centennial debate about nature and nurture (Galton, 1874; Haldane, 1946; Kong et al., 2018; Lundborg and Stenberg, 2010; Mulcaster, 1582), casting further doubts about genetic determinism. The influence of genetic variants on our choices and outcomes is modulated by the environment around us, just as the response to environmental shocks is filtered through the prism of our genetic predispositions.

Our results show that genetic factors can influence health decisions and strategic behaviors, and therefore should be taken into consideration when evaluating the effectiveness and fairness of different policies, such as health insurance. Fairness considerations should take into account the fact that genetic endowments are passed down from one generation to the next, are fixed at conception, and cannot be changed by an individual's choices or effort, raising questions of deservedness, merit, and luck (Harden, In Press; Kweon et al., 2020; Pereira, 2021). Efficiency considerations should consider that genetic endowments are usually unobserved to the individual, the insurance companies, and the government. This unobservability raises important regulatory questions at the intersection between health and information economics: who, if anyone, should have this information? How should the information be provided? How will this information affect demand and supply? Should private contracts or public policies take this information into account? The recent rise of direct-to-consumer genetic testing services might force this discussion into the public debate sooner than expected.

More generally, future studies should build off of the idea of leveraging existing indices of genetic predispositions to provide biological measures of heterogeneity in human behaviors. This can enrich economic models and empirical studies, shedding new light on fundamental economic parameters.

\footnotetext{
${ }^{14}$ For example, see the model in Appendix E.
} 


\section{References}

Anastasi, Anne. 1958. "Heredity, environment, and the question "How?"." Psychological Review, 65: 197-208.

Angrist, Joshua D, and Jörn-Steffen Pischke. 2008. Mostly harmless econometrics: An empiricist's companion. Princeton University Press.

Arrow, Kenneth J. 1963. "Uncertainty and the Welfare Economics of Medical Care." The American Economic Review, 53(5): 941-973.

Barcellos, Silvia H, Leandro S Carvalho, and Patrick Turley. 2018. "Education can reduce health differences related to genetic risk of obesity." Proceedings of the National Academy of Sciences, 201802909.

Barnett, Jessica C, and Marina Vornovitsky. 2016. "Health Insurance Coverage in the United States: 2015." US Census Bureau, Washington DC.

Barth, Daniel, Nicholas W Papageorge, and Kevin Thom. 2019. "Genetic Endowments and Wealth Inequality." Journal of Political Economy, 705415.

Belsky, Daniel W, Benjamin W Domingue, Robbee Wedow, Louise Arseneault, and Jason D Boardman. 2018. "Genetic analysis of social-class mobility in five longitudinal studies." Proceedings of the National Academy of Sciences, 1-10.

Belsky, Daniel W, Terrie E Moffitt, Timothy B Baker, Andrea K Biddle, James P Evans, HonaLee Harrington, Renate Houts, Madeline Meier, Karen Sugden, Benjamin Williams, et al. 2013. "Polygenic risk and the developmental progression to heavy, persistent smoking and nicotine dependence: evidence from a 4-decade longitudinal study." JAMA psychiatry, 70(5): 534-542.

Bierut, Laura Jean, Eric O Johnson, and Nancy L Saccone. 2014. "A glimpse into the future-Personalized medicine for smoking cessation." Neuropharmacology, 76: 592-599.

Boardman, Jason D, Casey L Blalock, and Fred C Pampel. 2010. "Trends in the Genetic Influences on Smoking." Journal of Health and Social Behavior, 51(1): 108123.

Card, David, Carlos Dobkin, and Nicole Maestas. 2009. "Does Medicare Save Lives?" Quarterly Journal of Economics, 124(2): 597-636.

Card, D, C Dobkin, and N Maestas. 2008. "The impact of nearly universal insurance coverage on health care utilization: evidence from Medicare." American Economic Review, 98(5): 2242-58.

Caspi, Avshalom, Joseph McClay, Terrie E Moffitt, Jonathan Mill, Judy Martin, Ian W Craig, Alan Taylor, and Richie Poulton. 2002. "Role of genotype in the cycle of violence in maltreated children." Science, 297(5582): 851-4.

Chatterjee, Chirantan, Radhika Joshi, Neeraj Sood, and P. Boregowda. 2018. "Government health insurance and spatial peer effects: New evidence from India." Social Science and Medicine, 196: 131-141. 
Chen, Li-Shiun, Eric O Johnson, Naomi Breslau, Dorothy Hatsukami, Nancy L Saccone, Richard A Grucza, Jen C Wang, Anthony L Hinrichs, Louis Fox, Alison M Goate, et al. 2009. "Interplay of genetic risk factors and parent monitoring in risk for nicotine dependence." Addiction, 104(10): 1731-1740.

Clark, Andrew, and Fabrice Etilé. 2002. "Do health changes affect smoking? Evidence from British panel data." Journal of health economics, 21(4): 533-62.

Cohen, Robin A, Diane M Makuc, Amy B Bernstein, Linda T Bilheimer, and Eve Powell-Griner. 2009. "Health insurance coverage trends, 1959-2007: estimates from the National Health Interview Survey." National health statistics reports, 17: 125 .

Dave, Dhaval M, and Robert Kaestner. 2009. "Health insurance and ex ante moral hazard: evidence from Medicare." International Journal of Health Care Finance and Economics, 9(4): 367-390.

Demange, Perline A, Margherita Malanchini, Travis T Mallard, Pietro Biroli, Simon R Cox, Andrew D Grotzinger, Elliot M Tucker-drob, Abdel Abdellaoui, Louise Arseneault, Avshalom Caspi, David Corcoran, Benjamin W Domingue, Elsje Van Bergen, Dorret I Boomsma, Kathleen M Harris, Hill F Ip, Terrie E Moffitt, Richie Poulton, Joseph Prinz, Karen Sugden, Jasmin Wertz, Eveline L De Zeeuw, Daniel W Belsky, K Paige Harden, Michel G Nivard, Colter Mitchell, Elsje van Bergen, Dorret I Boomsma, Kathleen M Harris, Hill F Ip, Terrie Moffitt, Richie Poulton, Joseph Prinz, Karen Sugden, Jasmin Wertz, Benjamin Williams, Eveline de Zeeuw, Daniel W Belsky, K Paige Harden, and Michel G Nivard. 2020. "Investigating the Genetic Architecture of Non-Cognitive Skills Using GWASby-Subtraction." bioRxiv.

Domingue, Benjamin W, Dalton Conley, Jason Fletcher, and Jason D Boardman. 2016. "Cohort effects in the genetic influence on smoking." Behavior genetics, 46(1): $31-42$.

Dubois, Pierre, and Tomislav Vukina. 2009. "Optimal incentives under moral hazard and heterogeneous agents: Evidence from production contracts data." International Journal of Industrial Organization, 27(4): 489-500.

Einav, Liran, Amy Finkelstein, Stephen P Ryan, Paul Schrimpf, and Mark R Cullen. 2013. "Selection on Moral Hazard in Health Insurance." American Economic Review, 103(1): 178-219.

Einav, Liran, and Amy Finkelstein. 2018. "Moral Hazard in Health Insurance: What We Know and How We Know It." Journal of the European Economic Association, 16(4): 957-982.

Falba, Tracy. 2005. "Health events and the smoking cessation of middle aged Americans." Journal of behavioral medicine, 28(1): 21-33.

Finkelstein, Amy. 2014. Moral Hazard in Health Insurance. New York Chichester, West Sussex:Columbia University Press. 
Fletcher, Jason M. 2012. "Why have tobacco control policies stalled? Using genetic moderation to examine policy impacts." PloS one, 7(12): e50576.

Freese, Jeremy. 2018. "The Arrival of Social Science Genomics." Contemporary Sociology: A Journal of Reviews, 47(5): 524-536.

Galton, Francis. 1874. English men of science: Their nature and nurture. London:McMillan \& Co.

Goodchild, Mark, Nigar Nargis, and Edouard Tursan d'Espaignet. 2018. "Global economic cost of smoking-attributable diseases." Tobacco Control, 27(1): 5864 .

Haldane, John Burdon Sanderson. 1946. "The interaction of nature and nurture." Annals of Eugenics, 13(3): 197-205.

Hall, W, P Madden, and M Lynskey. 2002. "The genetics of tobacco use: methods, findings and policy implications." Tobacco control, 11(2): 119-24.

Hamer, D, and L. Sirota. 2000. "Beware the chopsticks gene." Molecular Psychiatry, 5(1): 11-13.

Harden, Kathryn Paige. In Press. The Genetic Lottery. Princeton University Press.

Harper, Peter S. 1993. "Insurance and genetic testing." The Lancet, 341(8843): 495.

Health and Retirement Study. HRS polygenic scores 2006-2010 genetic data, public use dataset. Produced and distributed by the University of Michigan with funding from the National Institute on Aging (grant number NIA U01AG009740). Ann Arbor, MI. 2018. n.d.b.

Health and Retirement Study. RAND HRS longitudinal file 2014, version P, public use dataset. Produced and distributed by the University of Michigan with funding from the National Institute on Aging (grant number NIA U01AG009740). Ann Arbor, MI. 2018. n.d.a.

Heath, Andrew C., Randall Cates, Nicholas G Martin, Joanne Meyer, John K. Hewitt, Michael C. Neale, and Lindon J. Eaves. 1993. "Genetic contribution to risk of smoking initiation: Comparisons across birth cohorts and across cultures." Journal of Substance Abuse, 5(3): 221-246.

Hoffmann, Roman. 2017. "Following the peers: The role of social networks for health care utilization in the Philippines." Working Paper.

HRS. 2017a. "Health and Retirement Study. Sample sizes and response rates." https://hrs.isr.umich. edu/sites/default/files/biblio/ ResponseRates_2017. pdf., Accessed on April 20, 2018.

HRS. 2017b. "Survey Research Center, Institute for Social Research, University of Michigan. The Health and Retirement Study - aging in the 21st century." http://hrsonline. isr. umich. edu/sitedocs/databook/inc/ pdf/HRS-Aging-in-the-21St-Century. pdf., Accessed on May 14, 2018. 
HRS. n.d.. "Health and Retirement Study. A public resource for data on aging in America since 1990." http://hrsonline. isr.umich. edu/, Accessed on May 6, 2018.

Jamal, Ahmed, Brian A. King, Linda J. Neff, Jennifer Whitmill, Stephen D. Babb, and Corinne M. Graffunder. 2016. "Current Cigarette Smoking Among Adults - United States, 2005-2015." MMWR. Morbidity and Mortality Weekly Report, 65(44): 1205-1211.

Johnson, Eric O, Li-Shiun Chen, Naomi Breslau, Dorothy Hatsukami, Tania Robbins, Nancy L Saccone, Richard A Grucza, and Laura J Bierut. 2010. "Peer smoking and the nicotinic receptor genes: an examination of genetic and environmental risks for nicotine dependence." Addiction, 105(11): 2014-2022.

Karlsson Linnér, Richard, Pietro Biroli, Edward Kong, S Fleur W Meddens, Robbee Wedow, Mark Alan Fontana, Maël Lebreton, Stephen P Tino, Abdel Abdellaoui, Anke R Hammerschlag, Michel G Nivard, Aysu Okbay, Cornelius A Rietveld, Pascal N Timshel, Maciej Trzaskowski, Ronald de Vlaming, Christian L Zünd, Yanchun Bao, Laura Buzdugan, Ann H Caplin, Chia-Yen Chen, Peter Eibich, Pierre Fontanillas, Juan R Gonzalez, Peter K Joshi, Ville Karhunen, Aaron Kleinman, Remy Z Levin, Christina M Lill, Gerardus A Meddens, Gerard Muntané, Sandra Sanchez-Roige, Frank JA van Rooij, Erdogan Taskesen, Yang Wu, Futao Zhang, Adam Auton, Jason D Boardman, David W Clark, Andrew Conlin, Conor C Dolan, Urs Fischbacher, Patrick J F Groenen, Kathleen Mullan Harris, Gregor Hasler, Albert Hofman, Mohammad A Ikram, Sonia Jain, Robert Karlsson, Ronald C Kessler, Maarten Kooyman, James MacKillop, Minna Männikkö, Carlos Morcillo-Suarez, Matthew B McQueen, Klaus M Schmidt, Melissa C Smart, Matthias Sutter, A Roy Thurik, André G Uitterlinden, Jon White, Harriet de Wit, Jian Yang, Lars Bertram, Dorret I Boomsma, Tõnu Esko, Ernst Fehr, David A Hinds, Magnus Johannesson, Meena Kumari, David Laibson, Patrik K E Magnusson, Michelle N Meyer, Arcadi Navarro, Abraham A Palmer, Tune H Pers, Danielle Posthuma, Daniel Schunk, Murray B Stein, Rauli Svento, Henning Tiemeier, Paul R H J Timmers, Patrick Turley, Robert J Ursano, Gert G Wagner, James F Wilson, Jacob Gratten, James J Lee, David Cesarini, Daniel J Benjamin, Philipp D Koellinger, and Jonathan P Beauchamp. 2019. "Genome-wide association analyses of risk tolerance and risky behaviors in over 1 million individuals identify hundreds of loci and shared genetic influences." Nature Genetics, 51(2): 245257.

Keenan, Patricia S. 2009. "Smoking and Weight Change After New Health Diagnoses in Older Adults." Archives of Internal Medicine, 169(3): 237.

Khera, Amit V, Mark Chaffin, Krishna G. Aragam, Mary E. Haas, Carolina Roselli, Seung Hoan Choi, Pradeep Natarajan, Eric S. Lander, Steven A. Lubitz, Patrick T. Ellinor, and Sekar Kathiresan. 2018. "Genome-wide polygenic scores for common diseases identify individuals with risk equivalent to monogenic mutations." Nature Genetics, 1. 
Khwaja, Ahmed, Frank Sloan, and Sukyung Chung. 2006a. "Learning about individual risk and the decision to smoke." International Journal of Industrial Organization, 24(4): 683-699.

Khwaja, Ahmed, Frank Sloan, and Sukyung Chung. 2006b. "The Effects of Spousal Health on the Decision to Smoke: Evidence on Consumption Externalities, Altruism and Learning Within the Household." Journal of Risk and Uncertainty, 32(1): $17-35$.

Kong, Augustine, Gudmar Thorleifsson, Michael L Frigge, Bjarni J Vilhjalmsson, Alexander I Young, Thorgeir E Thorgeirsson, Stefania Benonisdottir, Asmundur Oddsson, Bjarni V Halldorsson, Gisli Masson, Daniel F Gudbjartsson, Agnar Helgason, Gyda Bjornsdottir, Unnur Thorsteinsdottir, and Kari Stefansson. 2018. "The nature of nurture: Effects of parental genotypes." Science, 359(6374): 424-428.

Kowalski, Amanda E. 2018. "Extrapolation using Selection and Moral Hazard Heterogeneity from within the Oregon Health Insurance Experiment." NBER Working Paper Series, 24647: 1-38.

Kweon, Hyeokmoon, Casper A P Burik, Richard Karlsson Linnér, Ronald De Vlaming, Aysu Okbay, Daphne Martschenko, Kathryn Paige Harden, Thomas A Di Prete, and Philipp D Koellinger. 2020. "Genetic Fortune: Winning or Losing Education, Income, and Health." Working Paper.

Lee, James J, Robbee Wedow, Aysu Okbay, Edward Kong, Omeed Maghzian, Meghan Zacher, Tuan Anh Nguyen-Viet, Peter Bowers, Julia Sidorenko, Richard Karlsson Linnér, Mark Alan Fontana, Tushar Kundu, Chanwook Lee, Hui Li, Ruoxi Li, Rebecca Royer, Pascal N Timshel, Raymond K Walters, Emily A Willoughby, Loïc Yengo, Maris Alver, Yanchun Bao, David W Clark, Felix R Day, Nicholas A Furlotte, Peter K Joshi, Kathryn E Kemper, Aaron Kleinman, Claudia Langenberg, Reedik Mägi, Joey W Trampush, Shefali Setia Verma, Yang Wu, Max Lam, Jing Hua Zhao, Zhili Zheng, Jason D Boardman, Harry Campbell, Jeremy Freese, Kathleen Mullan Harris, Caroline Hayward, Pamela Herd, Meena Kumari, Todd Lencz, Jian'an Luan, Anil K Malhotra, Andres Metspalu, Lili Milani, Ken K Ong, John R B Perry, David J Porteous, Marylyn D Ritchie, Melissa C Smart, Blair H Smith, Joyce Y Tung, Nicholas J Wareham, James F Wilson, Jonathan P Beauchamp, Dalton C Conley, Tõnu Esko, Steven F Lehrer, Patrik K E Magnusson, Sven Oskarsson, Tune H Pers, Matthew R Robinson, Kevin Thom, Chelsea Watson, Christopher F Chabris, Michelle N Meyer, David I Laibson, Jian Yang, Magnus Johannesson, Philipp D Koellinger, Patrick Turley, Peter M Visscher, Daniel J Benjamin, and David Cesarini. 2018. "Gene discovery and polygenic prediction from a genome-wide association study of educational attainment in 1.1 million individuals." Nature Genetics, 1.

Li, Ming D, Rong Cheng, Jennie Z Ma, and Gary E Swan. 2003. "A metaanalysis of estimated genetic and environmental effects on smoking behavior in male and female adult twins." Addiction, 98(1): 23-31. 
Liu, Jason Z, Federica Tozzi, Dawn M Waterworth, Sreekumar G Pillai, Pierandrea Muglia, Lefkos Middleton, Wade Berrettini, Christopher W Knouff, Xin Yuan, Gérard Waeber, Peter Vollenweider, Martin Preisig, Nicholas J Wareham, Jing Hua Zhao, Ruth J F Loos, Inês Barroso, Kay-Tee Khaw, Scott Grundy, Philip Barter, Robert Mahley, Antero Kesaniemi, Ruth McPherson, John B Vincent, John Strauss, James L Kennedy, Anne Farmer, Peter McGuffin, Richard Day, Keith Matthews, Per Bakke, Amund Gulsvik, Susanne Lucae, Marcus Ising, Tanja Brueckl, Sonja Horstmann, H-Erich Wichmann, Rajesh Rawal, Norbert Dahmen, Claudia Lamina, Ozren Polasek, Lina Zgaga, Jennifer Huffman, Susan Campbell, Jaspal Kooner, John C Chambers, Mary Susan Burnett, Joseph M Devaney, Augusto D Pichard, Kenneth M Kent, Lowell Satler, Joseph M Lindsay, Ron Waksman, Stephen Epstein, James F Wilson, Sarah H Wild, Harry Campbell, Veronique Vitart, Muredach P Reilly, Mingyao Li, Liming Qu, Robert Wilensky, William Matthai, Hakon $\mathbf{H}$ Hakonarson, Daniel J Rader, Andre Franke, Michael Wittig, Arne Schäfer, Manuela Uda, Antonio Terracciano, Xiangjun Xiao, Fabio Busonero, Paul Scheet, David Schlessinger, David St Clair, Dan Rujescu, Gonçalo $\mathbf{R}$ Abecasis, Hans Jörgen Grabe, Alexander Teumer, Henry Völzke, Astrid Petersmann, Ulrich John, Igor Rudan, Caroline Hayward, Alan F Wright, Ivana Kolcic, Benjamin J Wright, John $\mathbf{R}$ Thompson, Anthony J Balmforth, Alistair S Hall, Nilesh J Samani, Carl A Anderson, Tariq Ahmad, Christopher G Mathew, Miles Parkes, Jack Satsangi, Mark Caulfield, Patricia B Munroe, Martin Farrall, Anna Dominiczak, Jane Worthington, Wendy Thomson, Steve Eyre, Anne Barton, Vincent Mooser, Clyde Francks, Jonathan Marchini, and Jonathan Marchini. 2010. "Meta-analysis and imputation refines the association of $15 \mathrm{q} 25$ with smoking quantity." Nature Genetics, 42(5): 436-440.

Liu, Mengzhen, Yu Jiang, Robbee Wedow, Yue Li, David M Brazel, Fang Chen, Gargi Datta, Jose Davila-Velderrain, Daniel McGuire, Chao Tian, Xiaowei Zhan, Hélène Choquet, Anna R Docherty, Jessica D Faul, Johanna R Foerster, Lars G Fritsche, Maiken Elvestad Gabrielsen, Scott D Gordon, Jeffrey Haessler, Jouke-Jan Hottenga, Hongyan Huang, SeonKyeong Jang, Philip R Jansen, Yueh Ling, Reedik Mägi, Nana Matoba, George McMahon, Antonella Mulas, Valeria Orrù, Teemu Palviainen, Anita Pandit, Gunnar W Reginsson, Anne Heidi Skogholt, Jennifer A Smith, Amy E Taylor, Constance Turman, Gonneke Willemsen, Hannah Young, Kendra A Young, Gregory J M Zajac, Wei Zhao, Wei Zhou, Gyda Bjornsdottir, Jason D Boardman, Michael Boehnke, Dorret I Boomsma, Chu Chen, Francesco Cucca, Gareth E Davies, Charles B Eaton, Marissa A Ehringer, Tõnu Esko, Edoardo Fiorillo, Nathan A Gillespie, Daniel F Gudbjartsson, Toomas Haller, Kathleen Mullan Harris, Andrew C Heath, John K Hewitt, Ian B Hickie, John E Hokanson, Christian J Hopfer, David J Hunter, William G Iacono, Eric O Johnson, Yoichiro Kamatani, Sharon L R Kardia, Matthew C Keller, Manolis Kellis, Charles Kooperberg, Peter Kraft, Kenneth S Krauter, Markku Laakso, Penelope A Lind, Anu Loukola, Sharon M Lutz, Pamela A F Madden, Nicholas G Martin, 
Matt McGue, Matthew B McQueen, Sarah E Medland, Andres Metspalu, Karen L Mohlke, Jonas B Nielsen, Yukinori Okada, Ulrike Peters, Tinca J C Polderman, Danielle Posthuma, Alexander $\mathbf{P}$ Reiner, John P Rice, Eric Rimm, Richard J Rose, Valgerdur Runarsdottir, Michael C Stallings, Alena Stančáková, Hreinn Stefansson, Khanh K Thai, Hilary A Tindle, Thorarinn Tyrfingsson, Tamara L Wall, David R Weir, Constance Weisner, John B Whitfield, Bendik Slagsvold Winsvold, Jie Yin, Luisa Zuccolo, Laura J Bierut, Kristian Hveem, James J Lee, Marcus R Munafò, Nancy L Saccone, Cristen J Willer, Marilyn C Cornelis, Sean P David, David A Hinds, Eric Jorgenson, Jaakko Kaprio, Jerry A Stitzel, Kari Stefansson, Thorgeir E Thorgeirsson, Gonçalo Abecasis, Dajiang J Liu, and Scott Vrieze. 2019. "Association studies of up to 1.2 million individuals yield new insights into the genetic etiology of tobacco and alcohol use." Nature Genetics.

Lloyd-Jones, Donald, Robert J. Adams, Todd M. Brown, Mercedes Carnethon, Shifan Dai, Giovanni De Simone, T. Bruce Ferguson, Earl Ford, Karen Furie, Cathleen Gillespie, Alan Go, Kurt Greenlund, Nancy Haase, Susan Hailpern, P. Michael Ho, Virginia Howard, Brett Kissela, Steven Kittner, Daniel Lackland, Lynda Lisabeth, Ariane Marelli, Mary M. McDermott, James Meigs, Dariush Mozaffarian, Michael Mussolino, Graham Nichol, Véronique L. Roger, Wayne Rosamond, Ralph Sacco, Paul Sorlie, Randall Stafford, Thomas Thom, Sylvia Wasserthiel-Smoller, Nathan D. Wong, and Judith Wylie-Rosett. 2010. "Heart Disease and Stroke Statistics-2010 Update." Circulation, 121(7).

Lundborg, Petter, and Anders Stenberg. 2010. "Nature, nurture and socioeconomic policy-what can we learn from molecular genetics?" Economics and Human Biology, 8(3): 320-30.

Ma, Jiemin, Rebecca L. Siegel, Eric J. Jacobs, and Ahmedin Jemal. 2018. "Smoking-attributable Mortality by State in 2014, U.S." American Journal of Preventive Medicine, 54(5): 661-670.

Marti, Joachim, and Michael R Richards. 2017. "Smoking Response to Health and Medical Spending Changes and the Role of Insurance." Health Economics, 26: 305320 .

Martin, Alicia R, Christopher R Gignoux, Raymond K Walters, Genevieve L Wojcik, Benjamin M Neale, Simon Gravel, Mark J Daly, Carlos D Bustamante, and Eimear E Kenny. 2017. "Human Demographic History Impacts Genetic Risk Prediction across Diverse Populations." The American Journal of Human Genetics, 100(4): 635-649.

Martin, Alicia R, Masahiro Kanai, Yoichiro Kamatani, Yukinori Okada, Benjamin M Neale, and Mark J Daly. 2019. "Clinical use of current polygenic risk scores may exacerbate health disparities." Nature Genetics 2019 51:4, 51(4): 584.

Mendoza, Roger Lee. 2016. "Which moral hazard? Health care reform under the Affordable Care Act of 2010." Journal of Health Organization and Management, 30(4): 510-529. 
Meyers, JL, Magdalena Cerda, S Galea, KM Keyes, AE Aiello, M Uddin, DE Wildman, and KC Koenen. 2013. "Interaction between polygenic risk for cigarette use and environmental exposures in the Detroit neighborhood health study." Translational psychiatry, 3(8): e290-e290.

Morrison, Patrick J. 2005. "Insurance, unfair discrimination, and genetic testing." The Lancet, 366(9489): 877-880.

Mulcaster, Richard. 1582. Mulcaster's Elementaire. London:Clarendon Press.

Obama, Barack. 2016. "United States Health Care Reform.” JAMA, 27(6): 1718-1727.

Olson, P. 2014. "Wearable tech is plugging into health insurance." https: //www. forbes. com/sites/parmyolson/2014/06/19/ wearable-tech-health-insurance/\#738954a118bd., Accessed on May 8, 2018.

Ottman, Ruth, and Dabeeru C Rao. 1990. "An epidemiologic approach to geneenvironment interaction." Genetic Epidemiology, 7(3): 177-185.

Papageorge, Nicholas W, and Kevin Thom. 2020. "Genes, Education, and Labor Market Outcomes: Evidence from the Health and Retirement Study." Journal of the European Economic Association, 18(3): 1351-1399.

Pei, Zhuan, Jörn Steffen Pischke, and Hannes Schwandt. 2018. "Poorly Measured Confounders are More Useful on the Left than on the Right." Journal of Business and Economic Statistics, 1-12.

Pereira, Rita Dias. 2021. "Inborn Ability and Equality of Opportunity in Education." Working Paper.

Peterson, Roseann E, Karoline Kuchenbaecker, Raymond K Walters, ChiaYen Chen, Alice B Popejoy, Sathish Periyasamy, Max Lam, Conrad Iyegbe, Rona J Strawbridge, Leslie Brick, Caitlin E Carey, Alicia R Martin, Jacquelyn L Meyers, Jinni Su, Junfang Chen, and Alexis C Edwards. 2019. "Leading Edge Primer Genome-wide Association Studies in Ancestrally Diverse Populations: Opportunities, Methods, Pitfalls, and Recommendations." Cell.

Plomin, Robert. 1990. Nature and nurture: An introduction to human behavioral genetics. Wadsworth Publishing Company.

Plomin, Robert, John C DeFries, and John C Loehlin. 1977. "Genotypeenvironment interaction and correlation in the analysis of human behavior." Psychological Bulletin, 84(2): 309-22.

Richards, Michael R, and Joachim Marti. 2014. "Heterogeneity in the smoking response to health shocks by out-of-pocket spending risk." Health Economics, Policy and Law, 9(04): 343-357.

Ritz, Beate R, Nilanjan Chatterjee, Montserrat Garcia-Closas, W James Gauderman, Brandon L Pierce, Peter Kraft, Caroline M Tanner, Leah E Mechanic, and Kimberly McAllister. 2017. "Lessons Learned From Past GeneEnvironment Interaction Successes." American Journal of Epidemiology, 186(7): 778786. 
Schmitz, Lauren, and Dalton Conley. 2016. "The long-term consequences of Vietnam-era conscription and genotype on smoking behavior and health." Behavior genetics, $46(1)$ : 43-58.

Schmitz, Lauren L, and Dalton C Conley. 2017a. "Modeling Gene-Environment Interactions With Quasi-Natural Experiments." Journal of Personality, 85(1): 10-21.

Schmitz, Lauren L, and Dalton C Conley. 2017b. "The effect of Vietnam-era conscription and genetic potential for educational attainment on schooling outcomes." Economics of Education Review, 61: 85-97.

Schork, Andrew J, M. Anthony Schork, and Nicholas J Schork. 2018. "Genetic risks and clinical rewards." Nature Genetics, 50(9): 1210-1211.

Slob, Eric A W, and Cornelius A Rietveld. 2020. "The moderating impact of the genetic predisposition to smoking behaviour on the response to tobacco excise taxes." medRxiv, 2020.12.02.20242388.

Smith, V. Kerry, Donald H. Taylor, Frank A. Sloan, F. Reed Johnson, and William H. Desvousges. 2001. "Do Smokers Respond to Health Shocks?" Review of Economics and Statistics, 83(4): 675-687.

Sonnega, Amanda, Jessica D Faul, M B Ofstedal, K M Langa, John W Phillips, and David R Weir. 2014. "Cohort Profile: the Health and Retirement Study (HRS)." International Journal of Epidemiology, 43(2): 576-585.

Stoker, Astrid K, and Athina Markou. 2013. "Unraveling the neurobiology of nicotine dependence using genetically engineered mice." Current opinion in neurobiology, 23(4): 493-499.

Sullivan, P F, and K S Kendler. 1999. "The genetic epidemiology of smoking." Nicotine $\&$ tobacco research : official journal of the Society for Research on Nicotine and Tobacco, 1 Suppl 2: S51-7; discussion S69-70.

Sundmacher, Leonie. 2012. "The effect of health shocks on smoking and obesity." The European Journal of Health Economics, 13(4): 451-460.

Teo, Koon K, Stephanie Ounpuu, Steven Hawken, MR Pandey, Vicent Valentin, David Hunt, Rafael Diaz, Wafa Rashed, Rosario Freeman, Lixin Jiang, Xiaofei Zhang, Salim Yusuf, and INTERHEART Study Investigators. 2006. "Tobacco use and risk of myocardial infarction in 52 countries in the INTERHEART study: a case-control study." The Lancet, 368(9536): 647-658.

The Tobacco and Genetics Consortium, Helena Furberg, YunJung Kim, Jennifer Dackor, Eric Boerwinkle, Nora Franceschini, Diego Ardissino, Luisa Bernardinelli, Pier M Mannucci, Francesco Mauri, Piera A Merlini, Devin Absher, Themistocles L Assimes, Stephen P Fortmann, Carlos Iribarren, Joshua W Knowles, Thomas Quertermous, Luigi Ferrucci, Toshiko Tanaka, Joshua C Bis, Curt D Furberg, Talin Haritunians, Barbara McKnight, Bruce M Psaty, Kent D Taylor, Evan L Thacker, Peter Almgren, Leif C Groop, Claes Ladenvall, Michael Boehnke, Anne U Jackson, Karen L Mohlke, Heather M Stringham, Jaakko Tuomilehto, Emelia J 
Benjamin, Shih-Jen Hwang, Daniel Levy, Sarah Rosner Preis, Ramachandran S Vasan, Jubao Duan, Pablo V Gejman, Douglas F Levinson, Alan R Sanders, Jianxin Shi, Esther H Lips, James D McKay, Antonio Agudo, Luigi Barzan, Vladimir Bencko, Simone Benhamou, Xavier Castellsagué, Cristina Canova, David I Conway, Eleonora Fabianova, Lenka Foretova, Vladimir Janout, Claire M Healy, Ivana Holcátová, Kristina Kjaerheim, Pagona Lagiou, Jolanta Lissowska, Ray Lowry, Tatiana V Macfarlane, Dana Mates, Lorenzo Richiardi, Peter Rudnai, Neonilia SzeszeniaDabrowska, David Zaridze, Ariana Znaor, Mark Lathrop, Paul Brennan, Stefania Bandinelli, Timothy M Frayling, Jack M Guralnik, Yusplitri Milaneschi, John R B Perry, David Altshuler, Roberto Elosua, Sekar Kathiresan, Gavin Lucas, Olle Melander, Christopher J O'Donnell, Veikko Salomaa, Stephen M Schwartz, Benjamin F Voight, Brenda W J H Penninx, Johannes H Smit, Nicole Vogelzangs, Dorret I Boomsma, Eco J C de Geus, Jacqueline M Vink, Gonneke Willemsen, Stephen J Chanock, Fangyi Gu, Susan E Hankinson, David J Hunter, Albert Hofman, Henning Tiemeier, Andre G Uitterlinden, Cornelia M van Duijn, Stefan Walter, Daniel I Chasman, Brendan M Everett, Guillaume Paré, Paul M Ridker, Ming D Li, Hermine H Maes, Janet Audrain-McGovern, Danielle Posthuma, Laura M Thornton, Caryn Lerman, Jaakko Kaprio, Jed E Rose, John P A Ioannidis, Peter Kraft, Dan-Yu Lin, and Patrick F Sullivan. 2010. "Genome-wide meta-analyses identify multiple loci associated with smoking behavior." Nature Genetics, 42(5): 441-447.

Thorgeirsson, Thorgeir E, Daniel F Gudbjartsson, Ida Surakka, Jacqueline M Vink, Najaf Amin, Frank Geller, Patrick Sulem, Thorunn Rafnar, Tonu Esko, Stefan Walter, Christian Gieger, Rajesh Rawal, Massimo Mangino, Inga Prokopenko, Reedik Mägi, Kaisu Keskitalo, Iris H Gudjonsdottir, Solveig Gretarsdottir, Hreinn Stefansson, John R Thompson, Yurii S Aulchenko, Mari Nelis, Katja K H Aben, Martin den Heijer, Asger Dirksen, Haseem Ashraf, Nicole Soranzo, Ana M Valdes, Claire Steves, Andre G Uitterlinden, Albert Hofman, Anke Tönjes, Peter Kovacs, Jouke Jan Hottenga, Gonneke Willemsen, Nicole Vogelzangs, Angela Döring, Norbert Dahmen, Barbara Nitz, Michele L Pergadia, Berta Saez, Veronica De Diego, Victoria Lezcano, Maria D Garcia-Prats, Samuli Ripatti, Markus Perola, Johannes Kettunen, Anna-Liisa Hartikainen, Anneli Pouta, Jaana Laitinen, Matti Isohanni, Shen Huei-Yi, Maxine Allen, Maria Krestyaninova, Alistair S Hall, Gregory $\mathbf{T}$ Jones, Andre $\mathbf{M}$ van Rij, Thomas Mueller, Benjamin Dieplinger, Meinhard Haltmayer, Steinn Jonsson, Stefan E Matthiasson, Hogni Oskarsson, Thorarinn Tyrfingsson, Lambertus A Kiemeney, Jose I Mayordomo, Jes S Lindholt, Jesper Holst Pedersen, Wilbur A Franklin, Holly Wolf, Grant W Montgomery, Andrew C Heath, Nicholas G Martin, Pamela A F Madden, Ina Giegling, Dan Rujescu, Marjo-Riitta Järvelin, Veikko Salomaa, Michael Stumvoll, Timothy D Spector, H-Erich Wichmann, Andres Metspalu, Nilesh J Samani, Brenda W J H Penninx, Ben A Oostra, Dorret I Boomsma, Henning Tiemeier, Cornelia M van Duijn, Jaakko Kaprio, Jeffrey R Gulcher, Mark I McCarthy, Leena Peltonen, Unnur Thorsteinsdottir, and Kari Stefansson. 
2010. "Sequence variants at CHRNB3-CHRNA6 and CYP2A6 affect smoking behavior." Nature Genetics, 42(5): 448-453.

Thorgeirsson, Thorgeir E, Frank Geller, Patrick Sulem, Thorunn Rafnar, Anna Wiste, Kristinn P Magnusson, Andrei Manolescu, Gudmar Thorleifsson, Hreinn Stefansson, Andres Ingason, Simon N Stacey, Jon T Bergthorsson, Steinunn Thorlacius, Julius Gudmundsson, Thorlakur Jonsson, Margret Jakobsdottir, Jona Saemundsdottir, Olof Olafsdottir, Larus J Gudmundsson, Gyda Bjornsdottir, Kristleifur Kristjansson, Halla Skuladottir, Helgi J Isaksson, Tomas Gudbjartsson, Gregory T Jones, Thomas Mueller, Anders Gottsäter, Andrea Flex, Katja K H Aben, Femmie de Vegt, Peter F A Mulders, Dolores Isla, Maria J Vidal, Laura Asin, Berta Saez, Laura Murillo, Thorsteinn Blondal, Halldor Kolbeinsson, Jon G Stefansson, Ingunn Hansdottir, Valgerdur Runarsdottir, Roberto Pola, Bengt Lindblad, Andre M van Rij, Benjamin Dieplinger, Meinhard Haltmayer, Jose I Mayordomo, Lambertus A Kiemeney, Stefan E Matthiasson, Hogni Oskarsson, Thorarinn Tyrfingsson, Daniel F Gudbjartsson, Jeffrey R Gulcher, Steinn Jonsson, Unnur Thorsteinsdottir, Augustine Kong, and Kari Stefansson. 2008. "A variant associated with nicotine dependence, lung cancer and peripheral arterial disease." Nature, 452(7187): 638-642.

Thorpe, K. E., Curtis S Florence, and Peter Joski. 2004. "Which Medical Conditions Account For The Rise In Health Care Spending?" Health Affairs, Suppl Web: W4-437-45.

Torkamani, Ali, Nathan E Wineinger, and Eric J Topol. 2018. "The personal and clinical utility of polygenic risk scores." Nature Reviews Genetics, 1.

United States Department of Health and Human Services. 2014. "The Health Consequences of Smoking-50 Years of Progress A Report of the Surgeon General." The Health Consequences of Smoking-50 Years of Progress A Report of The Surgeon General.

Ware, E, L Schmitz, and J Faul. 2017. "HRS documentation report - HRS polygenic scores, 2006-2010 genetic data."

Wedow, Robbee, Meghan Zacher, Brooke M Huibregtse, Kathleen Mullan Harris, Benjamin W Domingue, and Jason D Boardman. 2018. "Education, Smoking, and Cohort Change: Forwarding a Multidimensional Theory of the Environmental Moderation of Genetic Effects." American Sociological Review, 83(4): 802-832.

Wray, L A, A R Herzog, R J Willis, and R B Wallace. 1998. "The impact of education and heart attack on smoking cessation among middle-aged adults." Journal of health and social behavior, 39(4): 271-94.

Xu, Xin, Ellen E. Bishop, Sara M. Kennedy, Sean A. Simpson, and Terry F. Pechacek. 2015. "Annual Healthcare Spending Attributable to Cigarette Smoking." American Journal of Preventive Medicine, 48(3): 326-333.

Yengo, Loic, Julia Sidorenko, Kathryn E Kemper, Zhili Zheng, Andrew R Wood, Michael N Weedon, Timothy M Frayling, Joel Hirschhorn, Jian 
Yang, Peter M Visscher, and GIANT Consortium. 2018. "Meta-analysis of genome-wide association studies for height and body mass index in $~ 700,000$ individuals of European ancestry." bioRxiv, 274654.

Young, K. 2017. "The integration of wearables and insurance." http://institute. swissre. com/research/library/Medical_Wearables_Kelvyn_Young. html., Accessed on May 8, 2018.

Zweifel, Peter, and Willard G. Manning. 2000. "Moral Hazard and Consumer Incentives in Health Care." Handbook of Health Economics, 1: 409-459. 


\section{A Appendix}

\section{Contents}

1 Introduction 1

2 Data 4

2.1 Study Sample . . . . . . . . . . . . . . . . . . 4

2.2 Variables of interest . . . . . . . . . . . . . . . . . 5

2.3 Sample Characteristics . . . . . . . . . . . . . . 7

3 Empirical Analysis $\quad 9$

4 Results $\quad 11$

4.1 Estimation Results . . . . . . . . . . . . . . . . . . . . . 11

4.2 Other Interpretations . . . . . . . . . . . . . . . . . . . . 14

4.3 Robustness checks . . . . . . . . . . . . . . . . . 18

$\begin{array}{llr}5 & \text { Discussion } & 19\end{array}$

5.1 Limitations . . . . . . . . . . . . . . . . . . . . 21

6 Conclusions 22

$\begin{array}{ll}\text { A Appendix } & 36\end{array}$

B Genetics for Economists 1

C Methods 1

C.1 DNA Extraction and Genotyping . . . . . . . . . . . . . 1

C.2 Study Sample . . . . . . . . . . . . . . . . . . 2

C.2.1 Reshaping, Merging, and Sample Restrictions . . . . . . . . . . 2

C.2.2 Ever-Smoker Status . . . . . . . . . . . . . . . 3

C.3 Outcome and Exposure Variables . . . . . . . . . . . . . . . 3

C.3.1 Smoking Status . . . . . . . . . . . . . . . . . 3

C.3.2 Health Shocks . . . . . . . . . . . . . . . . . . 3

C.3.3 Medicare Eligibility Status ........................ 4

C.3.4 Pre-65 Uninsured Status . . . . . . . . . . . . . . . . . 4

C.3.5 Polygenic Risk for Regular Smoking . . . . . . . . . . . . . . 4

C.4 Statistical Analysis . . . . . . . . . . . . . . . . . 6

C.4.1 Age Pattern of Health Shock Incidence . . . . . . . . . . . . 6

C.5 Derivation of the effects from the OLS coefficients . . . . . . . 8

C.5.1 OLS estimation: high and low PGS ........... 8

C.5.2 OLS estimation: Low, middle and high PGS . . . . . . . 10

$\begin{array}{ll}\text { D Results } & \mathbf{1 1}\end{array}$

D.1 Sample Characteristics . . . . . . . . . . . . . . . . . 11

D.2 Main Results . . . . . . . . . . . . . . . . . . 11

D.3 Robustness Checks . . . . . . . . . . . . . . . . . . . 13

D.3.1 Using all tertiles . . . . . . . . . . . . . . . . . 13 
D.3.2 Median Split of the polygenic score . . . . . . . . . . . . 13

D.3.3 Older GWAS Summary Statistics . . . . . . . . . . . . . . 13

D.3.4 Using different polygenic scores . . . . . . . . . . . . . . . . 14

D.3.5 Relaxing the Criteria for Inclusion in the Pre-65 Uninsured Group 23

D.3.6 Including Individuals with Shocks Reported at Ages 65 and $66 \quad$. 24

D.3.7 Using Medicare Enrollment Status instead of age 65 . . . . . . . 25

D.4 Confounders. . . . . . . . . . . . . . . . . . 25

E The Model $\mathbf{2 5}$

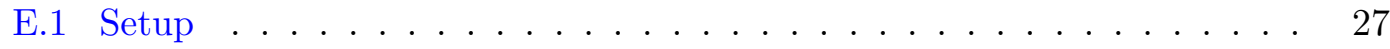

E.2 The optimal health-enhancing effort . . . . . . . . . . 28 


\section{B Genetics for Economists}

The human genome consists of over 3 billion base pairs ( 6 billion bases) in each cell nucleus, with four possible bases: adenine (A), thymine $(\mathrm{T})$, guanine $(\mathrm{G})$, and cytosine (C) ${ }^{15}$ Comparing any two unrelated human beings, over $99 \%$ of their genome will be identical. The remaining $<1 \%$ differs between individuals, with a Single Nucleotide Polymorphism (or SNP, pronounced snip) being the most common form of genetic variation. A SNP is a single base-pair substitution at a particular location (locus) on the human genome.

To identify genetic variants that are associated with a particular trait of interest, such as coronary heart disease, so-called Genome-Wide Association Studies (GWAS) relate each SNP to the trait in a hypothesis free-approach. Stringent p-values are then used to identify SNPs that are robustly associated with the trait of interest, and replication is performed in other, independent samples. Only SNPs that have consistent associations across the different samples are interpreted as robust. However, this does not guarantee that individual SNPs have large effect sizes. Most human complex traits are polygenic, meaning that they are affected by many SNPs, each with a very small effect size. To increase the predictive power of SNPs, they can then be aggregated into so-called polygenic scores (PGS), defined as:

$$
P G S_{i}=\sum_{j=1}^{J} \beta_{j} G_{i j}
$$

where $G_{i j}$ is SNP $j$ of individual $i$, and $\beta_{j}$ is the effect size of that SNP, obtained from an independent Genome-Wide Association Study. GWAS sample sizes have grown substantially in recent years, meaning that (a) SNPs with very small effects are more likely to be identified, and (b) that the effect sizes are estimated with increased precision. Indeed, we have seen large improvements in genetic prediction, with initial PGS being able to explain less than $1 \%$ of the variation in the trait of interest, to more recent ones explaining up to 11-13\% of the variation in educational attainment just by increasing the sample size of the discovery sample (see e.g., Lee et al., 2018). PGS have been shown to be powerful tools to identify patients with increased risk for coronary artery disease, atrial fibrillation, type 2 diabetes, inflammatory bowel disease, and breast cancer. Indeed, Khera et al. (2018) propose the use of polygenic prediction in clinical care.

\section{Methods}

\section{C.1 DNA Extraction and Genotyping}

In 2006, the Health and Retirement Study (HRS) introduced enhanced face-to-face interviews (EFTFs), which expanded the core interview with measures of physical function, blood-based biomarkers, and DNA samples. Sample selection for the EFTFs was conducted as follows: A random 50\% of the 2006 sample was preselected for an EFTF, and the other half was selected in 2008. A new cohort of households was added to the HRS in 2010. Of these new households, a random 50\% was selected for EFTF data collection in 2010, while the other half was selected in 2012. The households selected

\footnotetext{
${ }^{15} \mathrm{~A}$ base pair is set of two bases, with $\mathrm{A}$ always pairing with $\mathrm{T}$, and $\mathrm{C}$ always pairing with $\mathrm{G}$.
} 
for EFTFs in 2012 are not yet included in the polygenic scores data used in this study. In 2006, saliva collection was conducted using a mouthwash collection method. From 2008 onwards, the Oragene DNA Collection Kit (OG-250) was used.

Genotype data was obtained for over 15,000 HRS participants. Genotyping was conducted by the Center for Inherited Disease Research (CIDR) in 2011, 2012, and 2015, using the Illumina HumanOmni 2.5 BeadChips (HumanOmni2.4-4v1, HumanOmni2.58v1). Approximately 2.4 million single nucleotide polymorphisms (SNPs) were measured. Of the roughly 1.9 million genotyped SNPs that passed quality control, 21 million SNPs were imputed using the 1000 Genomes Reference Panels (phase 3, version 5). More details on genotyping and imputation can be found in the official HRS Documentation Report.

\section{C.2 Study Sample}

To improve replicability of the results, we mostly use data from the publicly available RAND HRS file (version P)(, n.d.a) - an easy-to-use longitudinal data set based on the HRS data - as well as the publicly available initial release of the HRS polygenic scores data (, n.d.b).

\section{C.2.1 Reshaping, Merging, and Sample Restrictions}

This section describes how the study sample was constructed from the RAND HRS version $\mathrm{P}$ data file. First, the data file was reshaped from wide to long format, with each observation corresponding to a respondent-wave entry. Second, polygenic risk scores (PGSs) for the HRS phenotype "smoking initiation" (referred to as "regular smoking" in this study, for clarity purposes) from the initial HRS PGS data release, using genetic data from 2006 to 2010, were merged for the 9,991 genotyped individuals of European ancestry. The following shows the list of restrictions that were then imposed to arrive at the study sample used in the main analysis. Regarding notation, note that VARIABLE refers to the long-format version of the variables that were called R1VARIABLE to R12VARIABLE in the RAND HRS data file. From the reshaped data file, the study sample was reached by carrying out the following steps (in this exact order):

1. Drop observations with an age (AGEY_E; see Section C.3.3) below 60 or above 70 years

2. Drop individuals with only 1 observation

3. Drop observations with missing values for the PGS for smoking (PGS_EvrSmk_TAG10; see Section C.3.5), the self-constructed health shock indicator (Section C.3.2), or the current smoking status (SMOKEN; see Section C.3.1)

4. Drop individuals who in their first observation (the baseline) reported never having smoked (SMOKEV equal to 0; see Section C.2.2)

5. Drop individuals with missing values for the self-constructed pre-65 uninsured status indicator (Section C.3.4)

6. Drop individuals who reported a health shock (self-constructed health shock indicator equal to 1; see Section C.3.2) when interviewed at ages 65 or 66 


\section{C.2.2 Ever-Smoker Status}

"Ever-smoker" refers to the RAND variable SMOKEV, which indicates whether the respondent has ever smoked cigarettes. Ever smoking means having smoked more than 100 cigarettes throughout one's life, not including pipes or cigars. This is consistent with the Centers for Disease Control classification of the term "ever-smoker." Jamal et al. (2016) The ever-smoked question was usually only asked at the respondent's first interview and then carried forward for subsequent waves. For details on the survey questions and recodings for missings into yes/no answers, see the publicly available official RAND HRS documentation.

\section{C.3 Outcome and Exposure Variables}

\section{C.3.1 Smoking Status}

Current smoking status refers to the RAND variable SMOKEN, which indicates whether the respondent smokes at the time of the interview. The survey question about current smoking status was only asked for respondents who answered yes to being ever-smokers (having smoked more than 100 cigarettes in their lifetime). For details on the survey questions and recodings for missings into yes/no answers, see the RAND HRS documentation.

\section{C.3.2 Health Shocks}

The health shock indicator was defined using the RAND variables HEARTE and STROKE. The variable HEARTE indicates whether or not a doctor has ever told the respondent that he/she had 1 of the following conditions:

1. Heart attack

2. Coronary heart disease

3. Angina

4. Congestive heart failure

5. Other heart problems

The variable STROKE indicates whether or not a doctor has ever told the respondent that he/she had 1 of the following conditions:

1. Stroke

2. Transient ischemic attack

For details on the survey questions and the construction of these variables, see the RAND HRS documentation.

The health shock indicator used in this analysis was then defined as follows: It was set to 1 in a given wave if the lagged values of both HEARTE and STROKE were equal to 0 , and if either one of the current values (or both) was equal to 1. 


\section{C.3.3 Medicare Eligibility Status}

The Medicare eligibility status indicator was defined using the RAND variable AGEY_E. This variable indicates the respondent's age in years at the end of the HRS interview in a given wave. For details on the construction of this variable, see the RAND HRS documentation.

\section{C.3.4 Pre-65 Uninsured Status}

The pre-65 uninsured status indicator was defined using the RAND variables HIGOV, COVR, COVS, and HIOTHP. The variable HIGOV indicates whether the respondent was covered by any government health insurance program. COVR indicates whether the respondent was covered by health insurance from his/her current or previous employer. COVS indicates whether the respondent was covered by his/her spouse's employer. HIOTHP indicates whether the respondent was covered by any health insurance other than the government, employer-provided, or long-term care insurance. For details on the survey questions and the construction of these variables, see the RAND HRS documentation.

The pre-65 uninsured status indicator used in this analysis was then defined as follows: First, we defined a wave-specific uninsured indicator, which was set to 1 in a given wave if the values of HIGOV, COVR, COVS, and HIOTHP were all equal to 0. Then, the pre-65 uninsured status indicator was set to 1 for respondents whose wave-specific uninsured indicator was 1 in $100 \%$ of all pre-65 observations (i.e., where AGEY_E $<65$ ).

\section{C.3.5 Polygenic Risk for Regular Smoking}

The high-PGS indicator was defined using the PGS for the phenotype "smoking initiation" (referred to as "regular smoking" in this study, for clarity purposes) using all of the genetic variants (SNPs).

The PGS was calculated using the effect sizes estimated in a genome-wide association study (GWAS) meta-analysis Liu et al. (2019) conducted by the GWAS and Sequencing Consortium of Alcohol and Nicotine use (GSCAN). The phenotype "smoking initiation" studied in this GWAS was defined as ever versus never having been a regular smoker, where regular smokers were individuals who reported having smoked $\geq 100$ cigarettes throughout their life.

The PGSs used these GWAS-estimated effect sizes for all SNPs that overlapped between the HRS genetic database and the GWAS meta-analysis, without accounting for linkage disequilibrium between SNPs or considering P-value thresholds. Scores were calculated according to Equation (1) in the main text using the software packages PRSice and PLINK.

The high-PGS indicator used in this analysis was then defined as follows: It was set to 1 for individuals with a PGS above the lowest tertile, and to 0 for individuals with a PGS below or equal to the lowest tertile. The two upper-tertiles of the PGS distribution were combined to improve statistical power and simplify the exposition. Initial results using an indicator for each tertile of the distribution, displayed in Appendix Section C.5.2, show that the results for the two upper-tertiles of the PGS distribution are very similar to each other.

The polygenic score is predictive of smoking behavior, as expected and displayed in Figure 1, but not only. As shown in Appendix Figure 9-which displays the coefficients 
of simple OLS regressions of several outcomes on the linear PGS controlling for age, gender, and the 10 principal components of the genomewide matrix - the PGS is also predictive of other unfavorable outcomes: younger age at first birth as well as age started smoking, lower cognitive skills, perseverance, years of education, wealth, income, health rating, higher depressive symptoms, anxiety, non-cancer illnesses, drinking behavior. Reassuringly, the correlations with retirement, medications taken, and mortality are positive but extremely small and not distinguishable from zero.

Figure 9: PGS distribution and correlation with smoking behavior.

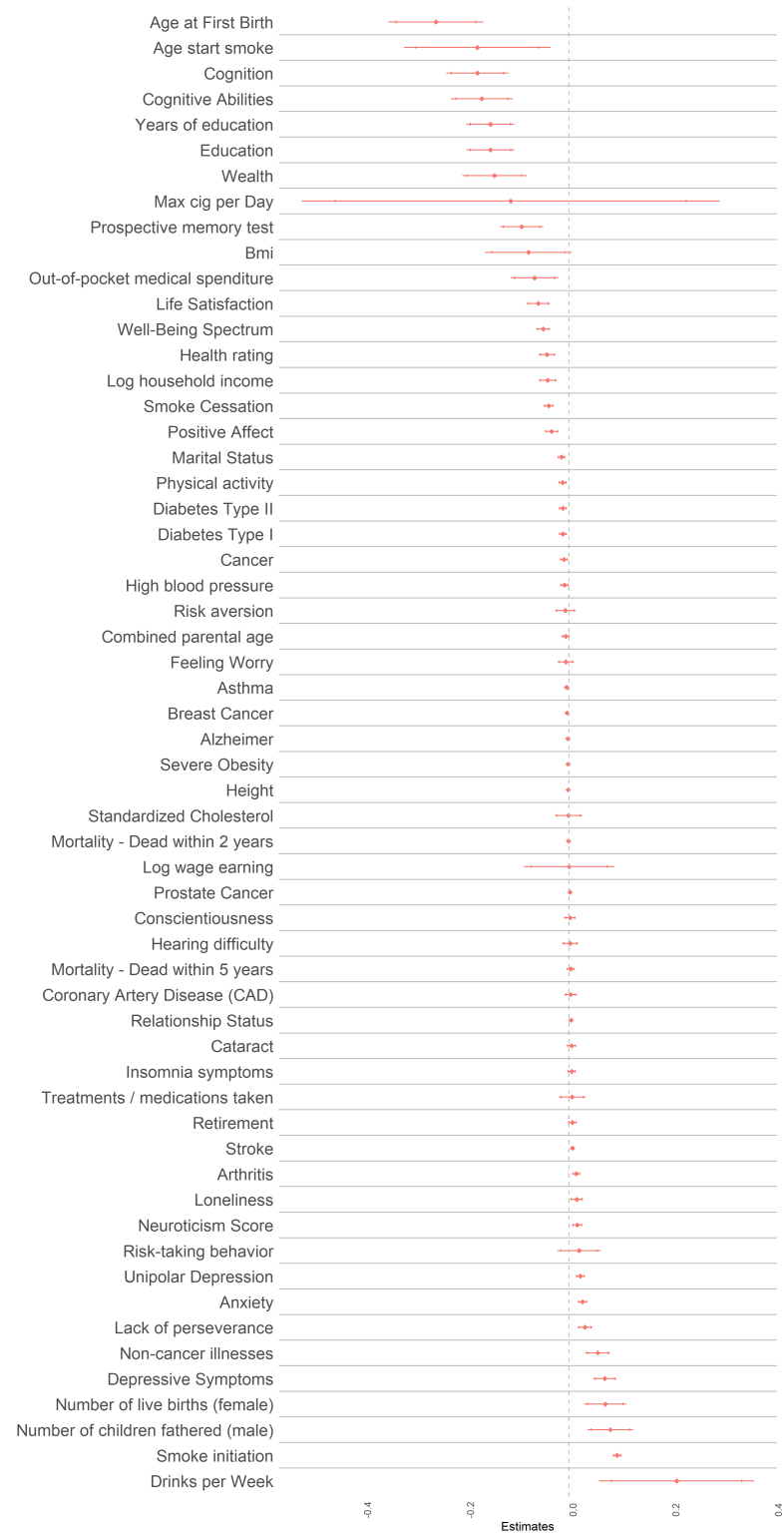

Notes: Plot of estimated coefficients associated with the PGS (entered linearly) from several OLS regressions of the different outcomes displayed on the y-axis on the PGS, age, age squared, age cubed, sex, and the first 10 principal components of the genomewide matrix.

Data used: HRS waves 1-13, restricted to observations with age between 60 and 70 years.

As shown in Figure 10, the PGS is mildly correlated with gender and almost uncor- 
related with the probability of suffering from a health shock.

Figure 10: PGS for Regular Smoking and Smoking Behavior in the HRS Data

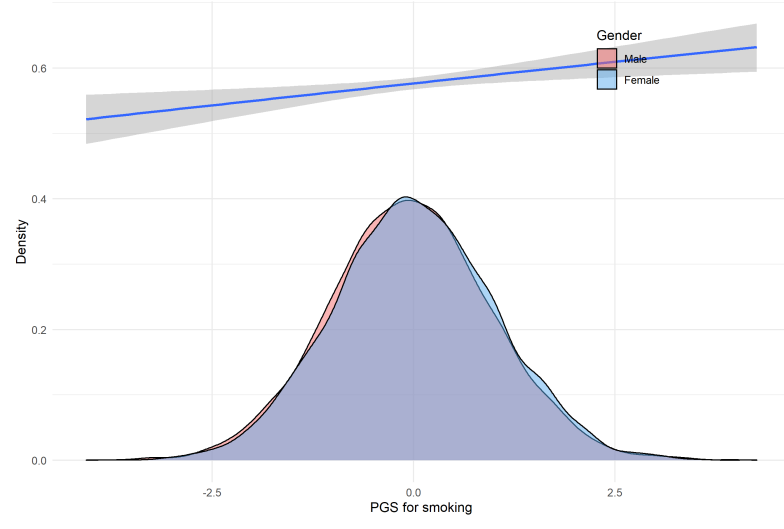

(a) PGS distribution and correlation with female gender.

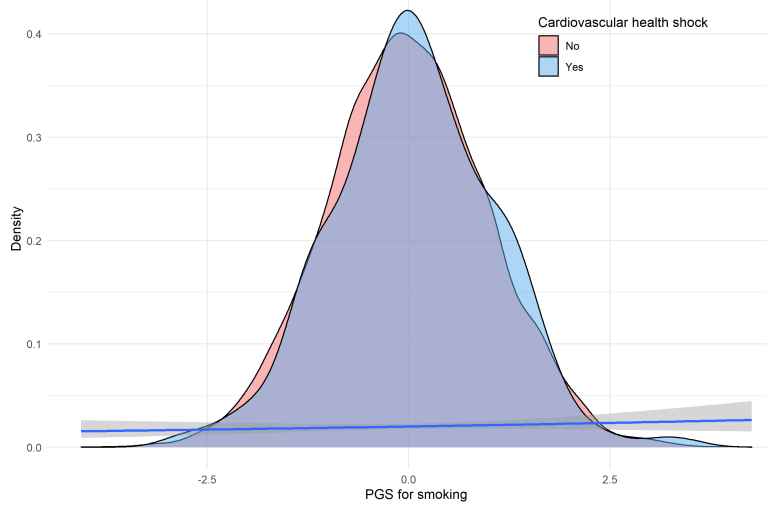

(b) PGS distribution and correlation with the health shock.

Notes: Distribution of Polygenic Score (PGS) for baseline smokers (blue) and non-smokers (red). Generalized linear smoothed correlation between current smoking and PGS shown in the blue line (with $95 \%$ confidence intervals in shaded grey area).

Data used: HRS waves 1-13, restricted to observations with age between 60 and 70 years.

\section{C.4 Statistical Analysis}

\section{C.4.1 Age Pattern of Health Shock Incidence}

With the data used in this study, it was not possible to narrow down the exact timing of a health shock to more than the between-survey 2-year window. Therefore, the probability of having a health shock at a specific age could not be determined. What could be said from this data about the age at the health shock is that for all shocks reported at ages 64 or below, the shocks must have occurred before the age of 65 . Similarly, for all health shocks reported at ages 67 or above, the shocks must have occurred after the age of 65 . For shocks reported at interview ages 65 or 66 , it could not be determined whether the shock occurred before or after age 65 (as interviews were conducted biennially).

Figure 11 visualizes the fraction of HRS respondents who reported experiencing a health shock since the last survey wave at a given interview age, stratified both by genetic group and by gender. By visual inspection, there seems to be a positive trend in the fraction of respondents reporting health events with age, with frequent deviations but no obvious jump between 64 and 67 .

To formally test for a jump or change in trend in the incidence of health shocks around the age of 65 , a segmented regression approach was used. Specifically, we tested if the change between the percentage of respondents who reported a health shock at age 64 and the percentage of respondents who reported a health shock at age 67 was larger than what could be explained by a linear age trend. For this test, all observations where respondents were aged 65 or 66 were excluded. For all remaining observations, 
Figure 11: Percentage of Reported Health Shocks by Age

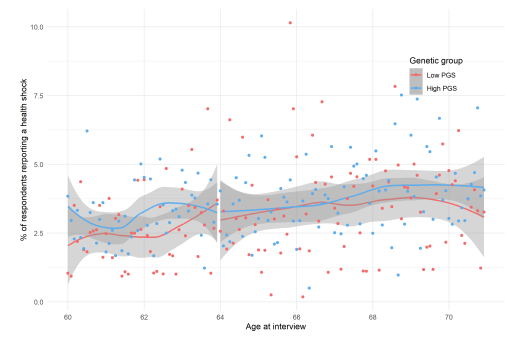

(a) Cutoff at age 64

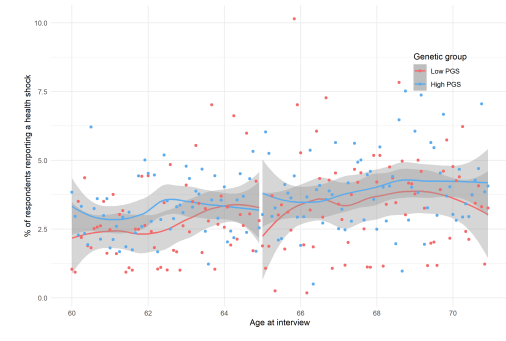

(b) Cutoff at age 65

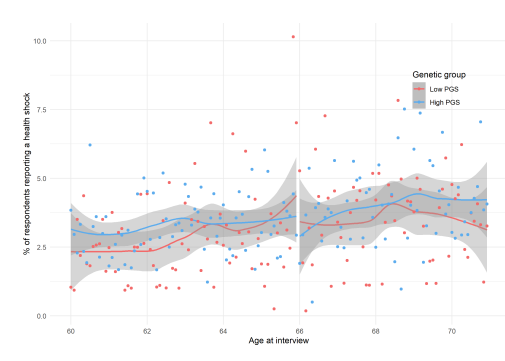

(c) Cutoff at age 66

Self-reported indicator of having been diagnosed for the first time with a cardiovascular condition since the last HRS survey. Age refers to the time of the survey, not the time of the health shock, which is unknown up to a 2-year windows, since HRS surveys are bi annual. Bin-scattered plot and generalized linear smoothed correlation between age at interview and cardiovascular health shock shown in red (low PGS) and blue (high PGS). Linear smoothed correlation estimated separately to the left and to the right of age cutoff: (a) age 64; (b) age 65; (c) age 66.

Data used: HRS waves 1-13, restricted to observations with age between 60 and 70 years.

the binary health shock indicator (shock) was regressed on the age variable (age), a post-age-67 indicator variable (post67), and a post-age-67 trend (post67slope):

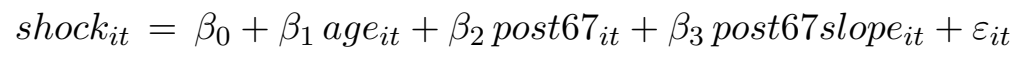

The post-age-67 indicator variable was defined to take the value 1 if a respondent was aged 67 or older at the time of the HRS interview. Therefore, it guaranteed that any potential health shocks were experienced after the age of 65 . The post-age- 67 slope variable was a continuous variable coded 0 up to and including age 67 , and increased sequentially from 1 thereafter. $\beta_{1}$ captured the general age trend in the probability of reporting a health shock; $\beta_{2}$ estimated the jump in the report of health shocks at age $67 ; \beta_{3}$ reflected changes in the age trend of reported health shocks after age 67 .

The linear probability model in Equation (3) was estimated using ordinary least squares (OLS) regression for (i) the study sample (HRS waves 1-12, restricted to observations with age between 60 and 70 years, and additionally excluding all observations with ages 65 or 66), (ii) both genetic groups separately, and (iii) both men and women separately. Estimation results are shown in Table 4. Across all groups, there were no statistically significant jumps for health shocks reported at age 67 compared to age 64 (accounting for a linear age trend). Similarly, the age trend was not significantly different after age 67 than before. In the study sample and in the low-PGS group, the increase with age in the probability of reporting a health shock was statistically significant. 
Table 4: Coefficients from Estimating the Linear Probability Model in Equation (3) Using OLS

\begin{tabular}{|c|c|c|c|c|c|}
\hline & \multicolumn{5}{|c|}{ Dependent variable: } \\
\hline & \multicolumn{5}{|c|}{ Probability of shock } \\
\hline & All & Low PGS & High PGS & Male & Female \\
\hline & $(1)$ & $(2)$ & (3) & $(4)$ & $(5)$ \\
\hline \multirow[t]{2}{*}{ Age } & $0.002^{*}$ & $0.003^{*}$ & 0.001 & 0.001 & $0.002^{*}$ \\
\hline & $(0.001)$ & $(0.001)$ & $(0.001)$ & $(0.001)$ & $(0.001)$ \\
\hline \multirow[t]{2}{*}{ Post-67 dummy } & -0.001 & -0.007 & 0.002 & -0.001 & -0.001 \\
\hline & $(0.005)$ & $(0.008)$ & $(0.006)$ & $(0.008)$ & $(0.006)$ \\
\hline \multirow[t]{2}{*}{ Post-67 slope } & -0.0005 & -0.002 & 0.0003 & 0.001 & -0.002 \\
\hline & $(0.001)$ & $(0.002)$ & $(0.002)$ & $(0.002)$ & $(0.002)$ \\
\hline \multirow[t]{2}{*}{ Constant } & -0.068 & -0.134 & -0.036 & -0.046 & -0.082 \\
\hline & $(0.049)$ & $(0.082)$ & $(0.060)$ & $(0.079)$ & $(0.061)$ \\
\hline Observations & 39,185 & 13,076 & 26,109 & 16,648 & 22,537 \\
\hline
\end{tabular}

Low PGS = lowest tertile of the polygenic score distribution; high PGS = upper two tertiles of the polygenic score distribution.

Data used: HRS waves 1-13, restricted to observations with age between 60 and 70 years and non-missing smoking status, and additionally excluding all observations with ages 65 or 66 .

\section{C.5 Derivation of the effects from the OLS coefficients}

\section{C.5.1 OLS estimation: high and low PGS}

Current smoking status $(Y)$ is regressed on the full set of interactions between the indicators for the health shock (shock), being uninsured pre-65 (uninsured), Medicare 
eligibility (post65), and high polygenic risk for smoking $(g)$ :

$$
\begin{aligned}
& Y_{i t}=\beta \text { shock }_{i t}+\gamma{\text { post } 65_{i t}} \\
& +\lambda_{1}\left(\text { shock }_{i t} \times{\text { post } \left.65_{i t}\right)}\right. \\
& \left.+\lambda_{2} \text { (shock }_{i t} \times \text { uninsured }_{i}\right)
\end{aligned}
$$

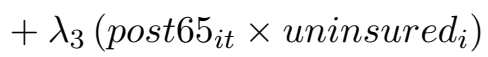

$$
\begin{aligned}
& +\lambda_{4}\left(\text { shock }_{i t} \times g_{i}\right)
\end{aligned}
$$

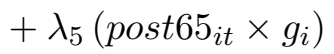

$$
\begin{aligned}
& +\delta_{1}\left(\text { shock }_{i t} \times{\text { post } \left.65_{i t} \times \text { uninsured }_{i}\right)}\right. \\
& +\delta_{2}\left(\text { shock }_{i t} \times \text { uninsured }_{i} \times g_{i}\right) \\
& +\delta_{3}\left(\text { shock }_{i t} \times{\text { post } \left.65_{i t} \times g_{i}\right)}\right.
\end{aligned}
$$

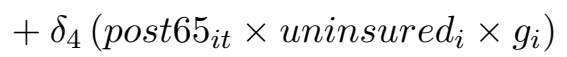

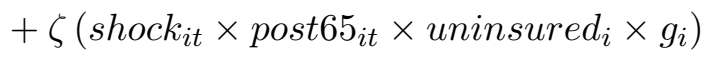

$$
\begin{aligned}
& +\sum_{a=1}^{3} \phi_{a} a g e_{i t}^{a}+\eta_{i}+\tau_{t}+\varepsilon_{i t}
\end{aligned}
$$

Effect of the health shock on the outcome for the previously uninsured To calculate the effect of the shock on the outcome, we evaluate the derivative of the outcome with respect to shock:

$$
\begin{aligned}
& \frac{\partial Y_{i t}}{\partial \text { shock }_{i t}}=\beta+\lambda_{1}{\text { post } 65_{i t}}_{i}+\lambda_{2} \text { uninsured }_{i}+\lambda_{4} g_{i}
\end{aligned}
$$

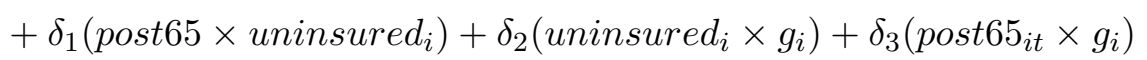

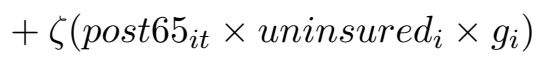

We can look at the decomposition for the different genotypes (high and low PGS) and shock timing (before and after 65):

$$
\begin{aligned}
& E\left[\frac{\partial Y_{i t}}{\partial \text { shock }_{i t}} \mid \text { post } 65_{i t}=0, g_{i}=0, \text { uninsured }_{i}=1\right]=\beta+\lambda_{2}
\end{aligned}
$$

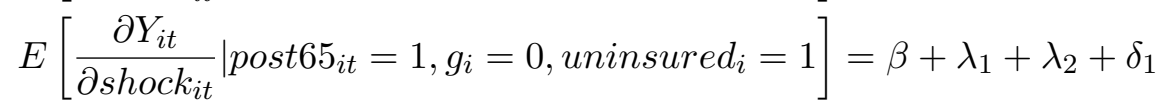

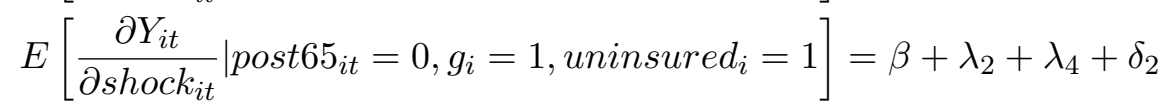

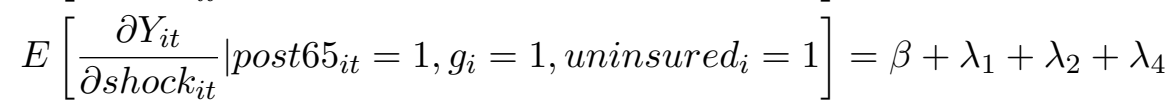

$$
\begin{aligned}
& +\delta_{1}+\delta_{2}+\delta_{3}+\zeta
\end{aligned}
$$

Calculating the first two differences as above::

$$
\begin{aligned}
& (6)-(5)=\lambda_{1}+\delta_{1} \\
& (8)-(7)=\lambda_{1}+\delta_{1}+\delta_{3}+\zeta
\end{aligned}
$$


And finally the genetic heterogeneity in this difference:

$$
(10)-(9)=\delta_{3}+\zeta
$$

\section{C.5.2 OLS estimation: Low, middle and high PGS}

Current smoking status $(Y)$ is regressed on the full set of interactions between the indicators for the health shock (shock), being uninsured pre-65 (uninsured), Medicare eligibility (post65), medium polygenic risk for smoking $\left(g^{m}\right)$ and high polygenic risk for smoking $\left(g^{h}\right)$ :

$$
\begin{aligned}
& Y_{i t}=\beta \text { shock }_{i t}+\gamma \text { post } 65_{i t} \\
& +\lambda_{1}\left(\text { shock }_{i t} \times{\text { post } \left.65_{i t}\right)}\right. \\
& +\lambda_{2}\left(\text { shock }_{i t} \times \text { uninsured }_{i}\right)
\end{aligned}
$$

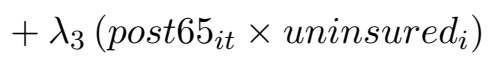

$$
\begin{aligned}
& +\lambda_{4}\left(\text { shock }_{i t} \times g_{i}^{m}\right) \\
& +\lambda_{5}\left(\text { post } 65_{i t} \times g_{i}^{m}\right) \\
& +\lambda_{6}\left(\text { shock }_{i t} \times g_{i}^{h}\right)
\end{aligned}
$$

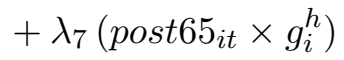

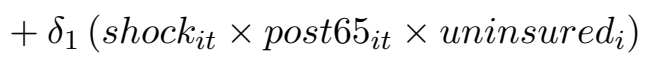

$$
\begin{aligned}
& +\delta_{2}\left(\text { shock }_{i t} \times \text { uninsured }_{i} \times g_{i}^{m}\right)
\end{aligned}
$$

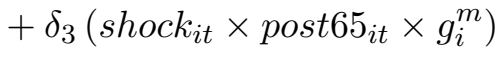

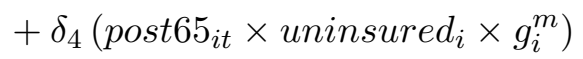

$$
\begin{aligned}
& +\delta_{5}\left(\text { shock }_{i t} \times \text { uninsured }_{i} \times g_{i}^{h}\right)
\end{aligned}
$$

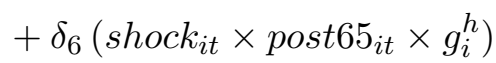

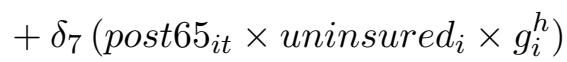

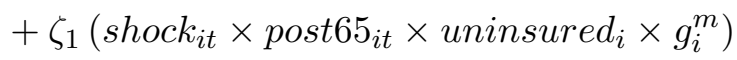

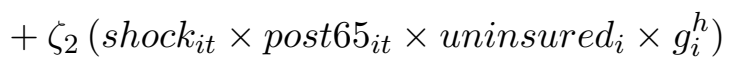

$$
\begin{aligned}
& +\sum_{a=1}^{3} \phi_{a} a g e_{i t}^{a}+\eta_{i}+\tau_{t}+\varepsilon_{i t}
\end{aligned}
$$

Effect of the shock on the outcome The derivative of the outcome with respect to shock is:

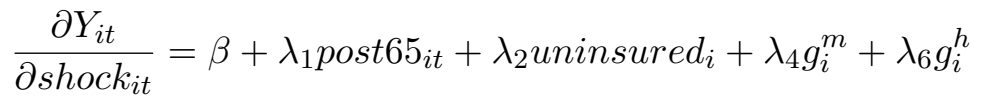

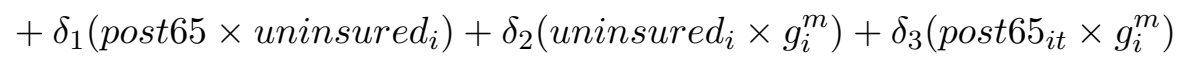

$$
\begin{aligned}
& +\delta_{5}\left(\text { uninsured }_{i} \times g_{i}^{h}\right)+\delta_{6}\left({\text { post } \left.65_{i t} \times g_{i}^{h}\right)}^{2}\right.
\end{aligned}
$$

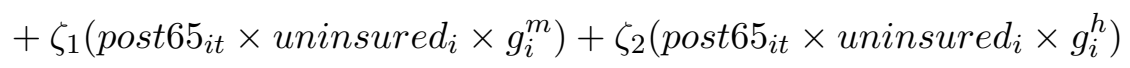


Again, we can look at the decomposition:

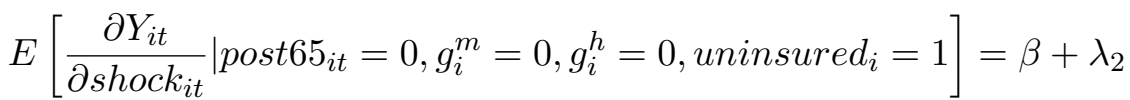

$$
\begin{aligned}
& E\left[\frac{\partial Y_{i t}}{\partial \text { shock }_{i t}} \mid{\text { post } 65_{i t}}=1, g_{i}^{m}=0, g_{i}^{h}=0, \text { uninsured }_{i}=1\right]=\beta+\lambda_{1}+\lambda_{2}+\delta_{1} \\
& E\left[\frac{\partial Y_{i t}}{\partial \text { shock }_{i t}} \mid{\text { post } 65_{i t}}=0, g_{i}^{m}=1, g_{i}^{h}=0, \text { uninsured }_{i}=1\right]=\beta+\lambda_{2}+\lambda_{4}+\delta_{2}
\end{aligned}
$$

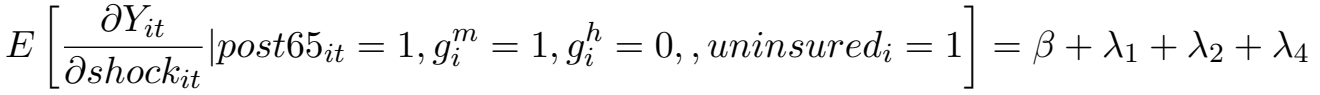

$$
\begin{aligned}
& +\delta_{1}+\delta_{2}+\delta_{3}+\zeta_{1} \\
& E\left[\frac{\partial Y_{i t}}{\partial \text { shock }_{i t}} \mid{\text { post } 65_{i t}}=0, g_{i}^{m}=0, g_{i}^{h}=1, \text { uninsured }_{i}=1\right]=\beta+\lambda_{2}+\lambda_{6}+\delta_{5}
\end{aligned}
$$

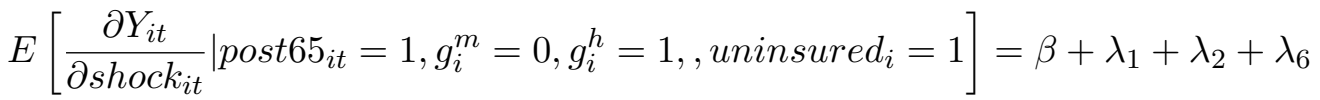

$$
\begin{aligned}
& +\delta_{1}+\delta_{5}+\delta_{6}+\zeta_{2}
\end{aligned}
$$

Calculating the first two differences as above::

$$
\begin{aligned}
& (29)-(28)=\lambda_{1}+\delta_{1} \\
& (31)-(30)=\lambda_{1}+\delta_{1}+\delta_{3}+\zeta_{1} \\
& (33)-(32)=\lambda_{1}+\delta_{1}+\delta_{6}+\zeta_{2}
\end{aligned}
$$

And again the genetic heterogeneity in this difference:

$$
\begin{aligned}
& (35)-(34)=\delta_{3}+\zeta_{1} \\
& (36)-(34)=\delta_{6}+\zeta_{2}
\end{aligned}
$$

\section{Results}

\section{D.1 Sample Characteristics}

Table 5 displays summary statistics for the subset of the study sample that experienced a cardiovascular health shock over the course of the observation period, stratified by timing of the shock (pre-65 versus post-65) and genetic group. Within a genetic group, demographics are mostly similar across the timing strata. However, in both groups, those experiencing the shock after age 65 are on average older at baseline. In the highPGS group, there are also relatively more women experiencing the shock after the age of 65 than before 65 . This is consistent with the general pattern that women experience cardiovascular disease later in life than men (Lloyd-Jones et al., 2010).

The subset of respondents affected by cardiovascular illness during the observed years differed in some characteristics from those unaffected. Table 6 shows a comparison.

\section{D.2 Main Results}

Table 7 reports the covariance matrix of these estimated coefficients. These coefficients and standard errors are used to calculate the effect of health shocks on the smoking 
Table D.5: Descriptive Statistics for the Subset of the study sample with a Health Shock, Stratified by Timing of the Shock and Genetic Group

\begin{tabular}{|c|c|c|c|}
\hline & Low PGS & High PGS & $P$ value \\
\hline \multicolumn{4}{|l|}{ Shock at ages $60-64$} \\
\hline & Mean (SD) & Mean (SD) & \\
\hline Age (baseline) & $60.49(0.57)$ & $60.47(0.64)$ & 0.78 \\
\hline Smoking PGS & $-0.97(0.54)$ & $0.63(0.68)$ & 0.00 \\
\hline Years of education & $12.2(3.41)$ & $12.11(3.17)$ & 0.81 \\
\hline Income (nominal \$1000) & $19.79(27.82)$ & $18.95(30.14)$ & 0.79 \\
\hline No. waves present & $\begin{array}{l}4.65(1.32) \\
\%\end{array}$ & $\begin{array}{l}4.59(1.32) \\
\%\end{array}$ & 0.65 \\
\hline Female & 48.7 & 45.05 & 0.51 \\
\hline Smoking (baseline) & 31.3 & 37 & 0.28 \\
\hline Persistently uninsured & 4.35 & 6.59 & 0.36 \\
\hline Avg. cessation rate (baseline smokers) & 12.05 & 12.17 & 0.97 \\
\hline No. of individuals & 115 & 273 & \\
\hline No. of Person-year individuals & 535 & 1252 & \\
\hline \multicolumn{4}{|l|}{ Shock at ages $67-70$} \\
\hline & Mean (SD) & Mean (SD) & \\
\hline Age (baseline) & $61.33(2.15)$ & $61.04(1.4)$ & 0.19 \\
\hline Smoking PGS & $-0.94(0.48)$ & $0.75(0.79)$ & 0.00 \\
\hline Years of education & $12.68(3.13)$ & $12.41(3.09)$ & 0.46 \\
\hline Income (nominal \$1000) & $17.81(27.44)$ & $15.74(20.15)$ & 0.48 \\
\hline No. waves present & $\begin{array}{l}5.06(1.15) \\
\%\end{array}$ & $\begin{array}{l}5.12(0.84) \\
\%\end{array}$ & 0.65 \\
\hline Female & 40.71 & 49.1 & 0.14 \\
\hline Smoking (baseline) & 30.09 & 35.59 & 0.31 \\
\hline Persistently uninsured & 8.85 & 6.31 & 0.42 \\
\hline Avg. cessation rate (baseline smokers) & 10.92 & 11.03 & 0.97 \\
\hline No. of individuals & 113 & 222 & \\
\hline No. of Person-year individuals & 572 & 1136 & \\
\hline
\end{tabular}

Pre-65: Health shock since the last survey reported at ages 60-64.

Post-65: Health shock since the last survey reported at ages 67-70.

$\mathrm{P}$-values report significance tests for the difference in means between the shock timing strata.

Low PGS = lowest tertile of the polygenic score distribution; high PGS = upper two tertiles of the polygenic score distribution.

Cessation rates are defined as smoking in the previous but not in the current wave.

Data used: study sample restricted to individuals experiencing a health shock during the observation period.

probability of individuals who are uninsured before the age of 65-the subgroup of interest-for the 4 combinations of shock timing (before or after 65) and polygenic score (high or low). The derivation of these effects is described in Appendix Section C.5. 
Table D.6: Descriptive Statistics for the Study Sample, Stratified by Future Health Shock Status

\begin{tabular}{lllll}
\hline & All & New Shock & No new Shock & P value \\
\hline & Mean (SD) & Mean (SD) & Mean (SD) & \\
\hline Age (baseline) & $61.15(1.87)$ & $60.74(1.14)$ & $61.21(1.94)$ & 0.00 \\
Smoking PGS & $0.1(0.99)$ & $0.18(1.02)$ & $0.09(0.99)$ & 0.03 \\
Years of education & $12.48(3.09)$ & $12.33(3.16)$ & $12.5(3.08)$ & 0.18 \\
Income (nominal \$ 1000) & $20.41(34.97)$ & $17.97(26.62)$ & $20.75(35.98)$ & 0.01 \\
No. waves present & $4.45(1.36)$ & $4.85(1.15)$ & $4.39(1.38)$ & 0.00 \\
& $\%$ & $\%$ & $\%$ & \\
Female & 49.86 & 45.9 & 50.42 & 0.02 \\
Smoking (baseline) & 29.5 & 34.08 & 28.86 & 0.01 \\
Persistently uninsured & 5.88 & 6.4 & 5.8 & 0.54 \\
CV health shock & 12.28 & 100 & 0 & - \\
Avg. cessation rate (baseline smokers) & 10.3 & 11.35 & 10.11 & 0.21 \\
No. of individuals & 5854 & 719 & 5135 & \\
\hline
\end{tabular}

Health shock: diagnosed with a new cardiovascular condition during the time since the last HRS survey, but no history of cardiovascular disease prior to this diagnosis. P-values report significance tests for the difference in means between the health shock strata. Cessation rates were defined as smoking in the previous but not in the current wave.

Data used: HRS study sample, $\mathrm{n}=5,854$.

\section{D.3 Robustness Checks}

\section{D.3.1 Using all tertiles}

In this section, we derive the results using all of the three tertiles of the PGS distribution, as derived in Appendix Section D.3.1. Results shown in Tables 8 and Figure 12, show that the effects for the upper two tertiles of the polygenic score are virtually the same. To improve statistical power and simplicity of exposition, the main results are always presented by pooling these two tertiles toghether into a single category labeled highPGS.

\section{D.3.2 Median Split of the polygenic score}

In this section, we derive the results by using a median-split for the PGS, instead of tertiles. Results shown in Tables 9 10, as well as Figure 13, show that the effects are virtually the same, albeit a bit smaller in magnitude and less precisely estimated, as when splitting the PGS according to tertiles.

\section{D.3.3 Older GWAS Summary Statistics}

In this section, we also use the polygenic score publicly provided by the HRS (Ware, Schmitz and Faul, 2017) for the smoking phenotype "regular smoking" (having smoked more than 100 cigarettes throughout one's life). This score is constructed as a weighted sum of the genotype over the 779,538 SNPs that overlap between the HRS genetic database and a 2010 GWAS meta-analysis conducted by the Tobacco and Genetics Consortium (The Tobacco and Genetics Consortium et al., 2010). 
Figure D.12: Effect of a Health Shock on the Smoking Probability in the Pre-65 Uninsured Subgroup, Stratified by Timing of the Shock and Genetic Type (median split)

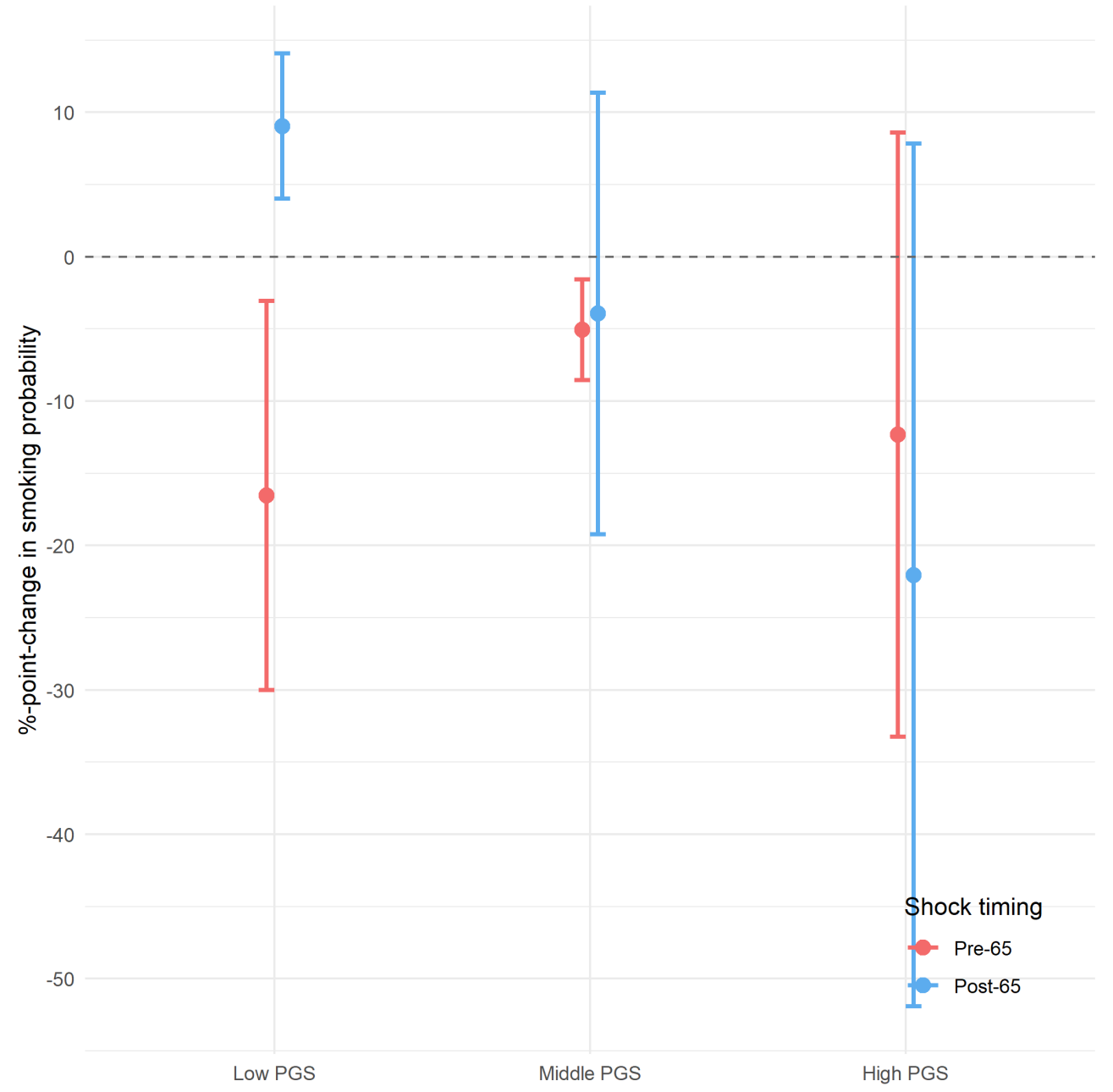

Notes: Low PGS = lowest tertile of the polygenic score distribution; Middle PGS = high PGS = upper two tertiles of the polygenic score distribution. Pre-65: Health shock since the last survey reported at ages 60-64. Post-65: Health shock since the last survey reported at ages 67-70. Estimates and standard errors are shown in Panel A of Table 2. Effects are estimated using the coefficients in Table 3 and following the derivation described in C.5. Bars show 95\% confidence intervals, standard error clustered at the individual level.

Data used: HRS study sample, $\mathrm{n}=5,854$. Supplement.

Results shown in Tables 11 and Figure 14, show that the effects are virtually the same, possibly even a bit stronger.

\section{D.3.4 Using different polygenic scores}

Other polygenic scores (PGS), besides the one for being a smoker, might be driving this heterogeneity in moral hazard. We estimated the same analysis outlined in equation 2 but replacing $g_{i}$ with the following PGS: the PGS for cigarettes per day (CPD) (Liu et al., 2019), the PGS for educational attainment and the one for cognitive abilities (Lee et al., 2018), the PGS for risk tolerance (Karlsson Linnér et al., 2019), the PGS for non-cognitive skills (Demange et al., 2020), and the PGS for Body-Mass-Index (Yengo 
Figure D.13: Effect of a Health Shock on the Smoking Probability in the Pre-65 Uninsured Subgroup, Stratified by Timing of the Shock and Genetic Type (median split)

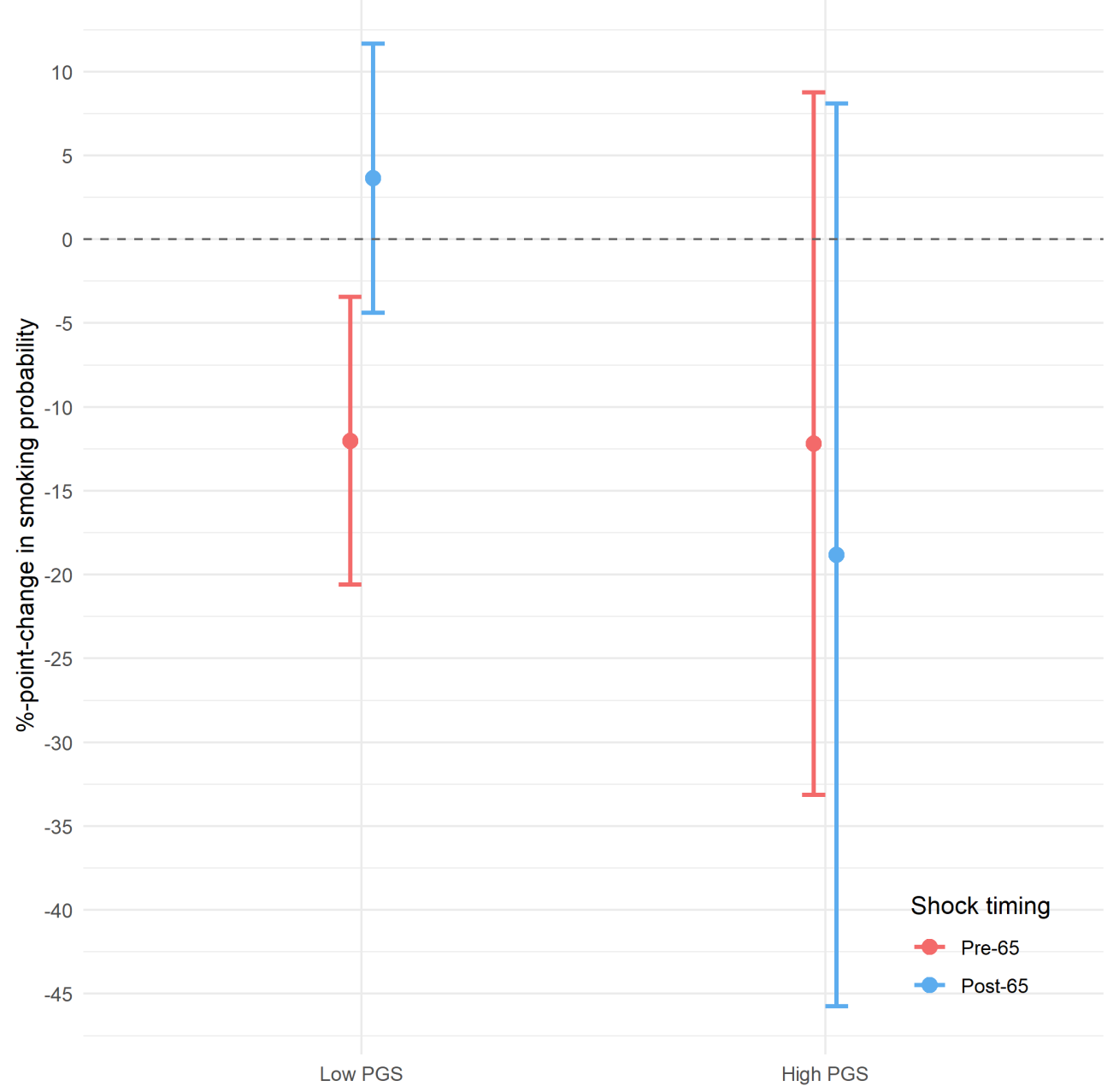

Notes: Low PGS = polygenic score below the median; high PGS = polygenic score above the median. Pre-65: Health shock since the last survey reported at ages 60-64. Post-65: Health shock since the last survey reported at ages 67-70. Estimates and standard errors are shown in Panel A of Table 2. Effects are estimated using the coefficients in Table 3 and following the derivation described in C.5. Bars show 95\% confidence intervals, standard error clustered at the individual level.

Data used: HRS study sample, $\mathrm{n}=5,854$.

et al., 2018). We chose polygenic scores for traits that are genetically correlated with smoking, such as CPD and risk tolerance, or plausibly related to strategic behaviors and moral hazard, such as education, cognition, and non-cognitive skills. BMI is meant more as a placebo. 
Figure D.14: Effect of a Health Shock on the Smoking Probability in the Pre-65 Uninsured Subgroup, Stratified by Timing of the Shock and Genetic Type (older PGS)

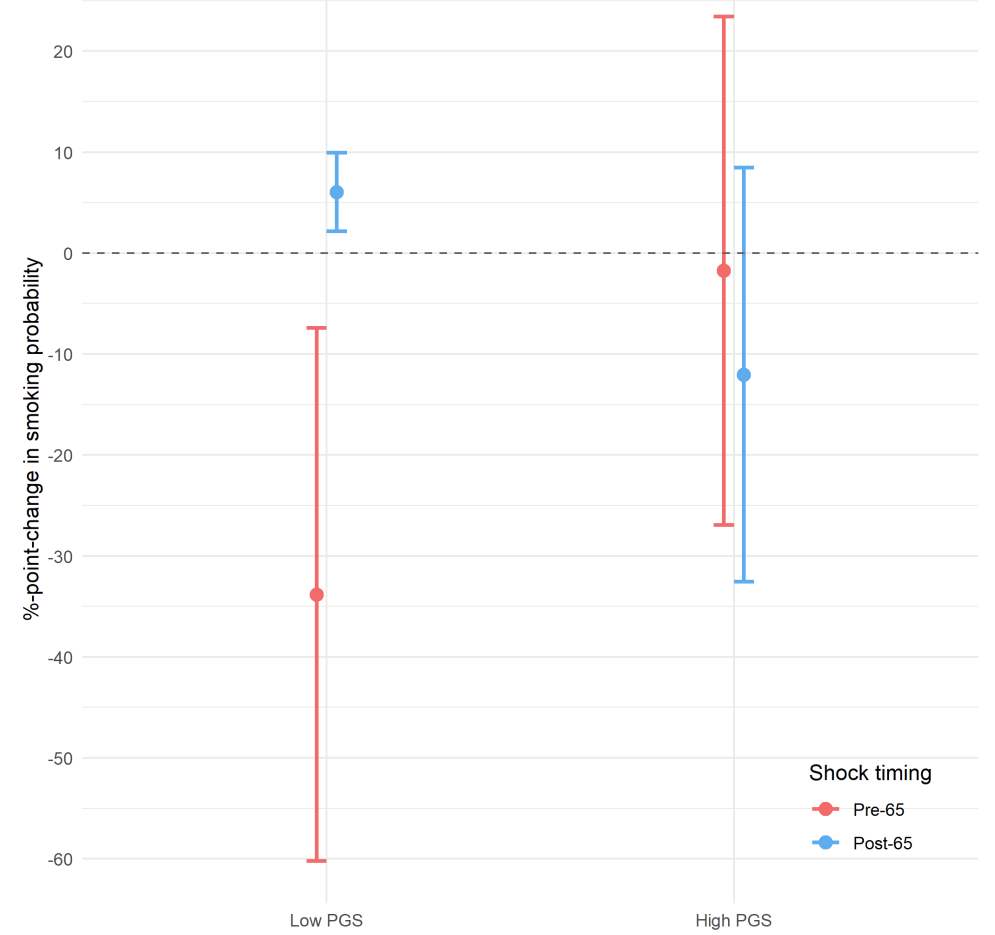

Notes: Low PGS = polygenic score below the median; high PGS = polygenic score above the median. Pre-65: Health shock since the last survey reported at ages 60-64. Post-65: Health shock since the last survey reported at ages 67-70. Estimates and standard errors are shown in Panel A of Table 2. Effects are estimated using the coefficients in Table 3 and following the derivation described in C.5. Bars show 95\% confidence intervals, standard error clustered at the individual level.

Data used: HRS study sample, $\mathrm{n}=5,854$. 
bioRxiv preprint doi: https://doi.org/10.1101/2021.03.05.434163; this version posted March 8, 2021. The copyright holder for this preprint (which was not certified by peer review) is the author/funder. All rights reserved. No reuse allowed without permission.

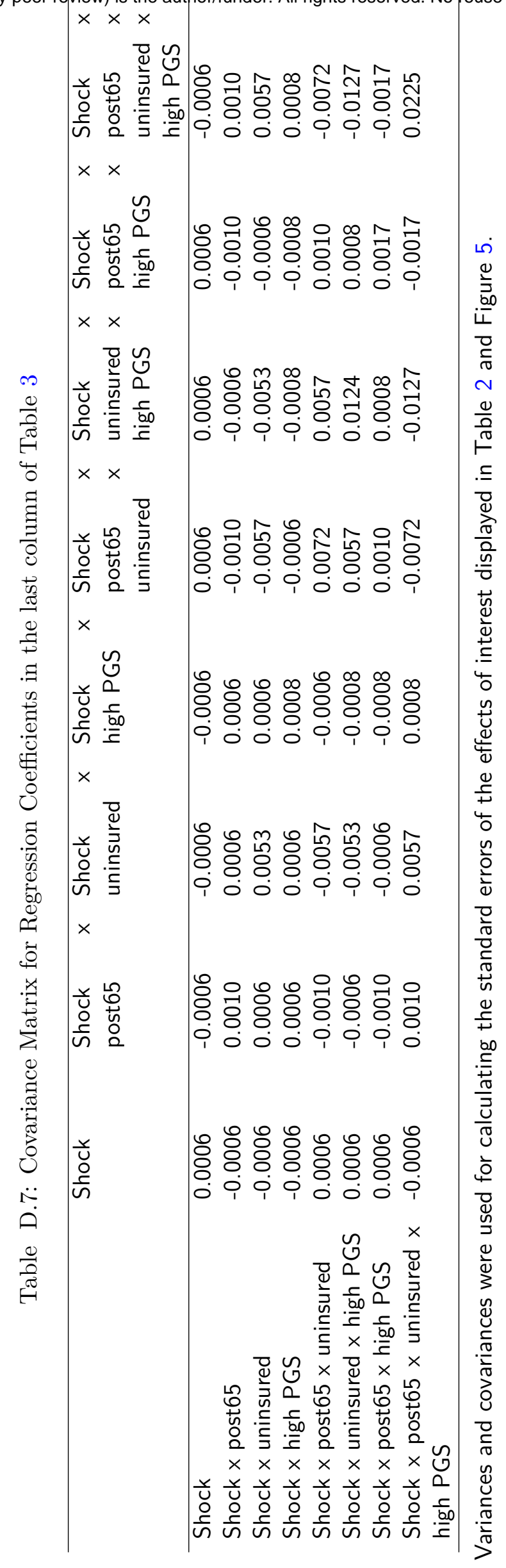


Table D.8: Summary of Statistical Results for the Pre-65 Uninsured Subgroup, Stratified by Timing of the Shock and Genetic Group (Median)

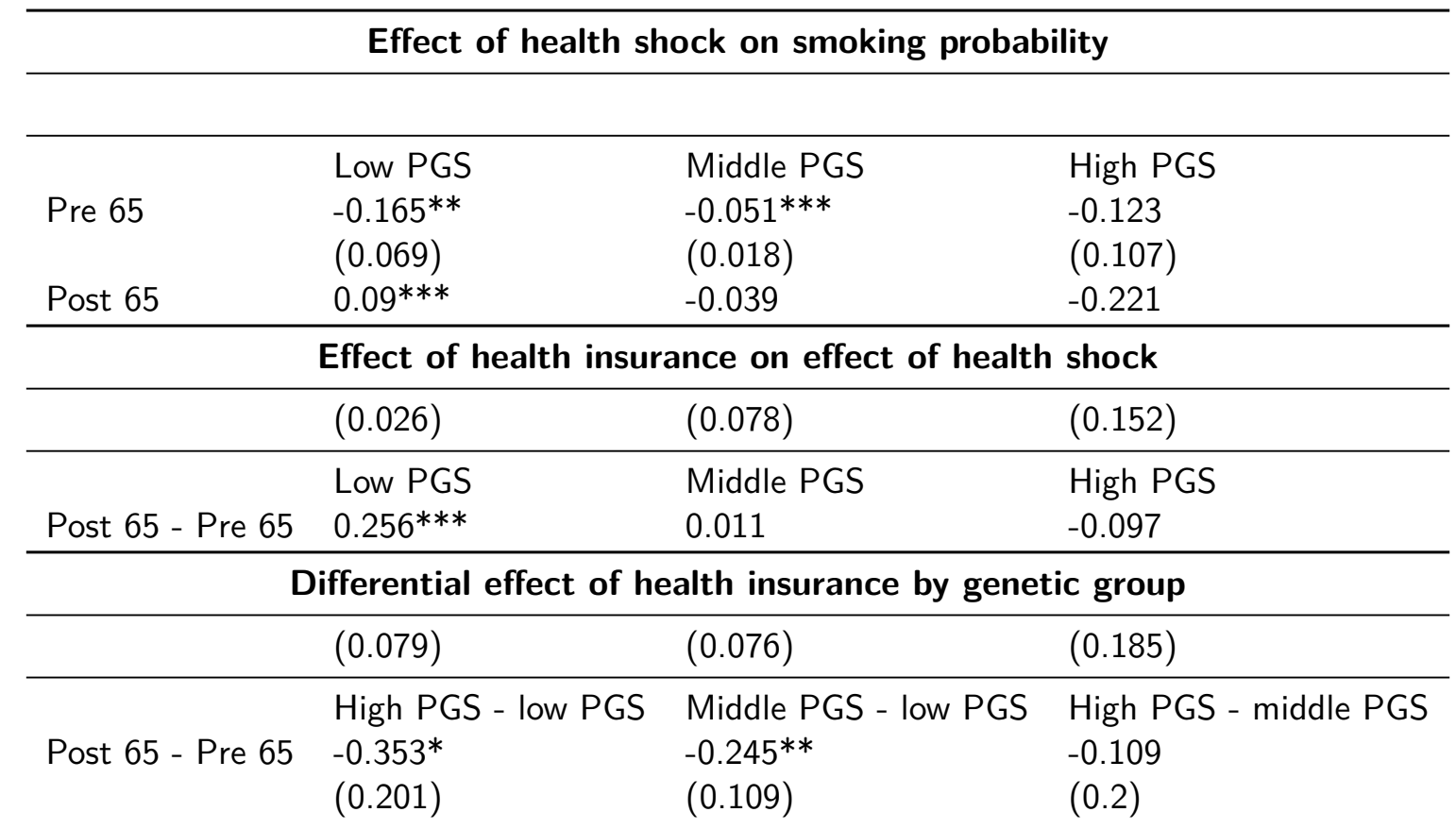

Low PGS = polygenic score below the median; high PGS = polygenic score above the median. Pre-65: Health shock since the last survey reported at ages 60-64. Post-65: Health shock since the last survey reported at ages 67-70. ${ }^{*} \mathrm{P}<0.1$; ${ }^{* *} \mathrm{P}<0.05 ;{ }^{* * *} \mathrm{P}<0.01$. Robust standard errors in parentheses are clustered at the individual level. The covariance matrix used for calculating standard errors is shown in Appendix Table 7. Effects are estimated using the coefficients in Table 3 and following the derivation described in C.5.

Data used: HRS study sample, $\mathrm{n}=5,854$. 
Table D.9: Coefficients from estimating the linear probability model in equation (2) using OLS (PGS median split)

\begin{tabular}{|c|c|c|c|c|c|}
\hline & \multicolumn{5}{|c|}{ Dependent variable: } \\
\hline & \multicolumn{5}{|c|}{ Smoking status } \\
\hline & $(1)$ & $(2)$ & (3) & $(4)$ & $(5)$ \\
\hline Health Shock & $\begin{array}{c}-0.034 \\
(0.031)\end{array}$ & $\begin{array}{r}-0.034 \\
(0.032)\end{array}$ & $\begin{array}{r}-0.033 \\
(0.031)\end{array}$ & $\begin{array}{c}-0.048^{* *} \\
(0.019)\end{array}$ & $\begin{array}{c}-0.047^{* *} \\
(0.019)\end{array}$ \\
\hline Post-65 & $\begin{array}{c}-0.066^{* * *} \\
(0.007)\end{array}$ & $\begin{array}{r}-0.022^{*} \\
(0.012)\end{array}$ & $\begin{array}{r}-0.021^{*} \\
(0.012)\end{array}$ & $\begin{array}{r}-0.013^{*} \\
(0.007)\end{array}$ & $\begin{array}{r}-0.012^{*} \\
(0.007)\end{array}$ \\
\hline Uninsured & $\begin{array}{l}0.168^{* * *} \\
(0.027)\end{array}$ & $\begin{array}{l}0.169^{* * *} \\
(0.027)\end{array}$ & $\begin{array}{l}0.169^{* * *} \\
(0.027)\end{array}$ & & \\
\hline High PGS & $\begin{array}{l}0.039^{* * *} \\
(0.012)\end{array}$ & $\begin{array}{l}0.040^{* * *} \\
(0.012)\end{array}$ & $\begin{array}{l}0.040^{\text {*** }} \\
(0.012)\end{array}$ & & \\
\hline Shock $\times$ Post- 65 & $\begin{array}{c}0.017 \\
(0.045)\end{array}$ & $\begin{array}{c}0.024 \\
(0.045)\end{array}$ & $\begin{array}{c}0.024 \\
(0.046)\end{array}$ & $\begin{array}{c}0.019 \\
(0.028)\end{array}$ & $\begin{array}{c}0.019 \\
(0.028)\end{array}$ \\
\hline Shock $\times$ Uninsured & $\begin{array}{c}-0.055 \\
(0.160)\end{array}$ & $\begin{array}{c}-0.055 \\
(0.160)\end{array}$ & $\begin{array}{c}-0.056 \\
(0.159)\end{array}$ & $\begin{array}{r}-0.071 \\
(0.048)\end{array}$ & $\begin{array}{r}-0.073 \\
(0.048)\end{array}$ \\
\hline Post- $65 \times$ Uninsured & $\begin{array}{c}0.026 \\
(0.036)\end{array}$ & $\begin{array}{c}0.025 \\
(0.037)\end{array}$ & $\begin{array}{c}0.025 \\
(0.037)\end{array}$ & $\begin{array}{r}-0.045^{*} \\
(0.025)\end{array}$ & $\begin{array}{r}-0.045^{*} \\
(0.025)\end{array}$ \\
\hline Shock $\times$ High PGS & $\begin{array}{c}0.052 \\
(0.046)\end{array}$ & $\begin{array}{c}0.050 \\
(0.046)\end{array}$ & $\begin{array}{c}0.048 \\
(0.046)\end{array}$ & $\begin{array}{c}0.024 \\
(0.027)\end{array}$ & $\begin{array}{c}0.024 \\
(0.027)\end{array}$ \\
\hline Post-65 $\times$ High PGS & $\begin{array}{c}0.004 \\
(0.010)\end{array}$ & $\begin{array}{c}0.004 \\
(0.010)\end{array}$ & $\begin{array}{c}0.003 \\
(0.010)\end{array}$ & $\begin{array}{c}0.0001 \\
(0.007)\end{array}$ & $\begin{array}{c}-0.0003 \\
(0.007)\end{array}$ \\
\hline Shock $\times$ Post $-65 \times$ Uninsured & $\begin{array}{c}0.090 \\
(0.212)\end{array}$ & $\begin{array}{c}0.090 \\
(0.213)\end{array}$ & $\begin{array}{c}0.090 \\
(0.212)\end{array}$ & $\begin{array}{c}0.136^{* *} \\
(0.067)\end{array}$ & $\begin{array}{c}0.137^{* *} \\
(0.067)\end{array}$ \\
\hline Shock $\times$ Uninsured $\times$ High PGS & $\begin{array}{c}0.004 \\
(0.211)\end{array}$ & $\begin{array}{c}0.014 \\
(0.211)\end{array}$ & $\begin{array}{c}0.015 \\
(0.210)\end{array}$ & $\begin{array}{r}-0.028 \\
(0.119)\end{array}$ & $\begin{array}{r}-0.026 \\
(0.119)\end{array}$ \\
\hline Shock $\times$ Post $-65 \times$ High PGS & $\begin{array}{r}-0.082 \\
(0.064)\end{array}$ & $\begin{array}{r}-0.078 \\
(0.064)\end{array}$ & $\begin{array}{r}-0.077 \\
(0.064)\end{array}$ & $\begin{array}{c}-0.086^{* *} \\
(0.042)\end{array}$ & $\begin{array}{c}-0.088^{* *} \\
(0.042)\end{array}$ \\
\hline Post-65 $\times$ Uninsured $\times$ High PGS & $\begin{array}{r}-0.072 \\
(0.057)\end{array}$ & $\begin{array}{c}-0.072 \\
(0.057)\end{array}$ & $\begin{array}{r}-0.072 \\
(0.057)\end{array}$ & $\begin{array}{c}0.041 \\
(0.033)\end{array}$ & $\begin{array}{c}0.041 \\
(0.033)\end{array}$ \\
\hline Shock $\times$ Post- $65 \times$ Uninsured $\times$ High PGS & $\begin{array}{c}0.154 \\
(0.310)\end{array}$ & $\begin{array}{c}0.145 \\
(0.312)\end{array}$ & $\begin{array}{c}0.142 \\
(0.311)\end{array}$ & $\begin{array}{r}-0.131 \\
(0.189)\end{array}$ & $\begin{array}{r}-0.136 \\
(0.188)\end{array}$ \\
\hline $\begin{array}{l}\text { Age } \\
\text { Year FE } \\
\text { Individual FE }\end{array}$ & & Yes & $\begin{array}{l}\text { Yes } \\
\text { Yes }\end{array}$ & $\begin{array}{l}\text { Yes } \\
Y e s \\
\end{array}$ & $\begin{array}{l}\text { Yes } \\
\text { Yes } \\
\text { Yes } \\
\end{array}$ \\
\hline $\begin{array}{l}\text { Observations } \\
\mathrm{R}^{2}\end{array}$ & $\begin{array}{c}26,022 \\
0.016\end{array}$ & $\begin{array}{c}26,022 \\
0.017\end{array}$ & $\begin{array}{c}26,022 \\
0.018\end{array}$ & $\begin{array}{l}26,022 \\
0.823\end{array}$ & $\begin{array}{c}26,022 \\
0.823\end{array}$ \\
\hline
\end{tabular}

Notes: Health shock = binary indicator for having suffered a cardiovascular health shock for the first time since the previous wave. Post- $65=$ indicator for age $>65$ at the time of the interview. Uninsured = binary indicator for being persistently uninsured in every observation of the study sample before the age of 65 . High PGS = indicator for being above the median polygenic score. Age = controls for $3^{\text {rd }}$ degree polynomial in age. $\mathrm{FE}=$ adding fixed effects. Robust standard errors in parentheses are clustered at the individual level. ${ }^{*} \mathrm{p}<0.1 ;{ }^{* *} \mathrm{p}<0.05 ;{ }^{* * *} \mathrm{p}<0.01$. 
Table D.10: Summary of Statistical Results for the Pre-65 Uninsured Subgroup, Stratified by Timing of the Shock and Genetic Group (Median)

\begin{tabular}{|c|c|c|}
\hline \multicolumn{3}{|c|}{ Effect of health shock on smoking probability } \\
\hline & Low PGS & High PGS \\
\hline Pre 65 & $\begin{array}{l}-0.12 * * * \\
(0.044)\end{array}$ & $\begin{array}{l}-0.122 \\
(0.107)\end{array}$ \\
\hline Post 65 & $\begin{array}{l}0.036 \\
(0.041) \\
\end{array}$ & $\begin{array}{l}-0.188 \\
(0.137) \\
\end{array}$ \\
\hline \multicolumn{3}{|c|}{ Effect of health insurance on effect of health shock } \\
\hline & Low PGS & High PGS \\
\hline Post 65 - Pre 65 & $\begin{array}{l}0.157^{* *} \\
(0.061) \\
\end{array}$ & $\begin{array}{l}-0.066 \\
(0.173) \\
\end{array}$ \\
\hline \multicolumn{3}{|c|}{ Differential effect of health insurance by genetic group } \\
\hline & High PGS & - low PGS \\
\hline Post 65 - Pre 65 & $\begin{array}{l}-0.223 \\
(0.184)\end{array}$ & \\
\hline
\end{tabular}

Low PGS = polygenic score below the median; high PGS = polygenic score above the median. Pre-65: Health shock since the last survey reported at ages 60-64. Post-65: Health shock since the last survey reported at ages $67-70$. ${ }^{*} \mathrm{P}<0.1 ;{ }^{* *} \mathrm{P}<0.05 ;{ }^{* * *} \mathrm{P}<0.01$. Robust standard errors in parentheses are clustered at the individual level. The covariance matrix used for calculating standard errors is shown in Appendix Table 7. Effects are estimated using the coefficients in Table 3 and following the derivation described in C.5.

Data used: HRS study sample, $\mathrm{n}=5,854$. 
Table D.11: Summary of Statistical Results for the Pre-65 Uninsured Subgroup, Stratified by Timing of the Shock and Genetic Group (older PGS)

\begin{tabular}{|c|c|c|}
\hline \multicolumn{3}{|c|}{ Effect of health shock on smoking probability } \\
\hline & Low PGS & High PGS \\
\hline Pre 65 & $\begin{array}{l}-0.338^{* *} \\
(0.135)\end{array}$ & $\begin{array}{l}-0.018 \\
(0.128)\end{array}$ \\
\hline Post 65 & $\begin{array}{l}0.06 * * * \\
(0.02)\end{array}$ & $\begin{array}{l}-0.12 \\
(0.105) \\
\end{array}$ \\
\hline \multicolumn{3}{|c|}{ Effect of health insurance on effect of health shock } \\
\hline & Low PGS & High PGS \\
\hline Post 65 - Pre 65 & $\begin{array}{l}0.399 * * * \\
(0.139)\end{array}$ & $\begin{array}{l}-0.103 \\
(0.163) \\
\end{array}$ \\
\hline \multicolumn{3}{|c|}{ Differential effect of health insurance by genetic group } \\
\hline & High PGS & - low PGS \\
\hline Post 65 - Pre 65 & $\begin{array}{l}-0.501^{* *} \\
(0.214)\end{array}$ & \\
\hline
\end{tabular}

Low $\mathrm{PGS}=$ polygenic score below the median; high PGS = polygenic score above the median, constructed using the summary statistics from the Tobacco and Genetics Consortium (The Tobacco and Genetics Consortium et al., 2010) (PGS publicly available from the HRS website). Pre-65: Health shock since the last survey reported at ages 60-64. Post-65: Health shock since the last survey reported at ages $67-70$. ${ }^{*} \mathrm{P}<0.1$; ${ }^{* *} \mathrm{P}<0.05 ;{ }^{* * *} \mathrm{P}<0.01$. Robust standard errors in parentheses are clustered at the individual level. The covariance matrix used for calculating standard errors is shown in Appendix Table 7. Effects are estimated using the coefficients in Table 3 and following the derivation described in C.5.

Data used: HRS study sample, $\mathrm{n}=5,854$. 
Figure D.15: Other Polygenic Scores as Proxy for Moral Hazard Heterogeneity

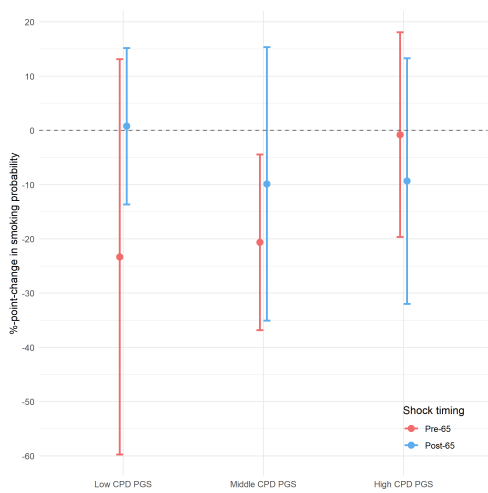

(a) PGS cigarettes per day

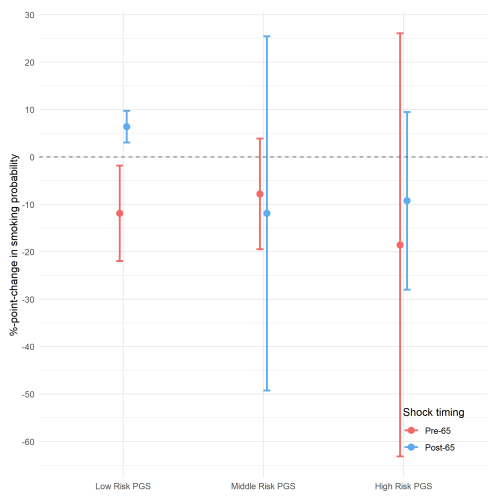

(d) PGS for risk tolerance

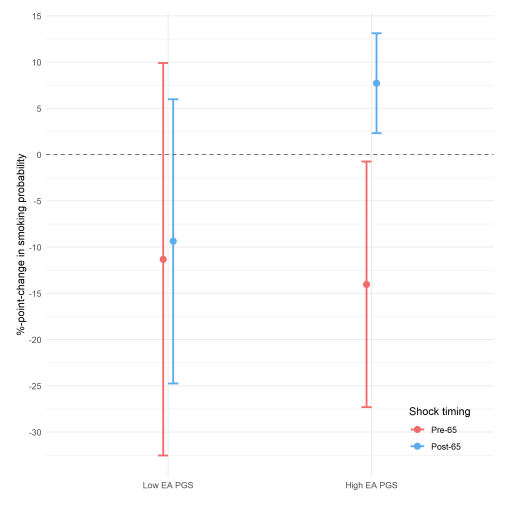

(b) PGS for educational attainment

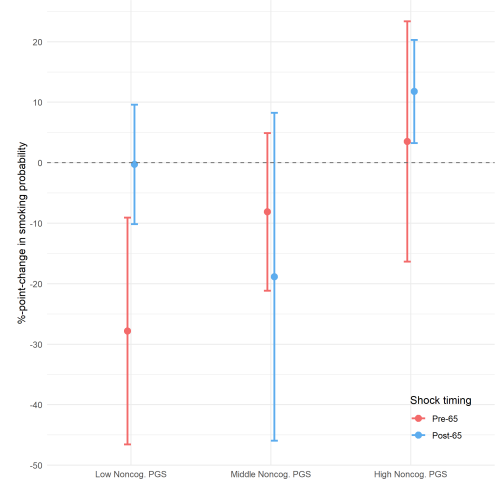

(e) PGS for non-cognitive skills

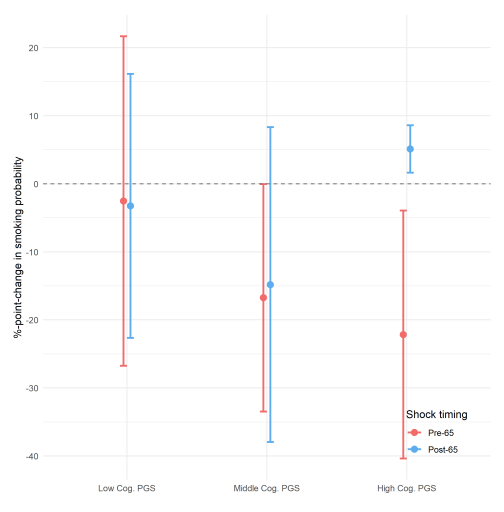

(c) PGS for cognitive abilities

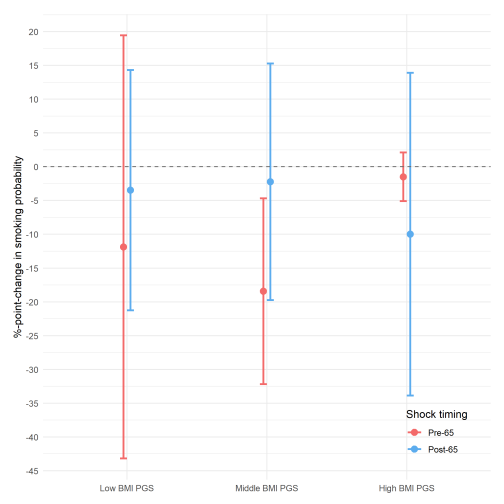

(f) PGS for BMI

Notes: The figures report the effect of suffering a health shock on the probability of smoking for the pre-65 uninsured subgroup, stratified by timing of the shock (before and after the age of 65) and different polygenic scores. Pre-65: Health shock since the last survey reported at ages 60-64. Post-65: Health shock since the last survey reported at ages 67-70. Effects are estimated using a combination of the coefficients from equation 2 where $g_{i}$ is replaced by the different polygenic scores reported in the sub-figure captions, following the derivation described in C.5. Bars show $95 \%$ confidence intervals, standard error clustered at the individual level.

Data used: HRS study sample, $\mathrm{n}=5,854$. 


\section{D.3.5 Relaxing the Criteria for Inclusion in the Pre-65 Uninsured Group}

Table D.12: Summary of Statistical Results for the Pre-65 Uninsured Subgroup (Using Different Definitions of the Pre-65 Uninsured Status Indicator)

\begin{tabular}{|c|c|c|c|c|c|c|}
\hline & \multicolumn{2}{|c|}{$100 \%$ uninsured } & \multicolumn{2}{|c|}{$66 \%$ uninsured } & \multicolumn{2}{|c|}{$33 \%$ uninsured } \\
\hline \multicolumn{7}{|c|}{ Effect of health shock on smoking probability } \\
\hline & Low PGS & High PGS & Low PGS & High PGS & Low PGS & High PGS \\
\hline $\begin{array}{l}\text { Pre } 65 \\
\text { Post } 65\end{array}$ & $\begin{array}{l}-0.165 * * \\
(0.069) \\
0.09 * * * \\
(0.026)\end{array}$ & $\begin{array}{l}-0.108 \\
(0.083) \\
-0.13 \\
(0.089)\end{array}$ & $\begin{array}{l}-0.147^{* *} \\
(0.059) \\
0.086 * * * \\
(0.021)\end{array}$ & $\begin{array}{l}-0.055 \\
(0.06) \\
-0.091 \\
(0.078)\end{array}$ & $\begin{array}{l}-0.055 \\
(0.068) \\
0.052 \\
(0.036)\end{array}$ & $\begin{array}{l}-0.09 * \\
(0.048) \\
-0.102 * * \\
(0.05)\end{array}$ \\
\hline \multicolumn{7}{|c|}{ Effect of health insurance on effect of health shock } \\
\hline & Low PGS & High PGS & Low PGS & High PGS & Low PGS & High PGS \\
\hline Post 65 - Pre 65 & $\begin{array}{l}0.256 * * * \\
(0.079)\end{array}$ & $\begin{array}{l}-0.023 \\
(0.121)\end{array}$ & $\begin{array}{l}0.233 * * * \\
(0.067)\end{array}$ & $\begin{array}{l}-0.036 \\
(0.098)\end{array}$ & $\begin{array}{l}0.107 \\
(0.076)\end{array}$ & $\begin{array}{l}-0.012 \\
(0.069)\end{array}$ \\
\hline
\end{tabular}

Differential effect of health insurance by genetic group

\begin{tabular}{l|ll|ll|ll}
\hline & High PGS & - low PGS & High PGS & - low PGS & High PGS & - low PGS \\
\hline Post 65 - Pre 65 & $-0.279^{*}$ & $-0.269^{* *}$ & & -0.119 \\
& $(0.144)$ & $(0.118)$ & & $(0.103)$
\end{tabular}

Main study results, for comparison.

Pre-65 uninsured status indicator set to 1 for respondents who were uninsured in at least $66 \%$ of all pre- 65 observations. Pre-65 uninsured status indicator set to 1 for respondents who were uninsured in at least 33\% of all pre- 65 observations. ${ }^{*} \mathrm{P}<0.1 ;{ }^{* *} \mathrm{P}<0.05 ;{ }^{* * *} \mathrm{P}<0.01$. Robust standard errors in parentheses were clustered at the individual level. Low PGS = lowest tertile of the polygenic score distribution; high PGS = upper two tertiles of the polygenic score distribution.

Pre-65: Health shock since the last survey reported at ages 60-64. Post-65: Health shock since the last survey reported at ages 67-70.

Data used: HRS study sample, $\mathrm{n}=5,854$. 


\section{D.3.6 Including Individuals with Shocks Reported at Ages 65 and 66}

Table D.13: Summary of Statistical Results for the Pre-65 Uninsured Subgroup (Including Individuals Reporting a Health Shock when Aged 65 or 66 in the study Sample)

Analytic Sample

Including reported at $65 / 66$

\begin{tabular}{|c|c|c|c|c|}
\hline & \multicolumn{2}{|c|}{ Analytic Sample } & \multicolumn{2}{|c|}{ Including reported at $65 / 66$} \\
\hline \multicolumn{5}{|c|}{ Effect of health shock on smoking probability } \\
\hline & Low PGS & High PGS & Low PGS & High PGS \\
\hline $\begin{array}{l}\text { Pre } 65 \\
\text { Post } 65\end{array}$ & $\begin{array}{l}-0.165 * * \\
(0.069) \\
0.09 * * * \\
(0.026) \\
\end{array}$ & $\begin{array}{l}-0.108 \\
(0.083) \\
-0.13 \\
(0.089) \\
\end{array}$ & $\begin{array}{l}-0.166^{* *} \\
(0.069) \\
0.091^{* * *} \\
(0.025) \\
\end{array}$ & $\begin{array}{l}-0.113 \\
(0.084) \\
-0.213^{* *} \\
(0.089) \\
\end{array}$ \\
\hline \multicolumn{5}{|c|}{ Effect of health insurance on effect of health shock } \\
\hline & Low PGS & High PGS & Low PGS & High PGS \\
\hline Post 65 - Pre 65 & $\begin{array}{l}0.256 * * * \\
(0.079)\end{array}$ & $\begin{array}{l}-0.023 \\
(0.121)\end{array}$ & $\begin{array}{l}0.257 * * * \\
(0.079)\end{array}$ & $\begin{array}{l}-0.1 \\
(0.121)\end{array}$ \\
\hline
\end{tabular}

Differential effect of health insurance by genetic group

\begin{tabular}{|c|c|c|c|c|}
\hline & High PGS & - low PGS & High PGS & - low PGS \\
\hline Post 65 - Pre 65 & $\begin{array}{c}-0.279 * \\
(0.144)\end{array}$ & & $\begin{array}{l}-0.356^{* *} \\
(0.145)\end{array}$ & \\
\hline
\end{tabular}

Main study results, for comparison.

study sample additionally includes individuals who reported experiencing a health shock since the last survey wave when interviewed at ages 65 or 66 .

${ }^{*} \mathrm{P}<0.1 ;{ }^{* *} \mathrm{P}<0.05 ;{ }^{* * *} \mathrm{P}<0.01$. Robust standard errors in parentheses were clustered at the individual level.

Low PGS = lowest tertile of the polygenic score distribution; high PGS = upper two tertiles of the polygenic score distribution.

Pre-65: Health shock since the last survey reported at ages 60-64. Post-65: Health shock since the last survey reported at ages 67-70.

Data used: study sample, but skipping Step 6 in Section C.2.1. 


\section{D.3.7 Using Medicare Enrollment Status instead of age 65}

Medicare enrollment refers to the RAND variable GOVMR, which indicates whether the respondent is covered by Medicare in a given wave. For details on the survey questions and construction of this variable, see the RAND HRS documentation.

Table D.14: Summary of Statistical Results for the Pre-65 Uninsured Subgroup (Using Medicare Enrollment Status Instead of Medicare Eligibility Status)

\begin{tabular}{|c|c|c|}
\hline \multicolumn{3}{|c|}{ Effect of health shock on smoking probability } \\
\hline & Low PGS & High PGS \\
\hline Without Medicare & $\begin{array}{l}-0.136 * * \\
(0.066)\end{array}$ & $\begin{array}{l}-0.109 \\
(0.083)\end{array}$ \\
\hline With Medicare & $\begin{array}{l}0.097 * * * \\
(0.028)\end{array}$ & $\begin{array}{l}-0.124 \\
(0.089) \\
\end{array}$ \\
\hline \multicolumn{3}{|c|}{ Effect of health insurance on effect of health shock } \\
\hline & Low PGS & High PGS \\
\hline With - Without Medicare & $\begin{array}{l}0.233^{* * * *} \\
(0.077)\end{array}$ & $\begin{array}{l}-0.016 \\
(0.121) \\
\end{array}$ \\
\hline \multicolumn{3}{|c|}{ Differential effect of health insurance by genetic group } \\
\hline & High PGS & - low PGS \\
\hline With - Without Medicare & $\begin{array}{c}-0.248^{*} \\
(0.144)\end{array}$ & \\
\hline
\end{tabular}

${ }^{*} \mathrm{P}<0.1 ;{ }^{* *} \mathrm{P}<0.05 ;{ }^{* * *} \mathrm{P}<0.01$. Robust standard errors in parentheses, clustered at the individual level. Low PGS = lowest tertile of the polygenic score distribution; high PGS = upper two tertiles of the polygenic score distribution. Effects are estimated using the coefficients in Table 3 and following the derivation described in C.5, but replacing the post-65 indicator with Medicare enrollment status. Data used: HRS study sample with the additional restriction of a non-missing Medicare enrollment status.

\section{D.4 Confounders}

Tables 15-17 report the results for the effect of the shock on potential confounding variables.

\section{E The Model}

In this section, we introduce a model to explore the theoretical basis and the testable empirical consequences of heterogeneity in moral hazard. ${ }^{16}$

What drives heterogeneity in moral hazard? In the context of health insurance, moral hazard is usually considered to be a reaction to insurance coverage: an increase in insurance coverage leads to changes in health behaviors, such as increased usage of

\footnotetext{
${ }^{16}$ This model was initially drafted by Regina Seibel, who was working on the project as a research assistant. An abridged version of the model is reported here with her permission.
} 
Table D.15: Summary of Placebo Checks for the Pre-65 Uninsured Subgroup for Income and Wealth

\begin{tabular}{|c|c|c|c|c|c|c|}
\hline & \multicolumn{6}{|c|}{ Effect of health shock on... } \\
\hline & \multicolumn{2}{|c|}{...individual earnings } & \multicolumn{2}{|c|}{...household earnings } & \multicolumn{2}{|c|}{...household wealth } \\
\hline & Low PGS & High PGS & Low PGS & High PGS & Low PGS & High PGS \\
\hline \multirow[t]{2}{*}{ Pre 65} & 0.403 & -0.11 & 0.389 & -0.369 & -5.42 & -1.687 \\
\hline & $(2.771)$ & $(1.178)$ & $(0.751)$ & $(0.744)$ & $(3.861)$ & $(2.017)$ \\
\hline \multirow[t]{4}{*}{ Post 65} & 0.016 & 0.59 & -0.087 & 0.328 & -1.26 & -0.326 \\
\hline & $(1.314)$ & $(0.786)$ & $(0.148)$ & $(0.497)$ & $(0.853)$ & $(2.021)$ \\
\hline & \multicolumn{6}{|c|}{ Effect of health insurance on effect of health shock } \\
\hline & Low PGS & High PGS & Low PGS & High PGS & Low PGS & High PGS \\
\hline \multirow[t]{4}{*}{ Post 65 - Pre 65} & -0.387 & & -0.476 & 0.697 & 4.159 & 1.361 \\
\hline & $(3.092)$ & $(1.434)$ & $(0.791)$ & $(0.903)$ & $(3.954)$ & $(2.866)$ \\
\hline & \multicolumn{6}{|c|}{ Differential effect of health insurance by genetic group } \\
\hline & High PGS & - low PGS & High PGS & - low PGS & High PGS & - low PGS \\
\hline Post 65 - Pre 65 & $\begin{array}{l}1.087 \\
(3.408)\end{array}$ & & $\begin{array}{l}1.173 \\
(1.201)\end{array}$ & & $\begin{array}{l}-2.798 \\
(4.884)\end{array}$ & \\
\hline
\end{tabular}

Table D.16: Summary of Placebo Checks for the Pre-65 Uninsured Subgroup for Retirement, Relationship Status and Out-of-Pocket Medical Expenditures

\begin{tabular}{|c|c|c|c|c|c|c|}
\hline & \multicolumn{6}{|c|}{ Effect of health shock on... } \\
\hline & \multicolumn{2}{|c|}{...retirement } & \multicolumn{2}{|c|}{...relationship status } & \multicolumn{2}{|c|}{...OOP medical expenditures } \\
\hline & Low PGS & High PGS & Low PGS & High PGS & Low PGS & High PGS \\
\hline & 0.212 & 0.094 & 0.081 & 0.044 & $2.384 * * *$ & $1.607 * * *$ \\
\hline \multirow{4}{*}{ Post 65} & 0.015 & 0.022 & 0.01 & 0.041 & 0.26 & -1.27 \\
\hline & $(0.093)$ & $(0.13)$ & $(0.01)$ & $(0.04)$ & $(0.658)$ & $(0.873)$ \\
\hline & \multicolumn{6}{|c|}{ Effect of health insurance on effect of health shock } \\
\hline & Low PGS & High PGS & Low PGS & High PGS & Low PGS & High PGS \\
\hline \multirow[t]{4}{*}{ Post 65 - Pre 65} & -0.197 & -0.071 & -0.071 & -0.003 & $-2.123 * *$ & $-2.878^{* * *}$ \\
\hline & $(0.28)$ & $(0.16)$ & $(0.07)$ & $(0.074)$ & $(1.008)$ & $(1.056)$ \\
\hline & \multicolumn{6}{|c|}{ Differential effect of health insurance by genetic group } \\
\hline & High PGS & - low PGS & High PGS & - low PGS & High PGS & - low PGS \\
\hline Post 65 - Pre 65 & $\begin{array}{l}0.125 \\
(0.322)\end{array}$ & & $\begin{array}{l}0.068 \\
(0.102)\end{array}$ & & $\begin{array}{l}-0.754 \\
(1.457)\end{array}$ & \\
\hline
\end{tabular}


Table D.17: Summary of Placebo Checks for the Pre-65 Uninsured Subgroup for Mortality within 2 and 5 years

\begin{tabular}{|c|c|c|c|c|}
\hline & \multicolumn{4}{|c|}{ Effect of health shock on mortality within... } \\
\hline & \multicolumn{2}{|c|}{$\ldots 2$ years } & \multicolumn{2}{|c|}{...5 years } \\
\hline & Low PGS & High PGS & Low PGS & High PGS \\
\hline Pre 65 & $\begin{array}{l}0.004 \\
(0.015)\end{array}$ & $\begin{array}{l}0.015 \\
(0.09)\end{array}$ & $\begin{array}{l}-0.046 \\
(0.061)\end{array}$ & $\begin{array}{l}-0.113 \\
(0.119)\end{array}$ \\
\hline \multirow[t]{3}{*}{ Post 65} & $\begin{array}{l}-0.001 \\
(0.011)\end{array}$ & $\begin{array}{l}-0.074 \\
(0.065)\end{array}$ & $\begin{array}{l}0.204 \\
(0.179) \\
\end{array}$ & $\begin{array}{l}0.009 \\
(0.103)\end{array}$ \\
\hline & \multicolumn{4}{|c|}{ Effect of health insurance on effect of health shock } \\
\hline & Low PGS & High PGS & Low PGS & High PGS \\
\hline \multirow[t]{3}{*}{ Post 65 - Pre 65} & $\begin{array}{l}-0.005 \\
(0.025)\end{array}$ & $\begin{array}{l}-0.089 \\
(0.113)\end{array}$ & $\begin{array}{l}0.25 \\
(0.191)\end{array}$ & $\begin{array}{l}0.122 \\
(0.154)\end{array}$ \\
\hline & \multicolumn{4}{|c|}{ Differential effect of health insurance by genetic group } \\
\hline & High PGS & - low PGS & High PGS & - low PGS \\
\hline Post 65 - Pre 65 & $\begin{array}{l}-0.085 \\
(0.116)\end{array}$ & & $\begin{array}{l}-0.129 \\
(0.245)\end{array}$ & \\
\hline
\end{tabular}

medical care (Einav and Finkelstein, 2018) or smoking. Hence moral hazard can be considered as a sort of price sensitivity of the agent (as in Einav et al., 2013). Knowing they can afford to go to the doctor if they fall sick, the insured agents might be more inclined to engage in immediately rewarding behavior which is harmful in the long run, such as smoking. ${ }^{17}$ Heterogeneity in this response to health care coverage can then be driven by social factors, like exposure to family or peers who behave similarly (Chatterjee et al., 2018; Hoffmann, 2017), or biological factors, like genetic propensity to smoke.

Following these insights, we model the demand side of a health insurance market with agents who are heterogeneous in two dimensions: exogenous health risk and a moral hazard parameter governing the behavioral response towards being insured.

\section{E.1 Setup}

Consider two time periods: in period 1, all agents are healthy ${ }^{18}$ and must make two decisions: whether to be insured, and how much effort to invest in reducing the probability of a health shock. More effort leads to a lower probability of falling sick, given an individual baseline level of risk. In period 2 the health risk realizes, with a probability mediated by the above-mentioned health-enhancing effort, and individuals can either be sick $(S)$ or healthy $(H)$. In case of sickness, insured agents receive the agreed-upon

\footnotetext{
${ }^{17}$ This change in risky health behaviors due to the anticipation of being able to afford health care in the future has been dubbed ex-ante moral hazard. Ex-post moral hazard refers to an increase in the use of medical care- such as doctor visits or medicines - following health insurance coverage.

${ }^{18}$ In other words, we do not consider the case of pre-existing conditions.
} 
coverage $1-\tau$ and pay the premium $p .{ }^{19}$ Uninsured agents pay the full medical treatment. In the healthy state of the world, insured agents still pay the premium while uninsured keep their full income for consumption.

Utility depends on consumption $c$ and the health state:

$$
u(c ; H)>u(c ; S)
$$

Utility is increasing and concave in consumption, i.e. $u^{\prime}(c ; \cdot)>0, u^{\prime \prime}(c ; \cdot) \leq 0$. Utility from no consumption at all is 0 irrespective of the state of health, $u(0 ; \cdot)=0$ and utility in consumption satisfies the Inada conditions ${ }^{20}$. The agent's consumption is equal to the money available for consumption goods, i.e. a fixed income $y$ which he receives in every period, less potentially insurance premia $p$ and medical expenses $m$ in case of sickness. Exerting health-enhancing effort $\mu$ is reducing his utility in the period it is exerted, which we phrase as health-enhancing effort cost. We assume effort costs to be additively separable from consumption utility and to be increasing and convex in the effort, i.e. $e^{\prime}(\mu ; \cdot)>0, e^{\prime \prime}(\mu ; \cdot)>0, e(0, \cdot)=0$. The effort costs are governed by the agent's moral hazard type $g$. This type can be interpreted as some characteristics of the individual, which make it harder for him to refrain from harmful behavior such as smoking and eating unhealthy food or similarly to engage in health-enhancing behavior such as exercising. In the current setting, we consider the moral hazard type $g$ to be proxied by an agent's genotype, but it could also be interpreted as self-discipline or another individual characteristic. Higher predisposition to unhealthy behavior $g$ leads to higher effort costs given the same level of effort, $\forall \mu$ : $e\left(\mu ; g^{\prime}\right)>e(\mu, g)$ if $g^{\prime}>g$. Regardless of whether the agent knows his genetic make-up, we assume that he is at least partly aware of his general type in the sense that he knows how easy it is for him to exert self-discipline.

The benefit of health-enhancing effort is the reduced probability of getting sick in the second period, which depends linearly on effort $\lambda=\lambda_{0}-\mu$. The ex-ante risk type of the agent $\lambda_{0}$ is equivalent to this probability, if no effort is exerted. The linear specification naturally bounds the maximal effort to $\mu \in\left[0, \lambda_{0}\right]$, which raises the question of boundary solutions, which we will address later when going through the steps of the model. ${ }^{21}$

\section{E.2 The optimal health-enhancing effort}

Since the game is finite, we solve it by backward induction. There is no decision to be made in the second period, the uncertainty about the health state just unfolds and the agent consumes what is left from his budget after paying his potential bills on insurance and medical expenditures. ${ }^{22}$ In the first period, the agent decides about whether to be

\footnotetext{
${ }^{19}$ To start off with a model as simple as possible, we abstract from the supply side and just assume that the insurer offers a fixed contract with premium $p$ and coverage rate $1-\tau$. A special case would be complete insurance with $\tau=0$.

${ }^{20}$ Inada conditions: $\lim _{c \rightarrow 0} u^{\prime}(c ; \cdot)=\infty, \lim _{c \rightarrow \infty} u^{\prime}(c ; \cdot)=0$

${ }^{21}$ Another way to model the problem would be to allow for a more general functional form $\lambda(\mu)$. It is reasonable to assume risk to be decreasing in effort, i.e. $\lambda^{\prime}(\mu)$. However, assumptions about convexity or concavity of the function are less straighforward and would require further supporting evidence. One could find examples supporting both increasing and decreasing marginal effects of effort on risk. Note that the results are robust to slight convexity or concavity. Extreme concavity might rule out an interior solution - the problem becomes a choice between no effort and maximal effort - while extreme convexity renders Proposition 1 is not as clear-cut.

${ }^{22}$ One could think additionally modeling the decision about the size of the medical expenditures, for example a choice between an expensive or a cheap treatment. This is what Einav et al. (2013) consider as moral hazard. Insured
} 
insured $I$ or not, as well as the health-enhancing effort $\mu$ he is willing to exert. Hence, he maximizes the present value of his utility stream:

$$
\begin{aligned}
\max _{I, \mu} I & \cdot V_{I}+(1-I) \cdot V_{N I} \\
V_{I}\left(\mu ; \lambda_{0}, g\right) & =u(y-p ; H)-e(\mu ; g)+\beta\left[\left(\lambda_{0}-\mu\right) u(y-p-\tau m ; S)+\left(1-\left(\lambda_{0}-\mu\right)\right) u(y-p ; H)\right] \\
V_{N I}\left(\mu ; \lambda_{0}, g\right) & =u(y ; H)-e(\mu ; g)+\beta\left[\left(\lambda_{0}-\mu\right) u(y-m ; S)+\left(1-\left(\lambda_{0}-\mu\right)\right) u(y ; H)\right]
\end{aligned}
$$

where $V_{I}$ is the value function when insured and $V_{N I}$ the value function when not insured, $\beta$ is the time discount factor, $y$ is income, $p$ is the insurance premium, $m$ is the medical expenditure, $\tau$ is the coverage rate, $H$ and $S$ are the healthy and sick state respectively, $\mu$ is the amount of health-enhancing effort, $g$ is the (genetic) moral hazard type, and $\lambda_{0}$ is the health risk type.

Proposition 1 The agent exerts at least as much health-enhancing effort $\mu$ if he is insured compared to if he is not insured.

Proof: Assuming an interior solution, if insured, the agent chooses optimal healthenhancing effort $\mu_{I}^{*}$ according to:

$$
\frac{e^{\prime}\left(\mu_{I}^{*} ; g\right)}{\delta}=u(y-p ; H)-u(y-p-\tau m ; S)
$$

If uninsured, the FOC can be rearranged to:

$$
\frac{e^{\prime}\left(\mu_{N I}^{*} ; g\right)}{\delta}=u(y ; H)-u(y-m ; S)
$$

Now irrespective of the specific form of the utility function, ${ }^{23} \mu_{N I}^{*}>\mu_{I}^{*}$. To see this more clearly consider subtracting (4) from (5):

$$
\frac{e^{\prime}\left(\mu_{N I} ; g\right)-e^{\prime}\left(\mu_{I} ; g\right)}{\delta}=[u(y ; H)-u(y-m ; S)]-[u(y-p ; H)-u(y-p-\tau m ; S)]
$$

Effort in the uninsured state is larger than in the insured state, if the RHS of this expression is larger than zero (since effort costs are increasing and convex), which can be rearranged to:

$$
u(y ; H)-u(y-p ; H)>u(y-m ; S)-u(y-p-\tau m ; S)
$$

The LHS of this inequality is always positive, since $y>y-p$, while the RHS must be negative, since $m>p+\tau m$, otherwise, no agent ever chooses the insurance. ${ }^{24}$ Consequently, the above inequality will always hold in an interior optimum.

Now, let's consider the boundary solutions. Since the marginal gains of exerting one extra unit of effort are constant, this consideration is rather simple. Suppose marginal

agents are more likely to choose the expensive treatment.

${ }^{23}$ In particular, irrespective of the interaction between health and income in determining the agent's utility, i.e. utility being sub-modular or supermodular in health and consumption.

${ }^{24}$ If $m \leq p+\tau m$, the insurance renders the agent weakly worse off in the sick state, while making him strictly worse off in the healthy state, since he has to pay the premium. A rational agent, irrespective of his idiosyncratic health risk, would never choose such an insurance. 
cost at zero effort is higher than marginal gain in the case of no insurance: $\frac{e^{\prime}(0)}{\delta}>$ $u(y ; H)-u(y-m ; S) \Rightarrow \mu_{N I}=0$. Then, we know that it must also be larger than marginal gain in case of insurance, i.e. $\mu_{I}=0$. In this case, the health-enhancing effort is the same in both cases and the agent does not gain anything from being given the possibility to exert it. If the marginal cost at zero effort is below marginal gain in case of no insurance, but above marginal gain in case of insurance, the effort will be positive if not insured and thus higher than if not insured.

On the other bound, if marginal cost at exerting $\lambda_{0}$ effort is lower than marginal gain if insured, then the agent will exert maximal effort in both cases. Finally, the effort will again be higher in case of no insurance compared to insurance, if marginal costs $e^{\prime}\left(\lambda_{0}\right)$ is lower than marginal gain in case of no insurance, but higher in case of insurance, $\mu_{I}<\mu_{N I}=\lambda_{0}$.

For the remaining part, we will assume an interior solution.

Proposition 2 Higher moral hazard parameter $g$ leads to

- a smaller difference in health-enhancing effort $\mu$ between an agent having insurance and an agent not having insurance, all else equal.

- lower levels of effort when being insured and when not being insured respectively, compared to an agent with lower $g$ and all else equal.

Proof: As already mentioned, we assume that $\forall \mu$ : $e\left(\mu ; g^{\prime}\right)>e(\mu, g)$ if $g^{\prime}>g$ and $\forall g: e(0, g)=0$. Therefore it must be true that effort costs are supermodular in effort and genetic predisposition, i.e. $\frac{\partial e^{\prime}(\mu ; g)}{\partial g}>0$. Consider (4) and (5) for two different values of genetic predisposition $g^{\prime}>g$. Since the RHS of both equations is independent of $g$, it follows from the assumptions that $\mu_{I}(g)>\mu_{I}\left(g^{\prime}\right)$ and $\mu_{N I}(g)>\mu_{N I}\left(g^{\prime}\right)$. Moreover, note that the RHS of equation (24) is independent of the moral hazard parameter $\mathrm{g}$. Hence, it must hold in equilibrium that:

$$
e^{\prime}\left(\mu_{N I}(g) ; g\right)-e^{\prime}\left(\mu_{I}(g) ; g\right)=e^{\prime}\left(\mu_{N I}\left(g^{\prime}\right) ; g^{\prime}\right)-e^{\prime}\left(\mu_{I}\left(g^{\prime}\right) ; g^{\prime}\right)
$$

But since $\mu_{N I}(g)>\mu_{I}(g)$, we know that $e^{\prime}\left(\mu_{N I}(g) ; g\right)-e^{\prime}\left(\mu_{I}(g) ; g\right)<e^{\prime}\left(\mu_{N I}\left(g^{\prime}\right) ; g^{\prime}\right)-$ $e^{\prime}\left(\mu_{I}\left(g^{\prime}\right) ; g^{\prime}\right)$. Consequently, it must hold that $\mu_{N I}(g)-\mu_{I}(g)>\mu_{N I}\left(g^{\prime}\right)-\mu_{I}\left(g^{\prime}\right)$.

Intuitively, Proposition 2 means, that agents for whom it is harder to engage in healthy or disengage in unhealthy behavior, e.g. starting to exercise or quit smoking, will react less to an increasing benefit to do so. Thus, a higher moral hazard parameter $g$ coincides with less moral hazard because there is less leeway for the individual to adjust effort to insurance coverage. A higher moral hazard parameter also implies a lower effort of the agent, in both states of the world. This agent is more risky from the perspective of the insurance ex-ante as well as ex-post despite showing less reaction to insurance coverage.

Our empirical results outlined above can be considered an empirical counterpart to this proposition, leveraging the occurrence of a health shock to make the situation more salient to the individual.

Proposition 3 Given genetic predisposition g, an agent with higher risk type $\lambda_{0}$ has a higher net benefit from being insured. 
Proof: Let us denote the present values of the optimal health-enhancing effort level given the moral hazard type $g$ as $V_{I}\left(\mu_{I}(g) ; \lambda_{0}, g\right)=v_{I}^{*}\left(\lambda_{0}, g\right), V_{N I}\left(\mu_{N I}(g) ; \lambda_{0}, g\right)=$ $v_{N I}^{*}\left(\lambda_{0}, g\right)$. In period 1 , the agent will choose to be insured, if $v_{I}^{*}\left(\lambda_{0}, g\right)>v_{N I}^{*}\left(\lambda_{0}, g\right)$. Both expressions consist of parts that are dependent on the optimal health preventing effort and those that are not :

$$
\begin{aligned}
v_{I}^{*}\left(\lambda_{0}, g\right)= & \underbrace{u(y-p ; H)+\delta\left[\lambda_{0} u(y-p-\tau m ; S)+\left(1-\lambda_{0}\right) u(y-p ; H)\right]}_{G_{I}\left(\lambda_{0}\right)} \\
v_{N I}^{*}\left(\lambda_{0}, g\right)= & \underbrace{-e\left(\mu_{I}(g) ; g\right)+\mu_{I} \delta[u(y-p ; H)-u(y-p-\tau m ; S)]}_{B_{I}(g)} \\
& \underbrace{-e\left(\mu_{N I}(g) ; g\right)+\mu_{N I} \delta[u(y ; H)-u(y-m ; S)]}_{G_{N I}\left(\lambda_{0}\right)}
\end{aligned}
$$

From equation (25), it follows that $v_{I}^{*}\left(\lambda_{0}, g\right)-v_{N I}^{*}\left(\lambda_{0}, g\right)=G_{I}\left(\lambda_{0}\right)-G_{N I}\left(\lambda_{0}\right)+B_{I}(g)-$ $B_{N I}(g)$ is linearly increasing in health risk $\lambda_{0}$.

Proposition 4 Higher genetic predisposition g leads to higher adverse selection on risk type.

Proof: For the lowest risk type $\lambda_{0}=0$ there is no effort he can exert to improve his health prospect, and he will never choose to be insured:

$$
v_{I}^{*}(0, g)=u(y-p ; H)+\delta u(y-p ; H)<u(y ; H)+\delta u(y ; H)=v_{N I}^{*}(0, g)
$$

Note that a risk type $\tilde{\lambda}_{0}$, who is indifferent between insurance and no insurance with zero health-enhancing effort, is not choosing the insurance with optimal effort: $v_{I}^{*}\left(\tilde{\lambda}_{0}, g\right)-$ $v_{N I}^{*}\left(\tilde{\lambda}_{0}, g\right)<G_{I}\left(\tilde{\lambda}_{0}\right)-G_{N I}\left(\tilde{\lambda}_{0}\right)=0$ Hence there exists a new threshold $\hat{\lambda}_{0}(g)>\tilde{\lambda}_{0}$, above which all agents choose to be insured given genetic predisposition.

From Proposition 4, we know that a higher moral hazard parameter $g$ leads to a higher net benefit in being insured. To evaluate how the threshold risk type $\tilde{\lambda}_{0}(g)$ is changing in the moral hazard parameter, we can use the implicit function theorem on equation (8):

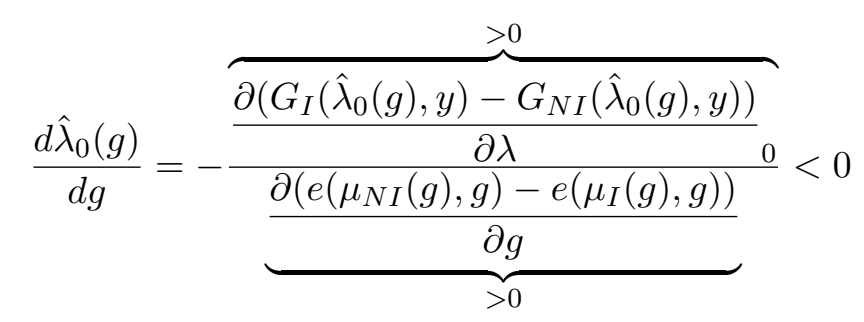

Consequently, if we have two groups of agents with genotype $g^{\prime}>g$, then adverse selection will be less severe for the group with the higher moral hazard parameter $\hat{\lambda}_{0}\left(g_{1}\right)<\hat{\lambda}_{0}\left(g_{2}\right)$ and the lower reaction of effort to insurance.

Note that because we did not further specify the insurance contract offered by the 
insurer, nothing prevents some thresholds to be above 1, i.e. no agent of a given genetic predisposition might choose the insurance. We assume that without health-enhancing effort, the highest risk type $\lambda_{0}=1$ would always like to choose the insurance, i.e. ${ }^{25}$ :

$$
G_{I}(1)-G_{N I}(1)=u(y-p ; H)+\delta u(y-p-\tau m ; S)-u(y ; H)-\delta u(y-m ; S)>0
$$

This is equivalent to stating that there exists a $\tilde{\lambda}_{0} \in(0,1)$. Now allowing for healthenhancing effort, it will depend on $g$, whether insurance is preferred to no insurance:

$$
\begin{aligned}
v_{I}^{*}(1, g)= & u(y-p ; H)+\delta u(y-p-\tau m ; S)+B_{I}(g) \\
& \gtrless u(y ; H)+\delta u(y-m ; S)+B_{N I}(g)=v_{N I}^{*}(1, g)
\end{aligned}
$$

Finally, if $\hat{\lambda}_{0}(g) \leq 1, \forall \lambda_{0} \in\left[\hat{\lambda}_{0}(g), 1\right]$ the agent is choosing the insurance and $\forall \lambda_{0} \in$ $\left[0, \hat{\lambda}_{0}(g)\right)$ the agent is not choosing the insurance, all else equal. This is the usual adverse selection result: Agents with a higher risk of falling sick inflict more costs to the insurance, but also have a higher valuation for insurance. If $\hat{\lambda}_{0}(g)>1$, which might happen for a very low level of $g$, we have the extreme case that no agent of a given moral hazard parameter $g$ is choosing to be insured.

The following picture summarizes the relationship:

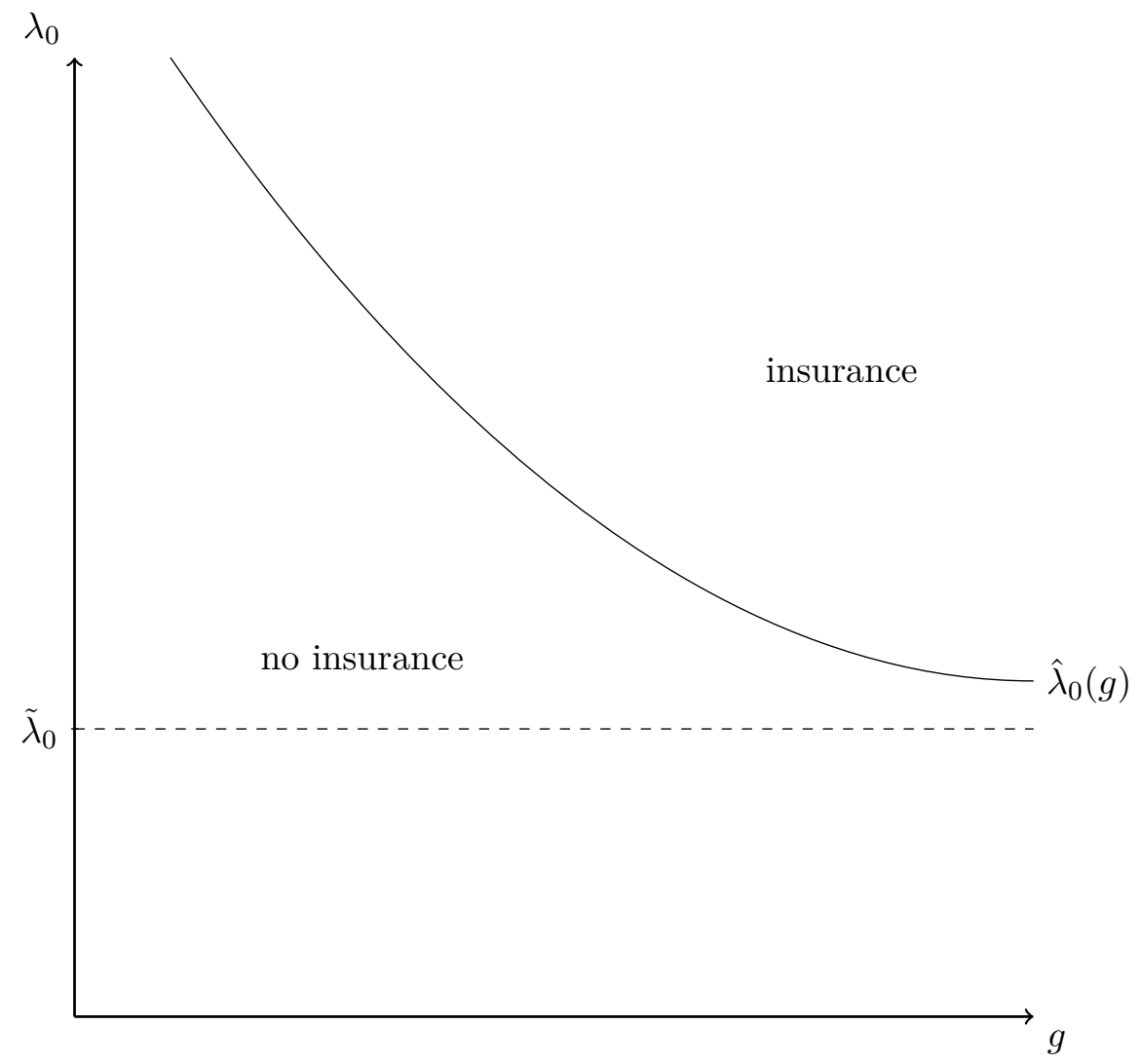

Over a population with independently distributed risk and moral hazard types we should expect to see agents of low risk type $\left(\lambda_{0}>\lambda_{0}^{\prime}\right)$ choosing an insurance only if

\footnotetext{
${ }^{25}$ This is an assumption that needs to be justified by looking at the firm side later and solve for the market equilibrium of the problem
} 
they have high costs of self-discipline $\left(g>g^{\prime}\right)$. Agents with high exogenous health risks should choose an insurance irrespective of their moral hazard type. Consequently, within a self-selected population with insurance we should observe a positive correlation of risk type and degree of moral hazard (or a negative correlation of risk type and moral hazard parameter g), despite advantageous selection on moral hazard, i.e. despite the fact that within each risk group, agents with the largest moral hazard potential do not choose the insurance.

While exogenous risk type $\lambda_{0}$ is an interesting variable to look at theoretically, it is neither the realized risk of the insured or uninsured agent. To compare the realized risk with and without health-enhancing effort, it is useful to divide the indirect utility when insured and uninsured into its components. We define $\hat{\lambda}(g)-\mu_{N I}(g)$ as the threshold exante risk of an insured agent, which is what researchers usually consider the exogenous risk type on which adverse selection occurs.

$$
\begin{aligned}
v_{I}^{*}\left(\lambda_{0}, g\right)= & u(y-p ; H)+\delta\left[\left(\lambda_{0}-\mu_{N I}(g)\right) u(y-p-\tau m ; S)+\left(1-\left(\lambda_{0}-\mu_{N I}(g)\right)\right) u(y-p ; H)\right] \\
& -e\left(\mu_{I}(g) ; g\right)+\left(\mu_{N I}(g)-\mu_{I}(g) \delta[u(y-p-\tau m ; S)-u(y-p ; H)]\right. \\
v_{N I}^{*}\left(\lambda_{0}, g\right)= & u(y ; H)+\delta\left[\left(\lambda_{0}-\mu_{N I}(g)\right) u(y-m ; S)+\left(1-\left(\lambda_{0}-\mu_{N I}(g)\right)\right) u(y ; H)\right] \\
& -e\left(\mu_{N I}(g) ; g\right)
\end{aligned}
$$

From this reformulation, it is easy to see that the relatively higher attractiveness of no insurance does not only result from the lower realized health risk $\lambda_{0}-\mu_{N I}(g)$ compared to exogenous risk type $\lambda_{0}$. Also, the behavioral reaction to being covered ${ }^{26}$ makes insurance less attractive. Moral hazard drives a wedge between the health risk if an agent is covered and the health risk if he is not covered, which can be interpreted as the agent's differential attempt to prevent the bad state of the world himself. Consequently, it must be true that $\hat{\lambda}_{0}(g)-\mu_{N I}(g)<\tilde{\lambda}_{0}$, but $\hat{\lambda}_{0}(g)-\mu_{I}(g)>\tilde{\lambda}_{0}$, so health-enhancing effort leads to an increase in realized risk among the insured agents given the same contract. This, in general, makes the adverse selection problem more severe. An insurer offering a fixed contract thus should increase premia in a world with a behavioral response of the agent compared to one without a behavioral response. which would exclude more agents from being insured. Notice, however, that not being insured has the positive side effect of the agents partly reduce risk themselves and staying healthy more likely.

\footnotetext{
${ }^{26}$ Note that $\mu_{N I} \delta(u(y-p ; H)-u(y-p-\tau m ; S))-e\left(\mu_{N I}(g) ; g\right)<\mu_{I} \delta(u(y-p ; H)-u(y-p-\tau m ; S))-e\left(\mu_{I}(g) ; g\right)$, since $\mu_{I}(g)$ is the maximum of the problem of the insured agent.
} 